Prepared in cooperation with the U.S. Army Corps of Engineers

\title{
Assessment of Suspended-Sediment Transport, Bedload, and Dissolved Oxygen during a Short-Term Drawdown of Fall Creek Lake, Oregon, Winter 2012-13
}

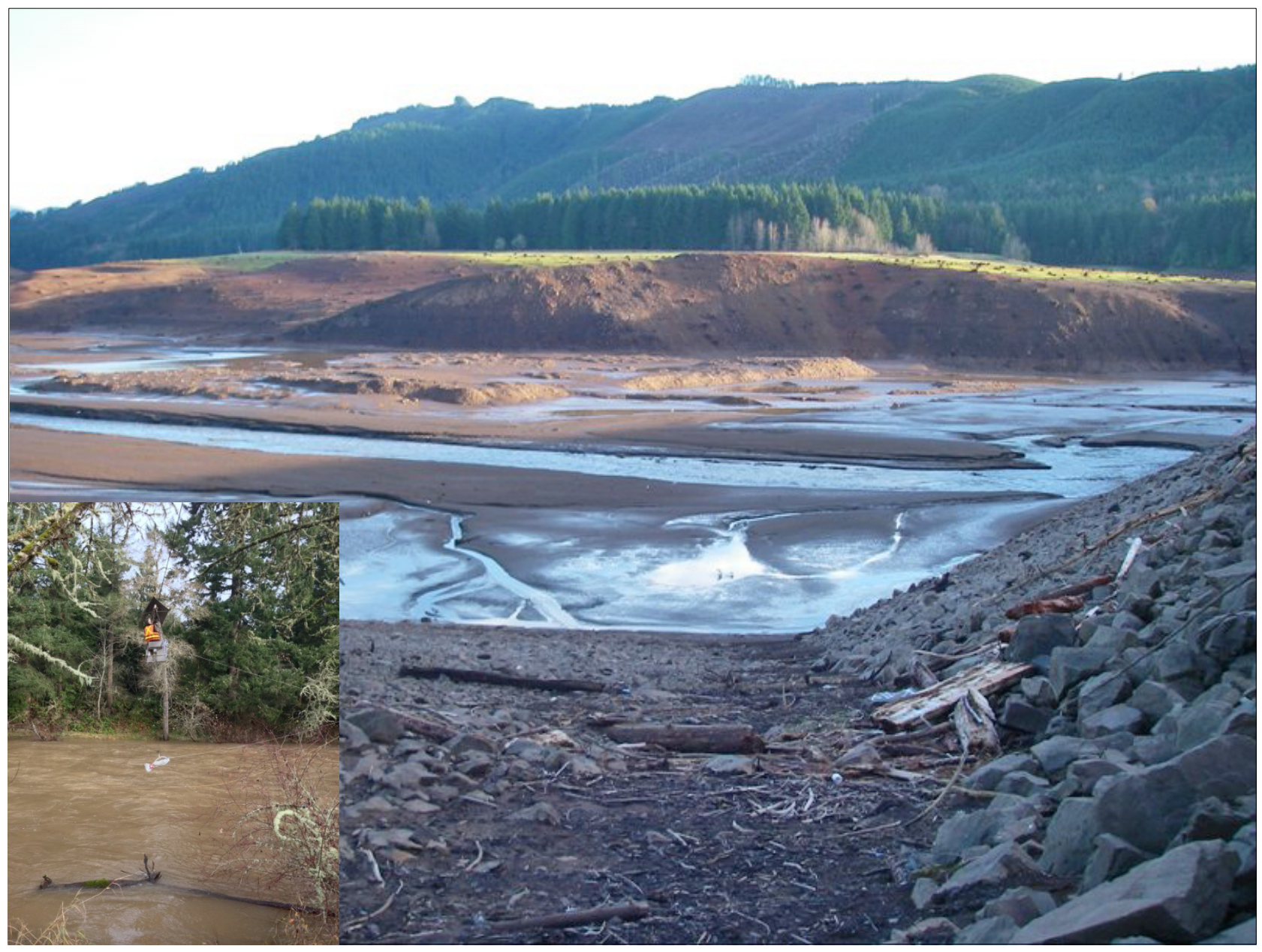

Open-File Report 2014-1114

U.S. Department of the Interior U.S. Geological Survey 
Cover: Fall Creek Reservoir, Oregon, during drawdown. (Photograph by Liam N. Schenk, U.S. Geological Survey, December 13, 2012.) Inset: A hydrologist collects bedload samples downstream from the reservoir during drawdown. (Photograph by Heather M. Bragg, U.S. Geological Survey, December 3, 2012.) 


\section{Assessment of Suspended-Sediment Transport, Bedload, and Dissolved Oxygen during a Short-Term Drawdown of Fall Creek Lake, Oregon, Winter 2012-13}

By Liam N. Schenk and Heather M. Bragg

Prepared in cooperation with the U.S. Army Corps of Engineers

Open File Report 2014-1114

U.S. Department of the Interior

U.S. Geological Survey 


\section{U.S. Department of the Interior \\ SALLY JEWELL, Secretary}

\section{U.S. Geological Survey \\ Suzette M. Kimball, Director}

U.S. Geological Survey, Reston, Virginia: 2014

For more information on the USGS-the Federal source for science about the Earth, its natural and living resources, natural hazards, and the environment-visit http://www.usgs.gov or call 1-888-ASK-USGS

For an overview of USGS information products, including maps, imagery, and publications, visit $h$ ttp://www.usgs.gov/pubprod

To order this and other USGS information products, visit $h$ ttp://store.usgs.gov

Suggested citation:

Schenk, L.N., and Bragg, H.M., 2014, Assessment of suspended-sediment transport, bedload, and dissolved oxygen during a short-term drawdown of Fall Creek Lake, Oregon, winter 2012-13: U.S. Geological Survey Open-File Report 2014-1114, 80 p., http://dx.doi.org/10.3133/ofr20141114.

ISSN 2331-1258 (online)

Any use of trade, firm, or product names is for descriptive purposes only and does not imply endorsement by the U.S. Government.

Although this information product, for the most part, is in the public domain, it also may contain copyrighted materials as noted in the text. Permission to reproduce copyrighted items must be secured from the copyright owner. 


\section{Contents}

Significant Findings

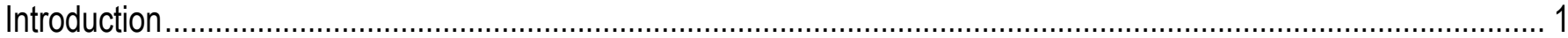

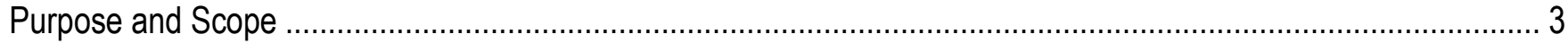

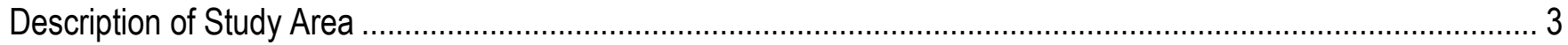

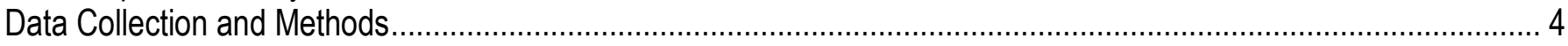

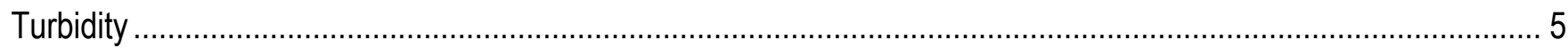

Suspended Sediment

Dissolved Oxygen ……………………………………

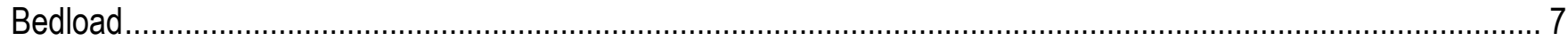

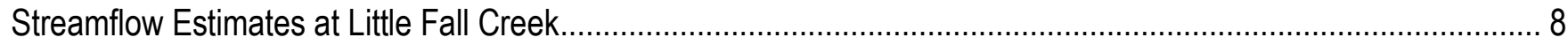

Suspended-Sediment Concentration Regression Model Development........................................................... 9

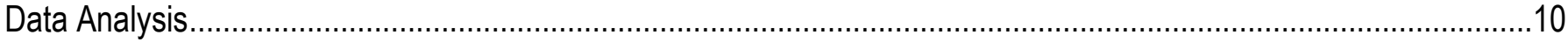

Suspended- Sediment Concentration Model Results..................................................................................

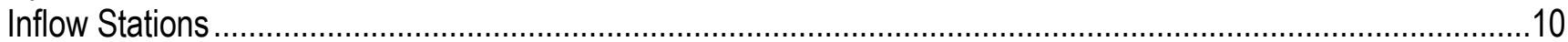

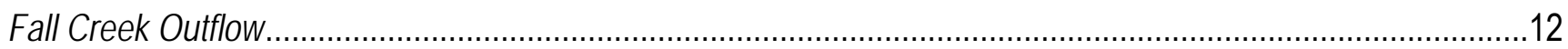

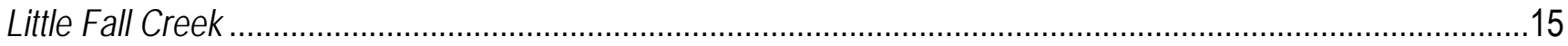

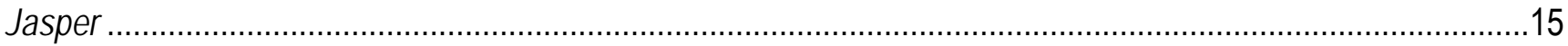

Dexter

Limitations to Regression Models..................................................................................................17

Estimated Suspended-Sediment Concentration Data …………...........................................................17

Suspended-Sediment Load Computations.................................................................................................. 18

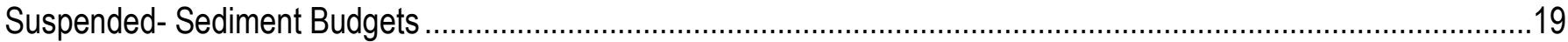

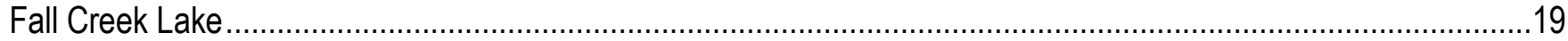

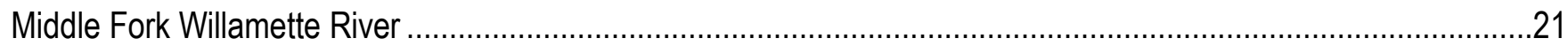

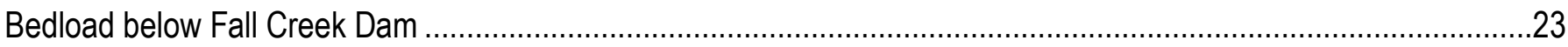

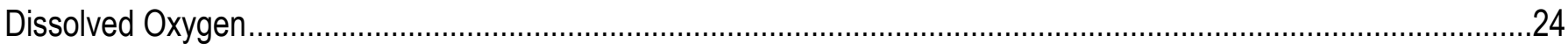

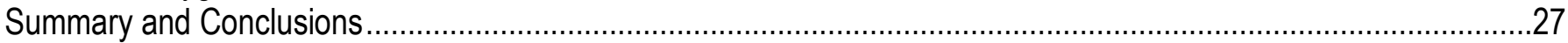

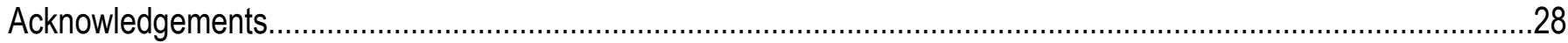

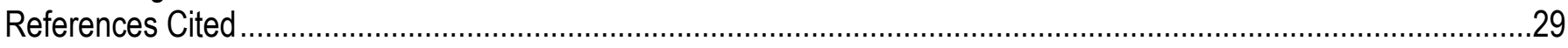

Appendix A-Monitoring Station Analyses and Sediment Model Descriptions ..........................................................31

\section{Figures}

Figure 1. Location of study area and monitoring stations, Middle Fork Willamette River Basin, Oregon.

Figure 2. Continuous streamflow at three U.S. Geological Survey streamflow-gaging stations (Jasper, Dexter, and Fall Creek Outflow), estimated streamflow at one water-quality monitoring station (Little Fall Creek), and elevation of Fall Creek Lake, Middle Fork Willamette River Oregon, 2012-13.

Figure 3. Scatterplots showing suspended-sediment concentration, turbidity, and streamflow for equal-widthintegrating samples collected at Fall Creek Outflow, Middle Fork Willamette River Basin, Oregon.

Figure 4. Percent fines of suspended-sediment concentration samples collected at Fall Creek Outflow and Jasper,

Middle Fork Willamette River Basin, Oregon

Figure 5. Time-series graphs showing suspended-sediment concentration and periods for separate regression

models at Fall Creek Outflow and Jasper, Middle Fork Willamette River Basin, Oregon, 2012-13. 
Figure 6. Regression scatterplots used to compute suspended-sediment concentration (SSC) at Jasper, Middle Fork Willamette River Basin, Oregon.

Figure 7. Time series graph showing computed daily suspended-sediment loads at the two Fall Creek Lake inflow stations (Fall Creek Inflow + Winberry Creek) and Fall Creek Lake Outflow, Middle Fork Willamette River Basin, Oregon, 2012-13

Figure 8. Time series graph showing computed daily suspended-sediment loads at three monitoring stations upstream of the Jasper monitoring station (Fall Creek Outflow, Dexter, and Little Fall Creek) and at Jasper, Middle Fork Willamette River Basin, Oregon, 2012-13.

Figure 9. Dissolved oxygen, turbidity, and streamflow during the drawdown at Fall Creek Outflow, Middle Fork Willamette River Basin, Oregon, December 2012.

\section{Tables}

Table 1. Streamflow and water-quality monitoring stations in the Middle Fork Willamette River Basin, Oregon....... 4

Table 2. Continuous water-quality data collection dates and parameters at the monitoring stations in the Middle Fork Willamette River Basin, Oregon.

Table 3. Summary statistics, missing unit values, and data rating for turbidity and dissolved oxygen at monitoring stations in the Middle Fork Willamette River Basin, Oregon.

Table 4. Suspended-sediment and bedload sample inventory at the monitoring stations in the Middle Fork Willamette River Basin, Oregon.

Table 5. Suspended-sediment concentration models for the monitoring stations in the Middle Fork Willamette River Basin, Oregon.

Table 6. Estimated suspended-sediment concentration data at the monitoring stations in the Middle Fork Willamette

River Basin, Oregon

Table 7. Suspended-sediment loads at the two inflow stations to Fall Creek Lake and the outflow of Fall Creek Lake, and net sediment transported from Fall Creek Lake, Middle Fork Willamette River Basin, Oregon.

Table 8. Suspended-sediment loads at the three monitoring stations upstream of Jasper, at Jasper, and the budget

for Fall Creek-Middle Fork Willamette River, Middle Fork Willamette River Basin,Oregon.....

Table 9. Bedload samples collected during the drawdown at Fall Creek Outflow, Middle Fork Willamette River Basin, Oregon, December 12-14, 2012.

Table 10. Grain size distribution of bedload samples at Fall Creek Outflow, below Fall Creek Lake, Oregon. 


\section{Conversion Factors}

Inch/Pound to SI

\begin{tabular}{|c|c|c|}
\hline Multiply & By & To obtain \\
\hline \multicolumn{3}{|c|}{ Length } \\
\hline inch (in.) & 2.54 & centimeter $(\mathrm{cm})$ \\
\hline inch (in.) & 25.4 & millimeter (mm) \\
\hline foot $(\mathrm{ft})$ & 0.3048 & meter $(\mathrm{m})$ \\
\hline mile (mi) & 1.609 & kilometer (km) \\
\hline \multicolumn{3}{|c|}{ Area } \\
\hline acre & 0.4047 & hectare (ha) \\
\hline acre & 0.004047 & square kilometer $\left(\mathrm{km}^{2}\right)$ \\
\hline \multicolumn{3}{|c|}{ Volume } \\
\hline quart (qt) & 0.9464 & liter (L) \\
\hline acre-foot (acre-ft) & 1,233 & cubic meter $\left(\mathrm{m}^{3}\right)$ \\
\hline \multicolumn{3}{|c|}{ Flow rate } \\
\hline cubic foot per second $\left(\mathrm{ft}^{3} / \mathrm{s}\right)$ & 0.02832 & $\begin{array}{l}\text { cubic meter per second } \\
\left(\mathrm{m}^{3} / \mathrm{s}\right)\end{array}$ \\
\hline \multicolumn{3}{|c|}{ Mass } \\
\hline pound, avoirdupois (lb) & 0.4536 & kilogram (kg) \\
\hline ton, short (2,000 lb) & 0.9072 & $\begin{array}{l}\text { metric ton (megagram } \\
{[\mathrm{Mg}] \text { ) }}\end{array}$ \\
\hline ton per day (ton/d) & 0.9072 & metric ton per day \\
\hline ton per day (ton/d) & 0.9072 & megagram per day $(\mathrm{Mg} / \mathrm{d})$ \\
\hline
\end{tabular}

SI to Inch/Pound

\begin{tabular}{lll}
\hline \multicolumn{1}{c}{ Multiply } & \multicolumn{1}{c}{ By } & \multicolumn{1}{c}{ To obtain } \\
\hline centimeter (cm) & Length & \\
millimeter (mm) & 0.3937 & inch (in.) \\
\hline & 0.03937 & inch (in.) \\
\hline liter (L) & Volume & ounce, fluid (fl. oz) \\
liter (L) & 33.82 & quart (qt) \\
\hline
\end{tabular}


Concentrations of chemical constituents in water are given either in milligrams per liter (mg/L) or micrograms per liter $(\mu \mathrm{g} / \mathrm{L})$.

\section{Datums}

Vertical coordinate information is referenced to the North American Vertical Datum of 1988 (NAVD 88).

Horizontal coordinate information is referenced to the North American Datum of 1983 (NAD 83).

Elevation, as used in this report, refers to distance above the vertical datum. 


\title{
Assessment of Suspended-Sediment Transport, Bedload, and Dissolved Oxygen during a Short-Term Drawdown of Fall Creek Lake, Oregon, Winter 2012-13
}

\author{
By Liam N. Schenk and Heather M. Bragg
}

\section{Significant Findings}

- The drawdown of Fall Creek Lake resulted in the net transport of approximately 50,300 tons of sediment from the lake during a 6-day drawdown operation, based on computed daily values of suspended-sediment load downstream of Fall Creek Dam and the two main tributaries to Fall Creek Lake.

- A suspended-sediment budget calculated for 72 days of the study period indicates that as a result of drawdown operations, there was approximately 16,300 tons of sediment deposition within the reaches of Fall Creek and the Middle Fork Willamette River between Fall Creek Dam and the streamgage on the Middle Fork Willamette River at Jasper, Oregon.

- Bedload samples collected at the station downstream of Fall Creek Dam during the drawdown were primarily composed of medium to fine sands and accounted for an average of 11 percent of the total instantaneous sediment load (also termed sediment discharge) during sample collection.

- Monitoring of dissolved oxygen at the station downstream of Fall Creek Dam showed an initial decrease in dissolved oxygen concurrent with the sediment release over the span of 5 hours, though the extent of dissolved oxygen depletion is unknown because of extreme and rapid fouling of the probe by the large amount of sediment in transport. Dissolved oxygen returned to background levels downstream of Fall Creek Dam on December 18, 2012, approximately 1 day after the end of the drawdown operation.

\section{Introduction}

The U.S. Geological Survey (USGS), in cooperation with the U.S. Army Corps of Engineers (USACE), monitored turbidity, suspended-sediment concentration (SSC), dissolved oxygen (DO), and bedload during a short-term operational drawdown of Fall Creek Lake, a reservoir operated by USACE in the upper Willamette Basin, Oregon, in the winter of 201213 (fig. 1). The USACE is an action agency listed in the 2008 National Marine Fisheries Service (NMFS) and U.S. Fish and Wildlife Service (USFWS) Biological Opinions (BiOps) on continued operations of the Willamette Valley Project, and, as such, is required to improve conditions at its facilities in the Willamette Basin for Endangered Species Act (ESA)-listed fish species (National Marine Fisheries Service, 2008). The BiOps state that the action agencies must carry out interim operational measures so downstream travelling ESA-listed fish species pass through dams as safely and efficiently as possible until permanent downstream fish passage facilities are constructed. 


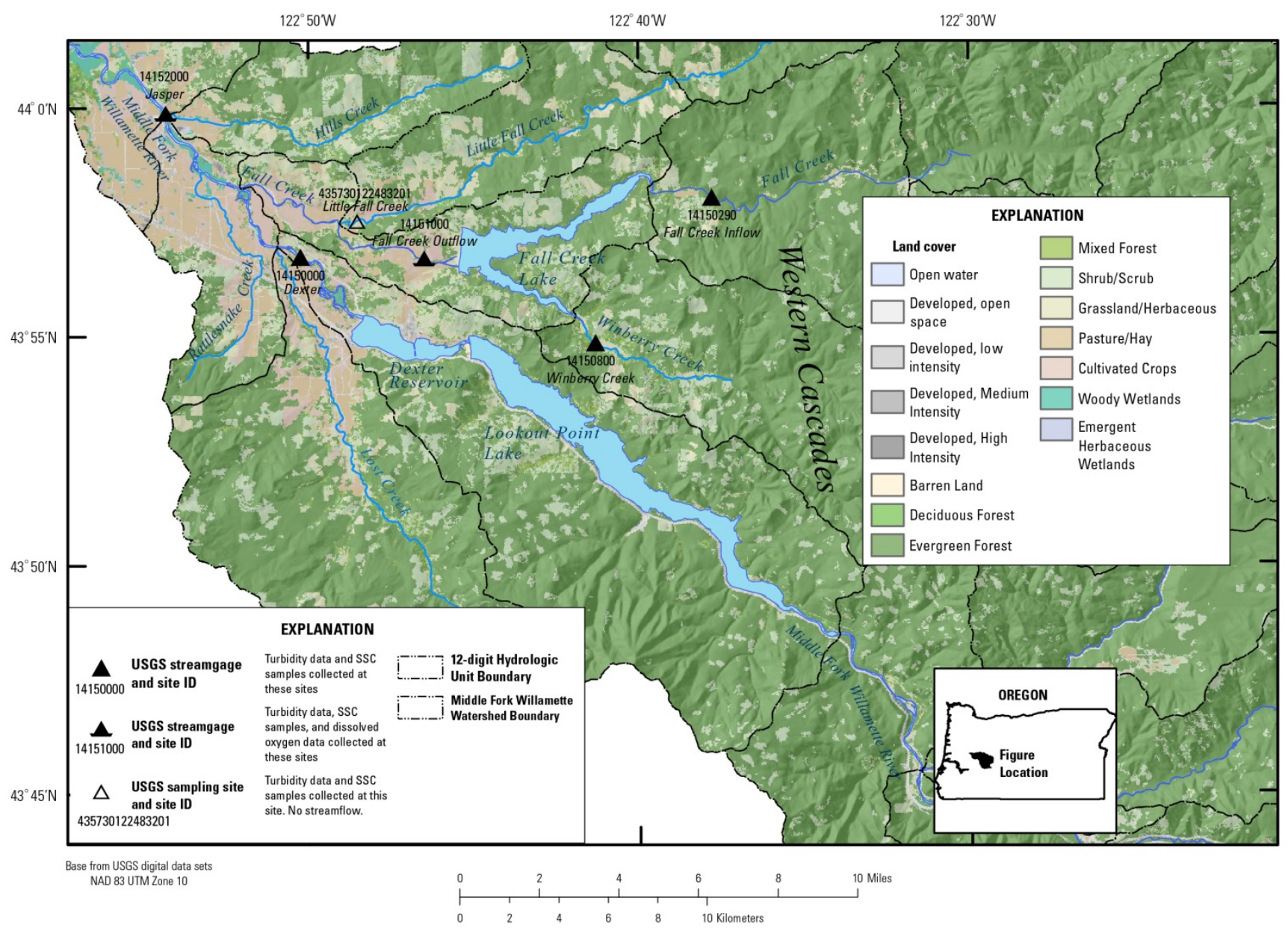

Figure 1. Location of study area and monitoring stations, Middle Fork Willamette River Basin, Oregon. Station names are referenced in table 1

In response, the USACE modified the operation of Fall Creek Lake in the winter of 2011-12 to improve passage for these downstream migrant fish. The modification involved lowering the lake elevation to approximately $680 \mathrm{ft}(48 \mathrm{ft}$ below the normal winter low-pool elevation of 728 $\mathrm{ft}$ ), allowing fish to pass through the regulating outlets of Fall Creek Dam rather than the fish horns, where mortality rates are high. This operational change was considered a success because of the passage and high survival rate of juvenile fish through the dam. (Greg Taylor, USACE, oral commun., October 2012). As expected, the drawdown also resulted in the release of large amounts of sediment through the dam, downstream in Fall Creek, and eventually into the Middle Fork Willamette River (Greg Taylor, USACE, oral commun., October 2012). Sediment was not monitored during the winter 2011-12 drawdown, but the USACE did attempt to collect turbidity data; however, the turbidity sensor was buried by the large amounts of sediment released from behind the dam.

For the winter 2012-13 drawdown, the USACE proposed a short-term study to monitor sediment transport during the drawdown operation. The USGS deployed turbidity and DO sensors and collected SSC and bedload samples from October 2012 through February 2013 to monitor sediment transport before, during, and after the drawdown, and to monitor the effect of the drawdown on DO at a subset of the study stations. Sampling frequency was increased at stations downstream of the dam at Fall Creek Lake and the Middle Fork Willamette River during the drawdown operation, when the lake remained at an elevation of approximately $680 \mathrm{ft}$ for 6 days from December 12 to 17. 
The winter 2011-12 and 2012-13 drawdowns were not the first such operational drawdowns at Fall Creek Lake. The USACE lowered the low pool elevation to $680 \mathrm{ft}$ three times between 1974 and 1988; therefore, the sediment released during the drawdown addressed in this report (December 2012) is not representative of all of the sediment entrained behind Fall Creek Dam since dam construction in 1966. Rather it represents the available sediment entrained behind the dam after four similar drawdowns from 1974 to 2011 (including the 2011 drawdown).

The transport of suspended sediment out of Fall Creek Lake and into Fall Creek and the Middle Fork Willamette River could possibly degrade downstream ecosystems. High concentrations of suspended solids in aquatic systems can lead to alterations in physical, chemical, and biological properties of water bodies; adversely affect salmonid spawning habitat and water quality; and increase costs of water treatment (Newcombe and MacDonald, 1991; Newcombe and Jensen, 1996; Bilotta and Brazier, 2008). Fine-grained, suspended sediment deposited in spawning redds can have lethal and sublethal effects on salmonid eggs that incubate within the gravel voids (Heywood and Walling, 2007). Additionally, bedload transport that results in streambed scour and fill also can result in high mortality rates of incubating salmonids (Shellberg and others, 2010). Because of the potentially detrimental effects of mobilizing sediment during reservoir drawdown operations, the USACE determined that monitoring of suspended sediment, bedload, and dissolved oxygen upstream and downstream of Fall Creek Lake were warranted during the winter 2012-13 drawdown.

\section{Purpose and Scope}

This report presents results of the winter 2012-13 drawdown sediment-transport study conducted in cooperation with the USACE. The USGS assessed turbidity and streamflow as possible surrogates for SSC at six study sites. The resulting simple linear or multiple linear regressions were used to calculate continuous (15minute) SSC values; these values were then used, with continuous streamflow, to compute instantaneous and daily suspended-sediment loads (SSL) at the study sites. The loads were used to generate a mass balance in an effort to determine the sediment transport past Fall Creek Dam and into Fall Creek and the Middle Fork Willamette River. Bedload sediment data collected from Fall Creek downstream of the dam during the week of the drawdown include instantaneous bedload discharge, grain size distribution, and loss on ignition (LOI). Dissolved oxygen data are reported for the two sites in the study area most directly affected by the drawdown on Fall Creek and the Middle Fork Willamette River.

\section{Description of Study Area}

Fall Creek Lake is located in the Middle Fork Willamette River watershed in west-central Oregon, on the fringe of the Willamette Valley Foothills and the Western Cascades Lowlands and Valleys (fig. 1). The lake is a flood control reservoir operated by the USACE, encompassing 1,820 acres at full pool (elevation $830 \mathrm{ft}$ ). The watershed is predominately forested (91 percent of total acreage, fig.1) with the exception of developed areas in the foothills, including some pasture and rangelands (Natural Resources Conservation Service, 2006). The watershed extends eastward into the High Cascades physiographic subprovince, and the elevation ranges from $454 \mathrm{ft}$ in the city of Springfield to approximately 6,500 ft in the High Cascades.

Fall Creek Lake’s two main tributaries, Winberry Creek and upper Fall Creek, drain the lower elevations of the Western Cascades east of the lake and enter the lake on separate arms (fig. 1). Combined, the two tributaries drain approximately $170 \mathrm{mi}^{2}$ of the western Cascade Range. Lower Fall Creek, the outflow of Fall Creek Lake, flows westward for approximately 7 mi to the confluence with the Middle Fork Willamette River. Little Fall Creek is an unregulated tributary to lower Fall Creek and contains the single monitoring station for this study where continuous streamflow data are not available (Little Fall Creek, table 1). The station on the Middle Fork Willamette River upstream of 
the Fall Creek confluence (Dexter) is the outflow streamflow-gaging station from Dexter Reservoir. Dexter Reservoir and Lookout Point Lake impound the upper Middle Fork Willamette River, which drains the high-elevation areas of the watershed. The Dexter station is located on a reach of the Middle Fork Willamette River that was unaffected by the drawdown operations at Fall Creek Lake, but contributes sediment to the
Middle Fork Willamette River upstream of the lower Fall Creek confluence. The farthest downstream station in the study area (Jasper) is on the Middle Fork Willamette River at Jasper, Oregon, and was used to estimate sediment loads from Fall Creek (including from Little Fall Creek), the Middle Fork Willamette River upstream of the confluence with Fall Creek, and unquantified tributaries.

Table 1. Streamflow and water-quality monitoring stations in the Middle Fork Willamette River Basin, Oregon.

[Locations of streamflow-gaging stations are shown in figure 1. Abbreviation: mi $^{2}$, square mile]

\begin{tabular}{lllc}
\hline \multicolumn{1}{c}{ USGS station No. } & \multicolumn{1}{c}{ Station name } & Station reference & $\begin{array}{c}\text { Drainage area } \\
\left(\mathrm{mi}^{2}\right)\end{array}$ \\
\hline 14150000 & Middle Fork Willamette River near Dexter, Oregon & Dexter & 1,000 \\
14150290 & Fall Creek above North Fork near Lowell, Oregon & Fall Creek Inflow \\
14150800 & Winberry Creek near Lowell, Oregon & Winberry Creek \\
14151000 & Fall Creek below Winberry Creek near Fall Creek, & Fall Creek Outflow \\
14152000 & Oregon & & 110 \\
435730122483201 & Middle Fork Willamette River at Jasper, Oregon & Jasper & Little Fall Creek \\
\hline
\end{tabular}

\section{Data Collection and Methods}

The USGS monitored sediment transport in the Fall Creek Lake area for approximately 4 months (late October 2012 to February 2013) to compute the sediment transport into and out of Fall Creek Lake before, during, and after the drawdown. The analysis also attempts to quantify the spatial extent of sediment transport downstream of the lake into Fall Creek and the Middle Fork Willamette River.

Six monitoring locations were selected in the study area, and five were co-located with existing USGS streamflow-gaging stations (fig. 1).

Continuous streamflow data were available at four of the stations (Dexter, Winberry Creek, Fall Creek Outflow, and Jasper). Streamflow and stage measurements at existing gaging stations followed protocols outlined in Turnipseed and Sauer (2010) and Sauer and Turnipseed (2010). Continuous river stage only was available at Fall Creek Inflow, so three streamflow measurements were collected to establish a short-term, stage-to-streamflow rating curve which was used to compute streamflow during the study period. Little Fall Creek is an ungaged station, so streamflow was estimated using data from the nearby stations on the Middle Fork Willamette River and Fall Creek (see section, "Streamflow Estimates at Little Fall Creek"). None of the six stations had existing turbidity, SSC, bedload, or dissolved oxygen data in the period of record prior to the study. During the study period, continuous turbidity data and discrete SSC samples were collected at all of the sites. These data were used to develop stationspecific SSC-turbidity and SSC-streamflow regression models to compute continuous SSC data. Dissolved oxygen was monitored at Fall Creek Outflow and Jasper to investigate the potential oxygen demand of the transported sediment (table 2). Bedload samples were collected at Fall Creek Outflow during the 6-day drawdown period to investigate the movement of material along the streambed during the sediment release. 
Table 2. Continuous water-quality data collection dates and parameters at the monitoring stations in the Middle Fork Willamette River Basin, Oregon.

[Station reference: Complete station names are shown in table 1; locations are shown in figure 1. Date format is $\mathrm{mm} / \mathrm{dd} / \mathrm{yy}]$

\begin{tabular}{lccll}
\hline \multicolumn{1}{c}{ Station reference } & Dates & Number of Days & Parameters \\
\hline Dexter & $11 / 01 / 12-03 / 05 / 13$ & 125 & Turbidity \\
Fall Creek Inflow & $11 / 08 / 12-02 / 08 / 13$ & 93 & Turbidity \\
Winberry Creek & $11 / 08 / 12-03 / 06 / 13$ & 119 & Turbidity \\
Fall Creek Outflow & $10 / 27 / 12-02 / 21 / 13$ & 118 & Turbidity, Dissolved oxygen \\
Jasper & $10 / 27 / 12-02 / 22 / 13$ & 119 & Turbidity, Dissolved oxygen \\
Little Fall Creek & $11 / 08 / 12-02 / 23 / 13$ & 108 & Turbidity \\
\hline
\end{tabular}

\section{Turbidity}

The use of turbidity sensors has proven to be an effective tool to monitor SSC in aquatic systems (Jastram and others, 2003; Rasmussen and others, 2009). Turbidity is not an inherent property of water, but rather an expression of the optical properties of a liquid that cause light rays to be scattered and absorbed rather than transmitted in straight lines through a sample (American Standard for Testing and Materials International, 2003). Turbidity was monitored at all six stations during the Fall Creek Lake drawdown in accordance with standard USGS protocols (Wagner and others, 2006). Turbidity sensors for the study used near-infrared light sources in the range of 780 to $900 \mathrm{~nm}$ with a single detector at 90 degrees to the light beam. Units of turbidity for all stations were measured in Formazin Nephelometric Units (FNU), following USGS standards (Anderson, 2005). Turbidity data were recorded every 15 minutes at all stations and stored in the USGS National Water Information System (NWIS; U.S. Geological Survey, 2013) using method codes specific to the instrument type. Turbidity sensors were equipped with wipers and were programmed to wipe the sensor face prior to taking a measurement.

All sensors were of the same technology (light source, wavelength, and detector angles) and manufacturer, but two sensor models were used. Self-contained McVan Analite ${ }^{\circledR}$ NEP 395 optical turbidity sensors were installed at the two inflow stations (Fall Creek Inflow and Winberry Creek) and transmitted data to Campbell Scientific ${ }^{\circledR}$ dataloggers, from which the data were periodically downloaded during the study period. The maximum range of the Analite ${ }^{\circledR}$ NEP 395 sensors is 1,000 FNU. Hydrolab ${ }^{\circledR}$ DS5x multiparameter data sondes, which incorporate $\mathrm{McVan}{ }^{\circledR}$ selfcleaning turbidity sensors, were used at the other four stations. The maximum range of the McVan sensors deployed on the Hydrolab ${ }^{\circledR}$ sondes is 3,000 FNU. Three of the four lower-basin stations (Fall Creek Outflow, Jasper, and Dexter) transmitted data over the existing USGS telemetry network, allowing for real-time reporting of turbidity data by way of the NWIS Web interface (http://waterdata.usgs.gov/nwis). Turbidity data at Little Fall Creek were logged internally on the deployed Hydrolab ${ }^{\circledR}$ sonde and were periodically downloaded throughout the study period.

The selection of turbidity sensors at the study stations allowed for direct comparison of turbidity between the two unregulated inflow stations and direct comparison of turbidity between the four lower-basin stations. Currently (2014), no data have been published comparing turbidity measurements between Analite ${ }^{\circledR}$ NEP 395 sensors and the self-cleaning turbidity sensors deployed on the Hydrolab ${ }^{\circledR}$ data sondes, so no direct comparisons of turbidity can be made between stations with these different instruments. Turbidity time-series records were worked, checked, and reviewed following the USGS Continuous Record Processing (CRP) Implementation Plan (U.S. 
Geological Survey, 2008) and following procedures outlined in Wagner and others (2006), resulting in approved continuous turbidity data pursuant to USGS data quality standards. Data ratings, missing unit values, and summary statistics of turbidity data are included in table 3.

Table 3. Summary statistics, missing unit values, and data rating for turbidity and dissolved oxygen at monitoring stations in the Middle Fork Willamette River Basin, Oregon.

[Turbidity data rated as "Good" is defined as the combined fouling and calibration drift corrections applied to the record greater than $\pm 0.5-1.0$ FNU or greater than $\pm 5-10$ percent, whichever is greater. Dissolved oxygen data rated as "Good” is defined as the combined fouling and calibration drift corrections applied to the record greater than or equal to $\pm 0.3-0.5 \mathrm{mg} / \mathrm{L}$ or greater than 5-10 percent, whichever is greater. Abbreviations: FNU, Formazin Nephelometric Units; DO, dissolved oxygen; mg/L, milligram per liter]

\begin{tabular}{|c|c|c|c|c|c|c|c|c|c|c|}
\hline \multirow[b]{2}{*}{ Station reference } & \multicolumn{5}{|c|}{ Turbidity } & \multicolumn{5}{|c|}{ Dissolved Oxygen } \\
\hline & $\begin{array}{c}\text { Planned } \\
\text { monitoring, } \\
\text { unit values }\end{array}$ & $\begin{array}{c}\text { Missing } \\
\text { unit values, } \\
\text { as percent } \\
\text { of total }\end{array}$ & $\begin{array}{c}\text { Maximuml } \\
\text { minimum } \\
\text { turbidity } \\
\text { (FNU) }\end{array}$ & $\begin{array}{l}\text { Meanl } \\
\text { median } \\
\text { turbidity } \\
\text { (FNU) }\end{array}$ & $\begin{array}{l}\text { Percentage } \\
\text { of data rated } \\
\text { "Good" or } \\
\text { better }\end{array}$ & $\begin{array}{c}\text { Planned } \\
\text { monitoring, } \\
\text { unit values }\end{array}$ & $\begin{array}{l}\text { Missing unit } \\
\text { values, as } \\
\text { percent of } \\
\text { total }\end{array}$ & $\begin{array}{l}\text { Maximuml } \\
\text { minimum } \\
\text { DO (mg/L) }\end{array}$ & $\begin{array}{c}\text { Mean/ } \\
\text { median DO } \\
(\mathrm{mg} / \mathrm{L})\end{array}$ & $\begin{array}{l}\text { Percentage } \\
\text { of data rated } \\
\text { "Good" or } \\
\text { better }\end{array}$ \\
\hline Dexter & 12,111 & 0.95 & $26.0 / 2.10$ & $9.75 / 9.70$ & 99 & - & - & - & - & - \\
\hline Fall Creek Inflow & 9,066 & 9.79 & $300 / 0.20$ & $6.37 / 3.00$ & 55 & - & - & - & - & - \\
\hline Winberry Creek & 11,504 & 0.60 & $379 / 0.00$ & $7.22 / 3.10$ & 94 & - & - & - & - & - \\
\hline Fall Creek Outflow & 11,428 & 0.78 & $2,960 / 0.00$ & $55.5 / 4.90$ & 99 & 10,661 & 5 & $13.8 / 6.49$ & $12.3 / 12.6$ & 100 \\
\hline Jasper & 10,857 & 13.1 & $514 / 0.00$ & $16.5 / 6.10$ & 93 & 10,764 & 14 & $13.2 / 11.7$ & $11.7 / 12.0$ & 100 \\
\hline Little Fall Creek & 10,409 & 3.60 & $168 / 0.20$ & $7.75 / 4.40$ & 100 & - & - & - & - & - \\
\hline
\end{tabular}

\section{Suspended Sediment}

Samples for SSC were collected according to USGS protocols using depth- and width- integrating (equal-width-integrating [EWI]) techniques as described by Edwards and Glysson (1999) and (Gray and others, 2008). For bridge, cableway, and boat sampling, either a USGS D-74 or a USGS DH-59 sediment sampler with a 1-quart glass bottle was used (Edwards and Glysson, 1999). Wading samples were collected in a DH-81 sediment sampler enclosing a 1-liter Nalgene ${ }^{\circledR}$ bottle. Samples were composited into 3-liter Nalgene ${ }^{\circledR}$ bottles. Sediment analysis was conducted at the USGS Cascade Volcano Observatory (CVO) sediment laboratory, reporting suspended-sediment concentration in milligrams per liter of dried sediment. A subset of samples at each station was analyzed for the percentage of suspended sediment less than $0.063 \mathrm{~mm}$ (fine fraction). During some sampling events at Jasper, high flows resulted in the EWI sample filling two 3-liter bottles. For most of those samples, the two bottles were analyzed separately to examine the cross-sectional variability of SSC at Jasper, which was observed to be poorly mixed at the start of the study. In addition, total SSC was composited mathematically by $\mathrm{CVO}$, and reported as a single concentration for the associated mean sample time. 
Pump samplers were installed at two stations to collect point samples on a more frequent basis than EWI samples could be collected by cableway, bridge, or boat sampling. One pump sampler was located at Dexter and one at Jasper. The pump sampler at Dexter was used because of the lack of a cableway or nearby bridge where samples could be easily collected on a periodic basis. Pump samples at Dexter were collected at varying intervals throughout the study period, depending on the station conditions and data needs. Two EWI samples were collected by boat at Dexter, simultaneous with pump samples, and were used to calculate box coefficients (Edwards and Glysson, 1999) to adjust the pump sample SSC to the cross-sectional SSC. The pump sampler at Jasper was installed to collect samples more frequently than could be collected manually, especially during the drawdown period. EWI samples at Jasper also provided data needed for calculating box coefficients to adjust the pump sample SSC to cross-sectional SSC. The number and type of samples collected at each station are listed in table 4. Details on box coefficient calculations and their applications to SSC data at Dexter and Jasper are included in the station analyses for both stations (appendix A).

Table 4. Suspended-sediment and bedload sample inventory at the monitoring stations in the Middle Fork Willamette River Basin, Oregon.

[Station reference: Complete station names are shown in table 1; locations are shown in figure 1. Abbreviations: SS, suspended-sediment, EWI, equal width increment.]

\begin{tabular}{llc}
\hline \multicolumn{1}{c}{ Station reference } & Sample type & $\begin{array}{c}\text { Number of } \\
\text { samples }\end{array}$ \\
\hline Dexter & SS - EWI & 2 \\
& SS - PUMP & 29 \\
\hline Fall Creek Inflow & SS - EWI & 5 \\
\hline Winberry Creek & SS - EWI & 5 \\
\hline Fall Creek Outflow & SS - EWI & 16 \\
& Bedload - EWI & 6 \\
\hline Jasper & SS - EWI & 15 \\
\hline Little Fall Creek & SS - EWI & 41 \\
\hline
\end{tabular}

Replicate samples (A and B sets) for EWI samples were periodically collected at Fall Creek Outflow, Dexter, and Jasper for quality assurance, and were collected more often during the drawdown. Samples represented a minimum 20 percent of the total number of EWI samples collected at Fall Creek Outflow and Jasper, with relative percent differences (RPD) of A and B sets ranging from 3 to 11 percent, except for one replicate sample at Jasper collected during the drawdown determined to be biased high. Replicate samples at Dexter were collected for the two EWI boat samples, representing 100 percent of the EWI samples collected at that station. The first replicate sample set at Dexter resulted in both A and B sets having identical concentrations (6 mg/L). The second replicate sample set resulted in A and B set concentrations of 2 and $3 \mathrm{mg} / \mathrm{L}$, respectively.

\section{Dissolved Oxygen}

DO was monitored at two of the study stations: Fall Creek Outflow and Jasper. Both stations had luminescent dissolved oxygen (LDO) sensors deployed on the Hydrolab ${ }^{\circledR}$ DS5x multiparameter data sondes with the turbidity sensors. Sensor operation and maintenance followed guidelines outlined in Wagner and others (2006). DO sensors were calibrated using the "aircalibration chamber in air" method described in Lewis (2006). Data were logged every 15 minutes throughout the study period. DO records were worked, checked, and reviewed through the USGS CRP Implementation Plan (U.S. Geological Survey, 2008) and followed procedures outlined in Wagner and others (2006), which resulted in approved continuous DO data pursuant to USGS data quality standards.

\section{Bedload}

Bedload sampling was conducted only at Fall Creek Outflow and only during the week of the drawdown. A US BL-84 sampler with a 3 by 3 in. opening and 1.4 expansion ratio was used to collect bedload samples from a cableway. A crosssectional stay-line was installed approximately 50 $\mathrm{ft}$ upstream of the cableway to maintain a vertical position of the sampler in the water column. The 
BL-84 sampler was lowered to the stream bottom where it rested for 40 seconds collecting moving bed material at each station in the cross section. A minimum of nine equally spaced stations along the cross section were sampled, and the sample material was composited into a single canvas bag at the stream bank. Samples were sent to the CVO sediment lab for analysis, reporting bedload in total mass of dried sediment, size fraction analysis, and LOI.

\section{Streamflow Estimates at Little Fall Creek}

Although periodic streamflow measurements have been made on Little Fall Creek downstream of the study station location, no continuous stage or discharge data were available at the sampling station for the study period. Streamflow data for Little Fall Creek were therefore estimated as the difference between streamflow at Jasper and the summed streamflow at Dexter and Fall Creek Outflow, adjusted for average time of travel, and scaled by watershed size according to the following equation:

$Q_{X}=\left[Q_{J}-\left(Q_{D}+Q_{F}\right)\right] \times\left[A_{X} /\left(A_{X}+A_{H}+A_{L}\right)\right]$

where

$Q_{X} \quad$ is streamflow at Little Fall Creek (- 2.0 hour time-of-travel);

$Q_{J} \quad$ is streamflow at Jasper;

$Q_{D} \quad$ is streamflow at Dexter $(+1.5$ hours timeof-travel);

$Q_{F} \quad$ is streamflow at Fall Creek Outflow (+ 2.0 hours time-of-travel);

$A_{X} \quad$ is drainage basin area of Little Fall Creek;

$A_{H} \quad$ is drainage basin area of Hills Creek;

and

$A_{L} \quad$ is drainage basin area of Lost Creek.

The times-of-travel for streamflow from Fall Creek Outflow to Jasper and Dexter to Jasper were determined by examining the timing of distinct changes in outflow from Fall Creek and Dexter Dams, respectively. The time difference between these measured changes at each station was examined over a range of conditions and then averaged. The time-of-travel from Little Fall Creek to Jasper was assumed to be the same as that of Fall Creek Outflow because of the similar distance and range of streamflow values.

The first streamflow-gaging station downstream of the Little Fall Creek confluence with Fall Creek is Jasper. Subtracting the streamflow at Dexter (correcting for an average of 1.5 hours travel time) and Fall Creek Outflow (correcting for an average of 2.0 hours travel time) from Jasper approximates the flow contribution of the ungaged tributaries between the stations, including the Middle Fork Willamette River reach between Jasper and Dexter, and the Fall Creek reach between its confluence with the Middle Fork Willamette River and Fall Creek Outflow (fig. 2). The three largest ungaged tributaries in the basin are Little Fall Creek, Lost Creek, and Hills Creek (fig. 1). The streamflow of the three tributaries is assumed to be proportional to their drainage basin areas, with Little Fall Creek Basin comprising 44.4 percent of the combined area. Finally, the computation is corrected for an estimated 2.0 hour travel time between Little Fall Creek and Jasper. The resulting unit values were used to assign discrete streamflow values to the SSC samples for the regression analysis at Little Fall Creek and to compute the continuous SSL record at the station.

USGS StreamStats (U.S. Geological Survey, 2014) was used to assess the streamflow estimates at Little Fall Creek by comparing the peak streamflow value during the study period to the peak at one of the gaged sites. The peak streamflow at Winberry Creek was $2,510 \mathrm{ft}^{3} / \mathrm{s}$ on November 20, 2012. This value is within 3 percent of the 2-year recurrence interval streamflow computed by StreamStats for the station $(2,570$ $\left.\mathrm{ft}^{3} / \mathrm{s}\right)$. StreamStats estimates the 2-year recurrence interval streamflow for Little Fall Creek as 2,840 $\mathrm{ft}^{3} / \mathrm{s}$. The peak streamflow estimated by the computations previously described was $2,730 \mathrm{ft}^{3} / \mathrm{s}$ on the same date, which is within 4 percent of the StreamStats value. Although the estimated unit streamflow values at Little Fall Creek seem to be reasonable, any future data collection at this station should include measurements of streamflow to further improve data accuracy. 


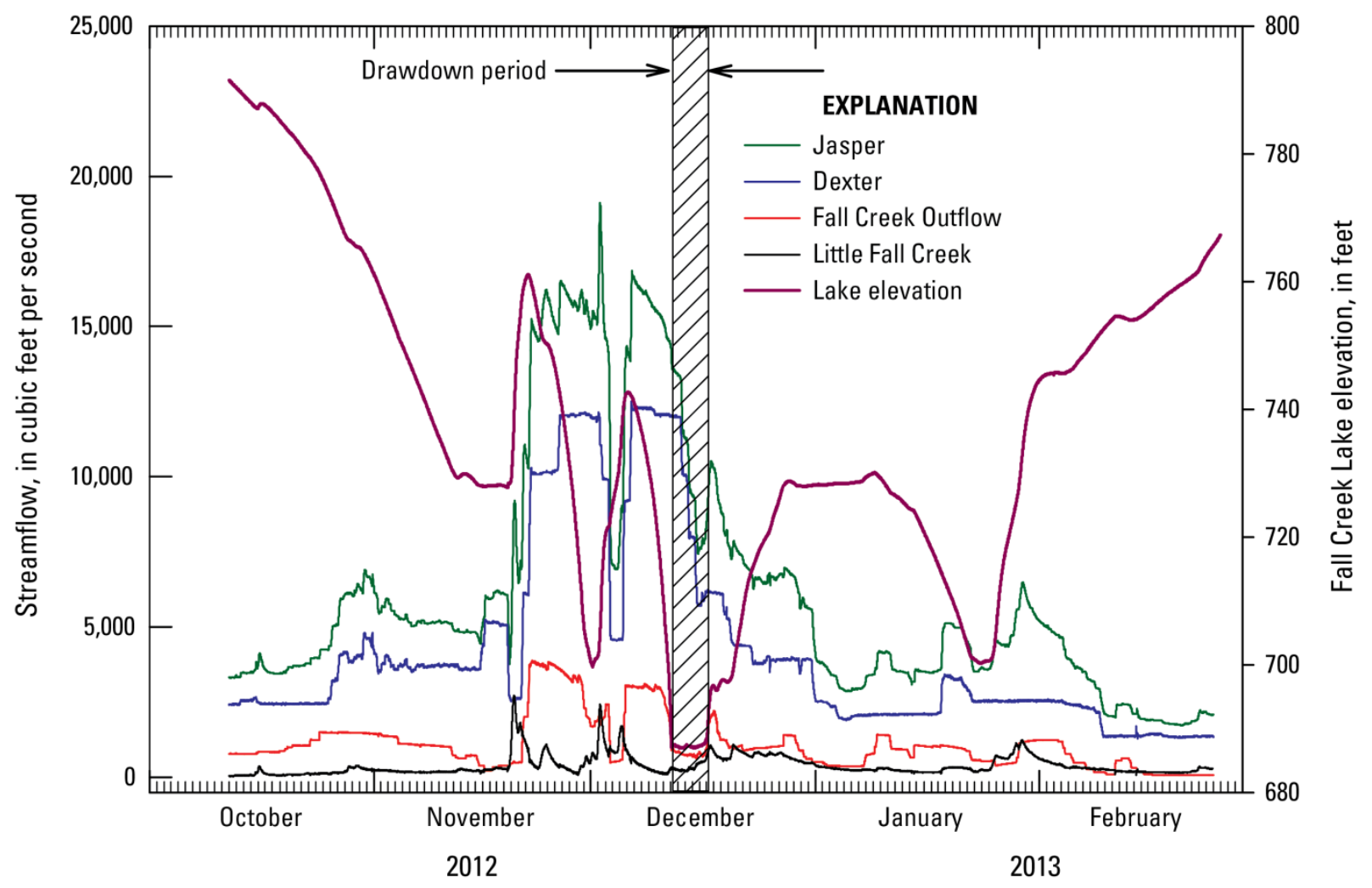

Figure 2. Continuous streamflow at three U.S. Geological Survey streamflow-gaging stations (Jasper, Dexter, and Fall Creek Outflow), estimated streamflow at one water-quality monitoring station (Little Fall Creek), and elevation of Fall Creek Lake, Middle Fork Willamette River Oregon, 2012-13. Lake elevations obtained from the U.S. Army Corps of Engineers dataquery website, http://www.nwd-wc.usace.army.mil/perl/dataquery.pl, accessed January 18, 2014.

\section{Suspended-Sediment Concentration Regression Model Development}

Time series of SSC were derived using linear regression techniques as described in Rasmussen and others (2009), evaluating turbidity and streamflow as explanatory variables. Turbidity has proven to be a useful surrogate for SSC in other basins draining the Western Cascades and High Cascades (Anderson, 2007; Bragg and others, 2007; Bragg and Uhrich, 2010). Simple linear regressions (SLR) and multiple linear regressions (MLR) were evaluated to compute SSC. Log transformation was used where appropriate to make model residuals more symmetric, linear, and homoscedastic. Appropriate station-specific models were selected based on minimal model standard prediction errors (MSPE), maximum adjusted coefficients of determination (Adj $\mathrm{R}^{2}$ ), evaluation of residuals with probability plots, and the probability plot correlation coefficients (PPCC) for log-transformed data.

Log-transformations that maximize PPCC values (correlation coefficient values close to 1 ) for regression residuals optimize the normality of the residuals (Helsel and Hirsch, 1992), and were used as a basis for choosing between logtransformed and non-transformed regressions. The PPCC test statistic is the correlation coefficient between model residuals and normal quantiles shown on the probability plot, and has been shown to be a powerful and conceptually simple method to test goodness-of-fit (Heo and others, 2008). For log-transformed regression equations, values of continuous SSC were computed from the base-10 logarithm of SSC as determined from the regression after correcting for transformation bias using Duan's bias correction factor (Helsel and Hirsch, 1992). 
MLR models were evaluated against SLR models on the basis of two criteria: (1) MSPE and Adj $\mathrm{R}^{2}$ and (2) multi-collinearity of turbidity and streamflow. When comparing a SLR to a MLR model, the model with the lowest MSPE and highest $\operatorname{Adj~} \mathrm{R}^{2}$ is used as the first determining factor in selecting the candidate model. If a MLR was selected as a candidate model, multi-collinearity of turbidity and streamflow were evaluated using the variance inflation factor (VIF) statistic, a measure of collinearity. The ideal VIF value is approximately 1 (Helsel and Hirsch, 1992, p. 305), and VIF values greater than 5 were used as a criteria for eliminating one of the explanatory variables, resulting in a SLR candidate model. The explanatory variable for the resulting SLR was again chosen based on minimum MSPE values, maximum Adj $\mathrm{R}^{2}$, and PPCC values close to 1 .

SSC time-series records were worked, checked, and reviewed through the USGS CRP Implementation Plan (U.S. Geological Survey, 2008), which resulted in approved continuous SSC data. Upon approval of SSC data for each station, time series were uploaded directly into the USGS Automatic Data Processing System (ADAPS) database. Individual regression equations used to compute time series of SSC at each station are included in table 5. Regression equations from each station were developed individually resulting in different explanatory variables for SSC, and at times, the use of MLR models.

\section{Data Analysis}

\section{Suspended- Sediment Concentration Model Results}

Station analysis documents for individual station SSC regression model development and results are included in appendix A. The station analysis includes model results; descriptions of equipment deployments at each station; details about the model calibration data sets; various figures, including time series plots of SSC with 90 percent confidence intervals; summary statistics of the regression models; extreme values; and data limitations.

\section{Inflow Stations}

Because of the short-term nature of the study, few samples were collected at the inflow stations (Fall Creek Inflow and Winberry Creek) to develop SSC-turbidity/streamflow regressions. Five samples were collected at each of the stations during the study period at low and medium flows, and one storm event was sampled on November 20, 2012, the largest such event during the study period. As a result, the statistics for the regression equations at both stations reported high Adj $\mathrm{R}^{2}$ values, caused by the single data point at the highest end of the turbidity and streamflow range for the study period (table 5 , appendix A). Two models were used to estimate SSC at the Fall Creek Inflow station: (1) a logtransformed SSC-turbidity model for most of the period of record, and (2) a log-transformed SSCstreamflow model for the period November 2029, 2012, when turbidity data were lost from damage to the instrument during the November 20 storm event. Owing to the loss of turbidity data during that time, streamflow was the only remaining surrogate that could have been used to estimate SSC. Four discrete SSC values were interpolated to transition between the two models, two values at the beginning and end of the log-transformed SSC-streamflow model (appendix A). SSC at Winberry Creek was calculated using an untransformed SSC-turbidity regression equation for the entire study period. The model calibration dataset of both inflow stations had few samples that were not well distributed over the range of streamflow and turbidity at the monitoring stations during the analysis period. Consequently, all daily mean values of SSC at both inflow stations are considered "estimated" and are flagged as such in the ADAPS database. 
Table 5. Suspended-sediment concentration models for the monitoring stations in the Middle Fork Willamette River Basin, Oregon

[Station reference: Complete station names are shown in table 1; locations are shown in figure 1. Date format is mm/dd/yy. Abbreviations: T, turbidity; Q, discharge; SSC, suspended-sediment concentration; MSPE, model standard prediction error; PPCC, probability plot correlation coefficient; BCF, Duan's bias correction factor]

\begin{tabular}{|c|c|c|c|c|c|c|c|}
\hline Station reference & Regression model equation & $\mathrm{BCF}$ & $\begin{array}{c}\text { Adjusted } \\
\text { coefficient of } \\
\text { determination } \\
\left(R^{2}\right)\end{array}$ & $\begin{array}{c}\text { MSPE } \\
\text { (percent) }\end{array}$ & PPCC & $\begin{array}{l}\text { Number of } \\
\text { samples used } \\
\text { in regression } \\
\text { equation }\end{array}$ & $\begin{array}{l}\text { Computation dates } \\
\text { (mm/dd/yy) }\end{array}$ \\
\hline \multirow{2}{*}{ Dexter } & \multirow{2}{*}{$\mathrm{SSC}=-1.23+0.258 \mathrm{~T}+0.000808 \mathrm{Q}$} & \multirow{2}{*}{ - } & \multirow{2}{*}{0.78} & +37.0 & \multirow{2}{*}{0.99} & \multirow{2}{*}{29} & \multirow{2}{*}{$11 / 01 / 12-03 / 05 / 13$} \\
\hline & & & & -37.0 & & & \\
\hline \multirow{4}{*}{ Fall Creek Inflow } & \multirow{2}{*}{$\log _{10} \mathrm{SSC}=-0.0841+1.17 \log _{10} \mathrm{~T}$} & \multirow{2}{*}{1.02} & \multirow{2}{*}{0.99} & +27.3 & \multirow{2}{*}{0.98} & \multirow{2}{*}{5} & 11/08/12-11/20/12, \\
\hline & & & & -21.4 & & & $11 / 29 / 12-02 / 08 / 13$ \\
\hline & \multirow{2}{*}{$\log _{10} \mathrm{SSC}=-2.96+1.38 \log _{10} \mathrm{Q}$} & \multirow{2}{*}{1.19} & \multirow{2}{*}{0.88} & +113 & \multirow{2}{*}{0.99} & \multirow{2}{*}{5} & \multirow{2}{*}{$11 / 20 / 12-11 / 29 / 12$} \\
\hline & & & & -53.1 & & & \\
\hline \multirow{2}{*}{ Winberry Creek } & \multirow{2}{*}{$\mathrm{SSC}=2.61+1.10 \mathrm{~T}$} & \multirow{2}{*}{ - } & \multirow{2}{*}{0.99} & +5.13 & \multirow{2}{*}{0.97} & \multirow{2}{*}{5} & \multirow{2}{*}{$11 / 07 / 12-03 / 07 / 13$} \\
\hline & & & & -5.13 & & & \\
\hline \multirow{4}{*}{ Fall Creek Outflow } & \multirow{2}{*}{$\mathrm{SSC}=4.91+0.764 \mathrm{~T}-0.00312 \mathrm{Q}$} & \multirow{2}{*}{-} & \multirow{2}{*}{0.99} & +5.42 & \multirow{2}{*}{0.98} & \multirow{2}{*}{5} & 10/26/12-12/12/12, \\
\hline & & & & -5.42 & & & $01 / 15 / 13-02 / 22 / 13$ \\
\hline & \multirow{2}{*}{$\begin{array}{l}\log _{10} \mathrm{SSC}=-1.07+0.966 \log _{10} \mathrm{~T}+ \\
0.612 \log _{10} \mathrm{Q}\end{array}$} & \multirow{2}{*}{1.02} & \multirow{2}{*}{0.99} & +28.7 & 000 & 10 & $1212 / 1201 / 15 / 12$ \\
\hline & & & & -22.0 & 0.98 & 10 & $12 / 12712-01 / 15 / 13$ \\
\hline & 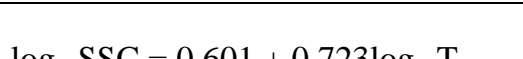 & 111 & 0.01 & +67.4 & 004 & 14 & $10 / 26 / 1212 / 10 / 12$ \\
\hline & $\log _{10} \mathrm{SSC}=0.601+0 . / 23 \log _{10} 1$ & 1.11 & 0.91 & -40.3 & 0.94 & 14 & $10 / 26 / 12-12 / 18 / 12$ \\
\hline & lox CSC $-005+251 \log$ & 111 & 0.91 & +65.0 & 0.00 & 17 & 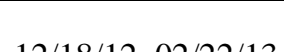 \\
\hline & $\log _{10} \mathrm{SSC}=-8.0 \mathrm{~S}+2.51 \log _{10} \mathrm{Q}$ & 1.11 & 0.81 & -39.4 & 0.99 & 17 & $12 / 18 / 12-02 / 22 / 13$ \\
\hline & log SSC $=0265+0881 \log$ & 114 & 088 & +99.2 & 094 & 5 & 11/07/12-11/19/12, \\
\hline & $\log _{10} \mathrm{SSC}=0.265+0.88110 \mathrm{~g}_{10} 1$ & 1.14 & 0.88 & -49.8 & 0.94 & 5 & $12 / 01 / 12-02 / 24 / 13$ \\
\hline & lox SSC $-360+175 \log$ & 107 & 0.05 & +59.6 & 0.05 & 5 & $11 / 10 / 1212 / 01 / 12$ \\
\hline & $\log _{10} 350-3.00+1.7310 g_{10} \mathrm{Q}$ & 1.07 & 0.95 & -37.3 & 0.95 & 5 & $11 / 19 / 12-12 / 01 / 12$ \\
\hline
\end{tabular}




\section{Fall Creek Outflow}

Computation of SSC time series at Fall Creek Outflow was challenging owing to the short study duration, extreme sensor fouling, and variations in the size fractions of transported sediment. To account for the size-fraction variation, two MLR models were used to compute SSC for the study period. A total of $16 \mathrm{EWI}$ samples were collected to calibrate the regression models. The samples were divided according to the reservoir conditions at the time they were collected: Pre-drawdown (samples 1-5), drawdown (samples 6-13), and post-drawdown (samples 14-16). Initial analysis

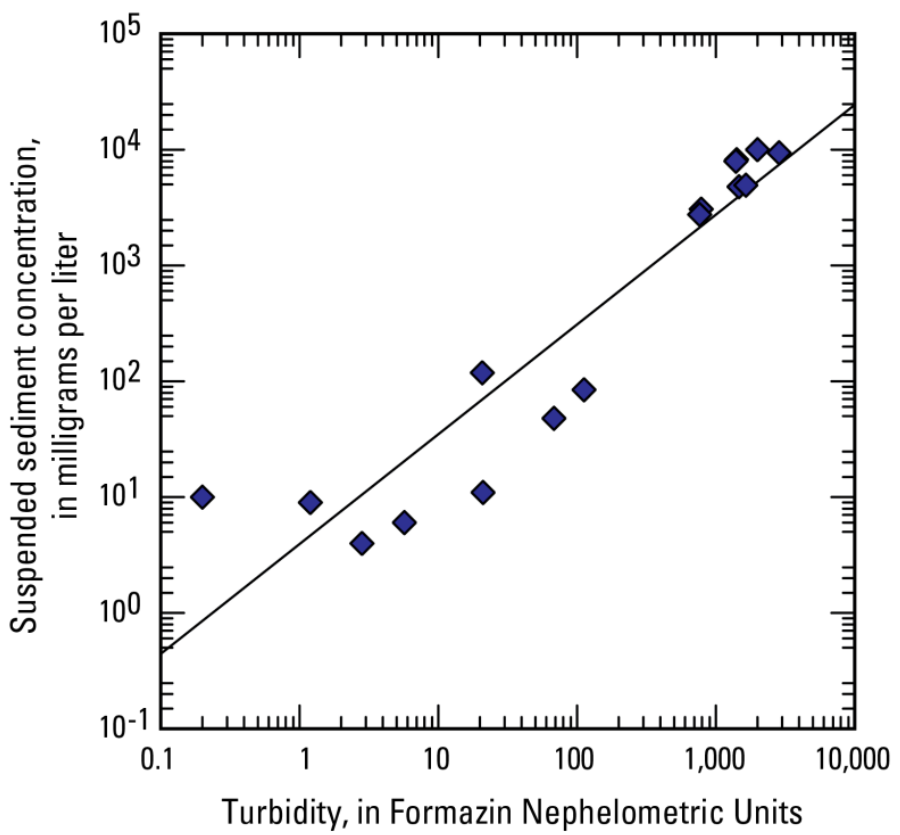

of these samples indicates that this timing is consistent with the ranges of concentrations and the percent fines of the samples, implying that sediment sources and characteristics were different for the different periods. Such differences would be expected to produce different turbidities for given sediment concentrations. Specifically, coarse sediment renders turbidity a less successful surrogate due to inconsistent scattering of light. Plots of the response variable (SSC) with the possible explanatory variables (turbidity and streamflow) indicated that there are correlations with one or both variables, possibly for subsets of the samples during these distinct periods (fig. 3).

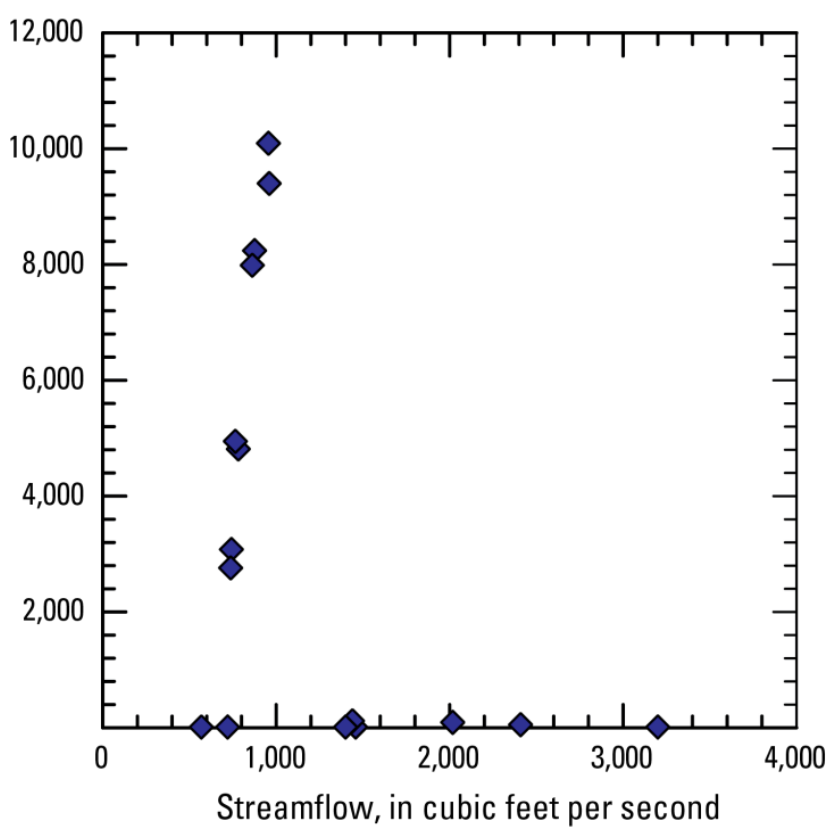

Figure 3. Scatterplots showing suspended-sediment concentration, turbidity, and streamflow for equal-widthintegrating samples collected at Fall Creek Outflow, Middle Fork Willamette River Basin, Oregon

Samples collected before the drawdown had high percentage of fines (86-99 percent) (fig. 4) and low to moderate SSC values. An MLR with turbidity and streamflow was selected as the best model for computing SSC based on the MSPE, PPCC, and $\mathrm{R}^{2}$ values. This model is used to compute SSC from the beginning of the analysis period (October 26, 2012, at 1130, 24-hour clock time) through the onset of the reservoir drawdown (December 12, 2012, at 0045). By mid-January 2013, sediment transport appeared to have gradually returned to pre-drawdown conditions (lower turbidity and higher percent fine values) and this model was again used to compute SSC from January 15, 2013, at 0415 through the end of the analysis period for this station (February 22, 2013, at 1215).

Samples collected during the drawdown had moderate percent fines (51-71 percent) (fig. 4) and high SSC (2,700-10,000 mg/L). After the drawdown operations ended on December 17, 2012, a marked decrease in the percent fines of samples collected at this station and downstream (10-17 percent) indicate a coarsening of the sediment load. This effect was temporary and tapered off by mid-January. Using the samples 
from the drawdown and post-drawdown periods, an MLR with log-transformed turbidity and streamflow was selected as the best model for computing SSC. This model was used to compute SSC from shortly after the beginning of the drawdown (December 12, 2012, at 0245) through mid-January (January 15, 2013, at 0400) (fig. 5).

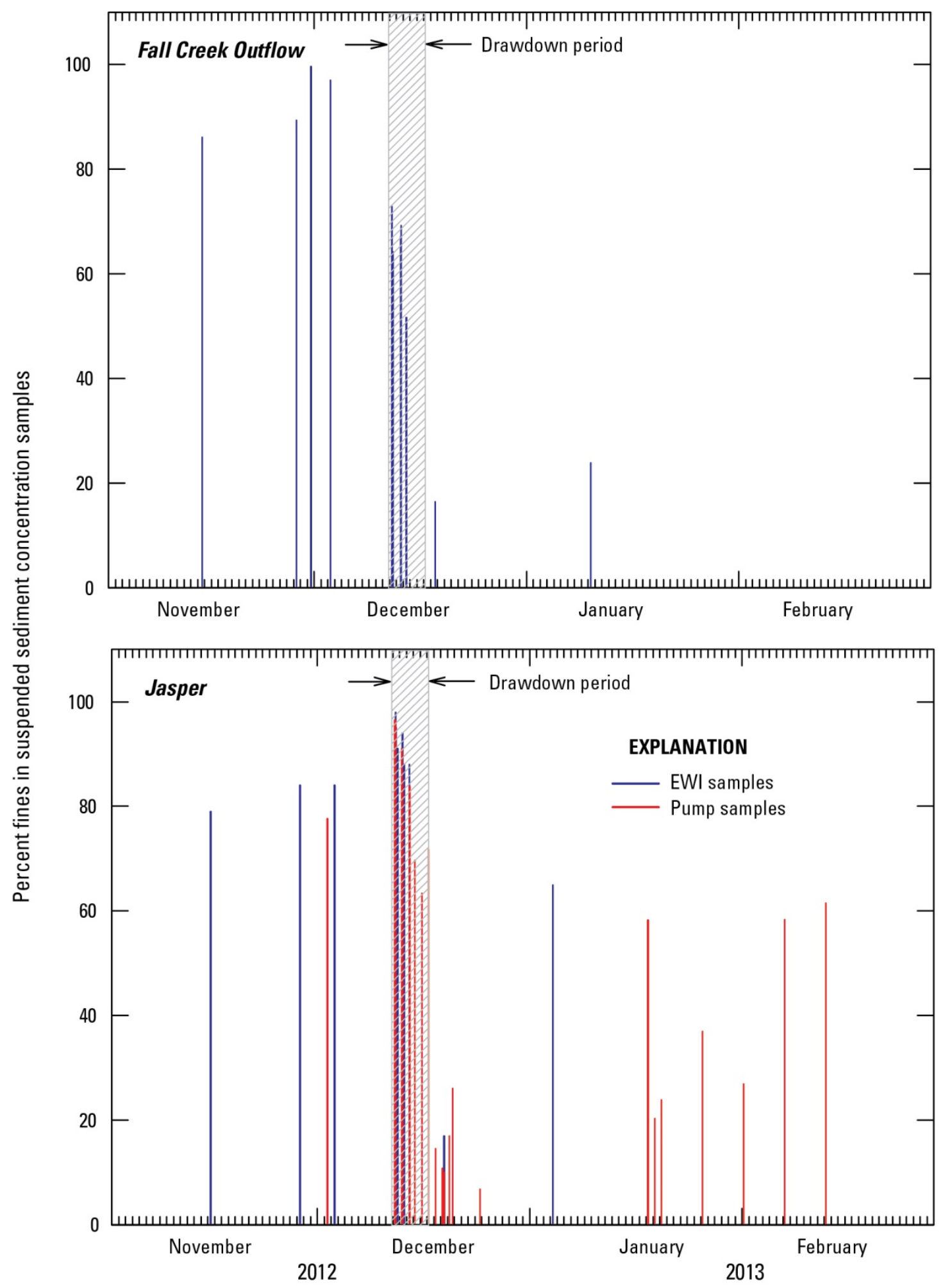

Figure 4. Percent fines of suspended-sediment concentration samples collected at Fall Creek Outflow and Jasper, Middle Fork Willamette River Basin, Oregon 

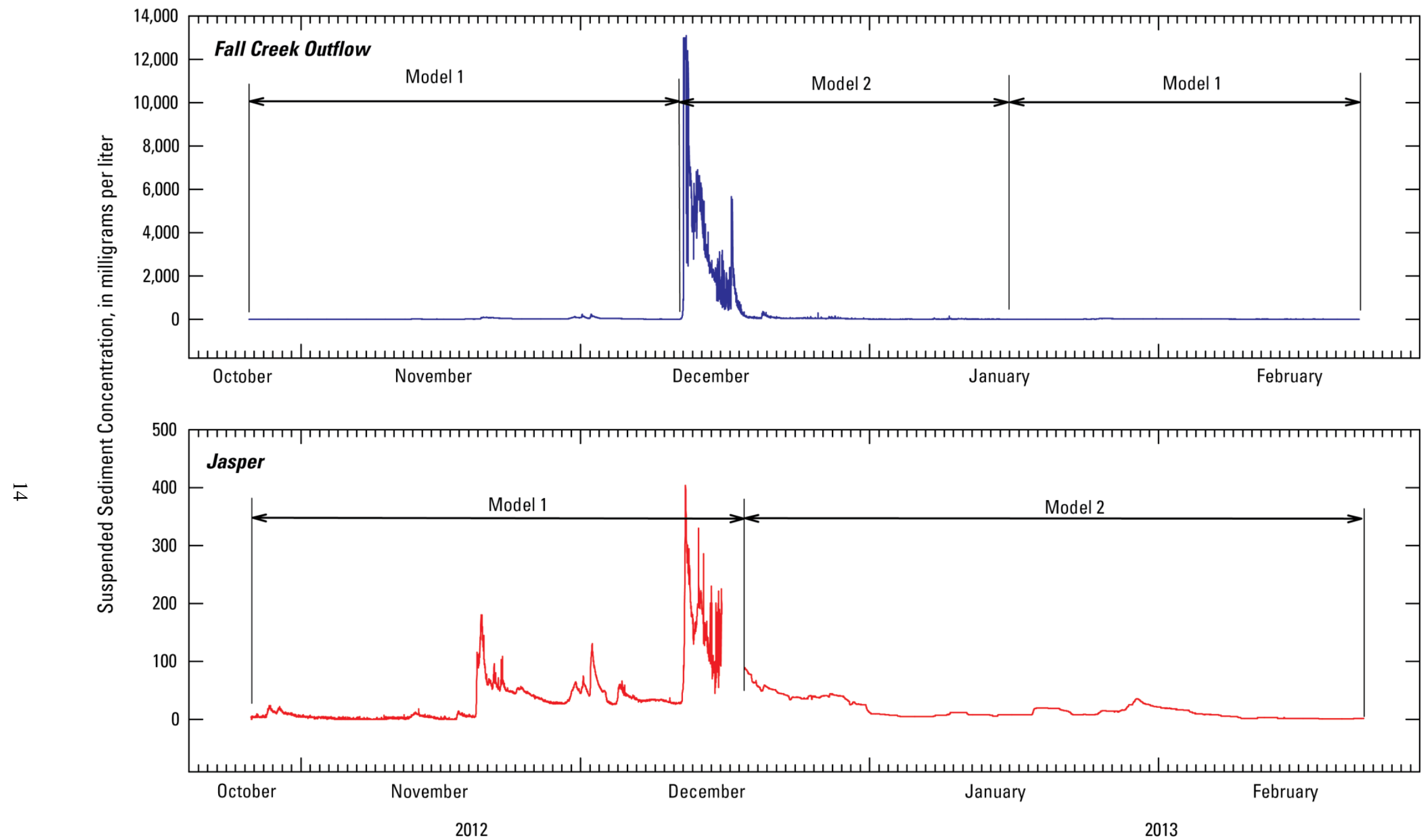

Figure 5. Time-series graphs showing suspended-sediment concentration and periods for separate regression models at Fall Creek Outflow and Jasper, Middle Fork Willamette River Basin, Oregon, 2012-13. Model information in table 5. 


\section{Little Fall Creek}

Little Fall Creek is an unregulated, ungaged tributary to Fall Creek, upstream of the Fall CreekMiddle Fork Willamette River confluence that has the potential to contribute large amounts of sediment to Fall Creek due to observed high turbidities at high streamflows, and a drainage area larger than Winberry Creek (table 1). No streamflow measurements were made during the analysis period. The streamflow values used to compute the SSC record were estimated by calculating the difference in streamflow from nearby gaging stations at Jasper, Fall Creek Outflow, and Dexter (see Data Collection and Methods section). The model calibration dataset consists of five samples that were not well distributed across the range of conditions at the station during the analysis period. Most samples were in the low-moderate range of streamflow and turbidity during the analysis period, except for one sample collected on November 20, 2012 that captured the largest storm event of the sampling period. Consequently, this single data point at the highest end of the turbidity and streamflow range for the study period probably exerted a disproportionately strong effect on statistics for the regression models (high Adj $\mathrm{R}^{2}$ ) similar to the inflow stations.

Initial plots of SSC with turbidity and streamflow indicated that both were correlated to SSC (appendix A) but at different times during the analysis period, resulting in the use of two models to compute SSC. The first model (Model 1) is an SLR with log-transformed turbidity as an explanatory variable and was used to compute SSC from the beginning of the analysis period (November 7, 2012) through the onset of the largest storm event of the season (November 19, 2012). This model was used again to compute SSC after a second, smaller storm in early December (December 1, 2013) through the end of the analysis period (February 24, 2013). Model 2 also is an SLR, but used log-transformed streamflow instead of turbidity as an explanatory variable for SSC. This model was used to compute SSC from the onset of the largest storm of the season until streamflow subsided following the storm in late November. Because of the small number of samples and the estimated streamflow used to compute SSC with Model 2, all daily mean values are flagged as "estimated" in the ADAPS database.

\section{Jasper}

The Middle Fork Willamette River at Jasper is the farthest downstream station in the study area. EWI samples collected from the cableway and pump samples collected from the right bank at the existing gaging station were used to calibrate regression models. Early in the study, poor mixing of the stream channel was observed following storm events, with higher concentrations of sediment evident in the right half of the channel. These high concentrations consistently occurred on the right bank during the study period, evidenced by separate analysis of sample bottles collected from individual EWI samples. This poor mixing was likely due to the influences of Hills Creek, approximately $500 \mathrm{ft}$ upstream of the gaging station on the right edge of water, and Fall Creek, which flows into the Middle Fork Willamette River on the right side of the channel approximately 3 river miles upstream of the gage. Consequently, the concentrations from the pump samples were deemed non-representative of cross section concentrations, and were adjusted using box coefficients, which ranged from 0.875 to 0.385 (appendix A).

Variations in the size fractions of suspended sediment at Jasper, represented by percent of sample finer than $0.063 \mathrm{~mm}$ in SSC samples (fig. 4), led to the use of two separate regressions to compute SSC during the study period (fig. 6, appendix A). SSC samples were separated into two groups based on percent fines and drawdown conditions at Fall Creek Lake: Pre-drawdown and drawdown (14 EWI samples), and post-drawdown (17 EWI and pump samples). Similar to Fall Creek Outflow, plots of the response variable (SSC) with the possible explanatory variables (turbidity and streamflow) indicated that there are correlations with one or both variables during these distinct periods. 

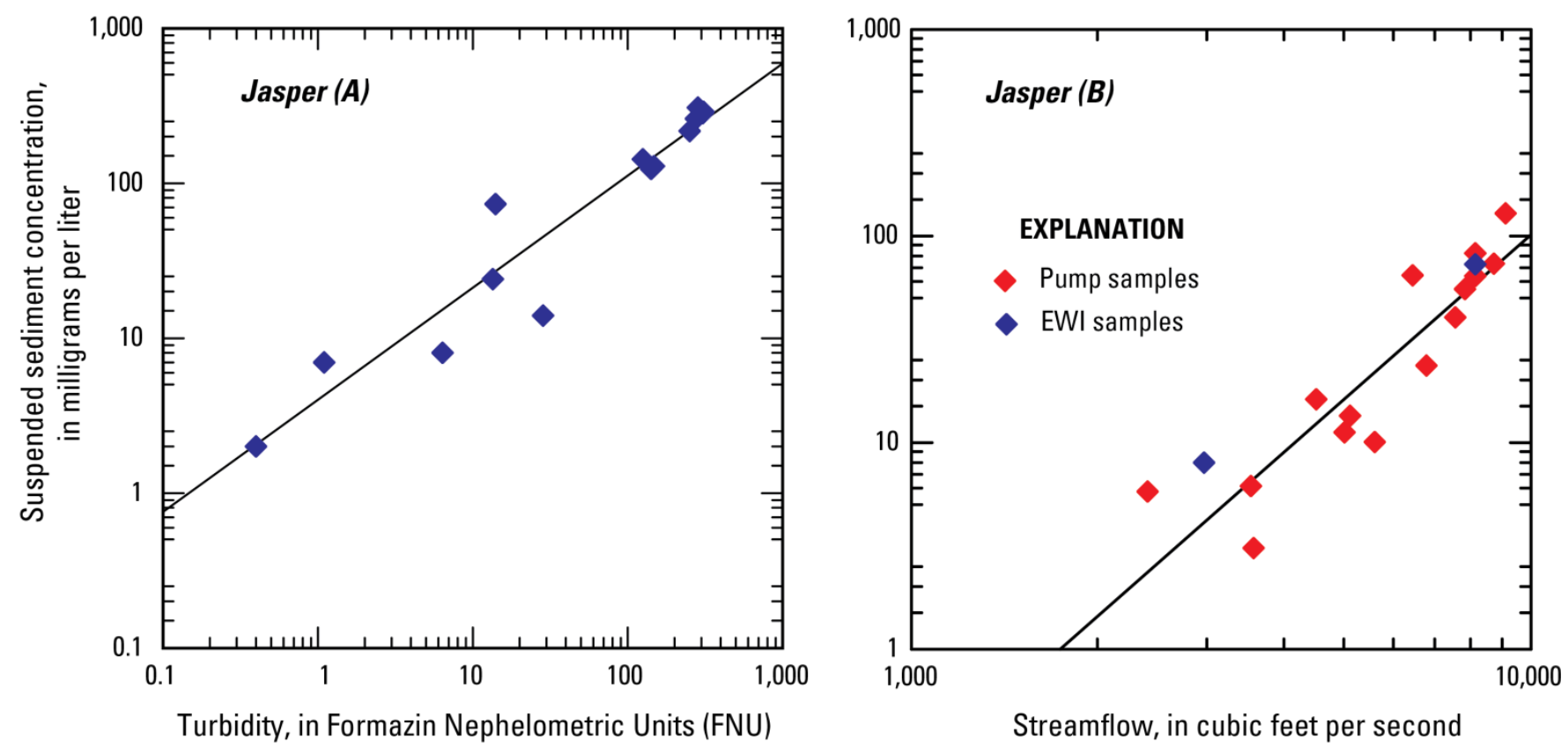

Figure 6. Regression scatterplots used to compute suspended-sediment concentration (SSC) at Jasper, Middle Fork Willamette River Basin, Oregon. Jasper (A): Regression used to compute SSC from October 26, 2012, to December 18, 2012 (pre-drawdown and drawdown). Jasper (B): Regression used to compute SSC from December 18, 2012 to February 22, 2013 (post-drawdown).

Samples collected before and during the drawdown (October 26-December 18, 2012) (fig. 5) had high percentage of fines and a wide range of SSC concentrations, with the highest SSC values occurring during the drawdown beginning on December 12, 2012. Fourteen EWI samples were used to calibrate the model, and log-transformed turbidity was selected as the best explanatory variable for this period.

The second model applied to the period after the drawdown (December 18, 2012-February 22, 2013) (fig. 5) and was calibrated with 2 EWI samples and 15 pump samples. Pump samples used in the calibration datasets were adjusted with a box coefficient before evaluation (appendix A). Log-transformed streamflow was selected as the best explanatory model for this period owing to the large amount of coarse sediment. The coarse sediment load toward the end of the drawdown, indicated by the low percentage of sample finer than $0.063 \mathrm{~mm}$, is likely due to the mobilization of larger particles that were released from behind Fall Creek Dam during the drawdown. When the drawdown operation ended on December 17, 2012, streamflow increased in Fall Creek, potentially transporting the coarse sediment to the Middle Fork Willamette River.

Dexter

The station on the Middle Fork Willamette River at Dexter was not affected by the drawdown, but contributes sediment to the Middle Fork Willamette River upstream of the Jasper station and to the confluence of Fall Creek with the Middle Fork Willamette River. SSC samples were collected from a pump sampler on the right edge of water at the existing streamflow gage. Twenty-nine samples were used to calibrate the regression models to estimate SSC. Two EWI samples also were collected by boat during the study period to determine if the pump samples were representative of the channel cross section. The two EWI samples were collected at lowmoderate streamflow and resulted in low SSC concentrations and high percentage of fines. Box coefficients were calculated to adjust the pump 
sample concentrations used in the regression calculations. An MLR with turbidity and streamflow as explanatory variables was used to estimate SSC for this station (table 5).

\section{Limitations to Regression Models}

The regression models have limitations due to some necessary or unavoidable deviations from USGS SSC computation protocols. The drawdown operations at Fall Creek Lake contributed large amounts of sediment downstream to Fall Creek and the Middle Fork Willamette River, and exceeded the detection capabilities of the Hydrolab ${ }^{\circledR}$ McVan turbidity sensor (>3,000 FNU) at Fall Creek Outflow 1 mile downstream of Fall Creek Dam. The release of sediments from the drawdown operation resulted in sediment concentrations and characteristics that are uncommon in natural unregulated systems or downstream of reservoirs operating under normal conditions, and complicated turbidity-SSC relations. Predrawdown conditions at Fall Creek Outflow were characterized by SSC samples with a high percentage of fines (grain sizes less than 0.063mm), but the drawdown of Fall Creek Lake transported sand-sized material through the dam, sourced from either the erosion of upstream deltaic sediments in Fall Creek Lake or incision and resuspension of coarse sediment in the lake thalweg during the drawdown. Changes in particle size in the sediment load ultimately led to the use of separate regression models for discrete periods at Fall Creek Outflow and Jasper (fig. 5). This study did not investigate possible changes in sediment sources during the drawdown, so the ultimate source of the coarse sediment is unknown.

Separate regression models were used for Fall Creek Inflow and Little Fall Creek during the study period because of lost turbidity data and better model fit with streamflow as an explanatory variable during high flows. Those two stations in addition to Winberry Creek also had a very small sample size from which to derive SSC-turbidity/streamflow regressions. Additional uncertainty of the sediment loads at
Little Fall Creek is attributed to continuous streamflow estimates at that station. High MSPE values for Fall Creek Inflow (table 5) were the result of the small $n$ values and inability to collect samples over the range of the hydrograph during the study period. Because Fall Creek Inflow accounts for more of the calculated sediment load into Fall Creek Lake than does Winberry, the uncertainty of the sediment loads into Fall Creek Lake is higher than the uncertainty of the sediment loads calculated for Fall Creek Outflow.

In addition to the changes in sediment particle size distributions, a number of other factors could have affected turbidity measurements used to compute SSC. Color, particle shape, particle density, and scratches on optical surfaces can all cause positive or negative bias in turbidity data (Anderson, 2005), and ultimately affect SSC time-series computations.

\section{Estimated Suspended-Sediment Concentration Data}

Subsets of SSC data at the six monitoring stations were considered estimated for various reasons. For purposes of this report, "computed" refers to SSC values computed from a regression model. SSC is considered "estimated" in this report for the following cases:

- SSC was estimated for periods of missing or deleted turbidity data. Turbidity data were occasionally deleted from the continuous records at the study stations owing to sensor fouling, power interruptions, or damage to deployment infrastructure. These missing computed SSC unit values were evenly interpolated over the duration of missing turbidity data between the last computed SSC value before the data gap and the next computed SSC value after the gap.

- SSC was considered estimated if it was computed from turbidity or streamflow values greater than the maximum values of the samples used in developing the regression model(s) for a station, when SSC values were extrapolated beyond the limits of the regression model. 
- SSC was considered estimated when unit values were extrapolated during periods when the turbidity values were truncated at the sensor maximum at Fall Creek Outflow (appendix A).

Fall Creek Outflow had the highest percentage of estimated SSC values of the six stations, primarily owing to extrapolated values prior to the drawdown operation, when streamflow at the station was greater than the maximum streamflow sampled in the regression model for much of the week following the late November storm. Little Fall Creek had the greatest number of interpolated SSC values. The turbidity data at the station were somewhat erratic and required deletion of many erroneously high values. All daily values of SSC based on interpolated or extrapolated SSC unit values were flagged as estimated in the ADAPS database. The number of each type of estimated SSC value was summed for each station during the entire study period (table 6).

Table 6. Estimated suspended-sediment concentration data at the monitoring stations in the Middle Fork Willamette River Basin, Oregon

[Station reference: Complete station names are shown in table 1; locations are shown in figure 1. \%, percent. Abbreviation: SSC, suspended-sediment concentration]

\begin{tabular}{lcccc}
\hline \multirow{2}{*}{ Station reference } & $\begin{array}{c}\text { Number of SSC values for } \\
\text { study period }\end{array}$ & \multicolumn{2}{c}{ Number of estimated SSC values for study period } \\
\cline { 2 - 5 } & 12,111 & 117 & 223 & Total \\
\hline Dexter & 9,066 & 58 & 15 & $730(2.8 \%)$ \\
Fall Creek Inflow & 11,501 & 72 & 2 & $74(0.6 \%)$ \\
Winberry Creek & 11,428 & 127 & 1,009 & $1136(9.9 \%)$ \\
Fall Creek Outflow & 11,460 & 225 & 53 & $278(2.4 \%)$ \\
Jasper & 10,409 & 371 & 11 & $382(3.7 \%)$ \\
Little Fall Creek & & & & Extrapolated SSC \\
\hline
\end{tabular}

\section{Suspended-Sediment Load Computations}

SSL was computed using approved timeseries of SSC and streamflow for individual stations. For each 15-minute interval (96 total for each day), computed or estimated SSC was multiplied by streamflow and a unit conversion to determine SSL (in pounds per second) according to equation (2)(Rasmussen and others, 2009).

$S S L=S S C \times Q \times C$

where

SSL is suspended-sediment load, in pounds per second;

SSC is suspended-sediment concentration, in milligrams per liter;

Q is streamflow, in cubic feet per second; and c is 0.00006242 , conversion factor used to convert units into pounds per second

For each day, the 96 instantaneous SSL values were multiplied by a time factor (60 seconds per minute $\times 15$ minutes), converted to tons, and summed to determine a total daily SSL. Two of the stations had periods when no instantaneous turbidity, and therefore no SSC, data were available. Instead, estimates of mean daily SSL, in pounds per second, were published in the SSC record at Jasper (December 16-18, 2012) and Little Fall Creek (November 19-December 1, 2012). Those estimated values were used to compute the daily SSL, in tons. The total daily SSL values were summed for different date ranges and the results were compared to determine the amount of sediment transported at each station. 


\section{Suspended- Sediment Budgets}

Suspended-sediment budgets for the study were computed for two areas of interest. The SSL into and out of Fall Creek Lake was investigated to determine the mass of sediment mobilized during the drawdown operation. The difference in the SSL between Fall Creek Outflow and Jasper also are investigated in an effort to determine how much of the mobilized sediment was deposited in the reach between those locations, and how much was transported farther downstream in the Middle Fork Willamette River.

\section{Fall Creek Lake}

Suspended-sediment budget computations were conducted for the period November 8, 2012February 8, 2013, when daily SSL values were available for the three relevant monitoring stations affecting sediment loads to Fall Creek Lake (Fall Creek Inflow, Winberry Creek, and Fall Creek Outflow) (table 7). During those dates, three periods were analyzed: pre-drawdown ( November 8-December 11, 2012; 34 days), drawdown (December 12-17, 2012; 6 days), and postdrawdown (December 18, 2012-February 8, 2013; 53 days). Before the daily SSL values were summed for each period at Fall Creek Inflow and Winberry Creek, they were adjusted to account for the ungaged area of each drainage basin downstream of the monitoring location but upstream of Fall Creek Lake. The sediment yields of these areas were assumed to be the same as the monitored part of each basin. The final daily SSL values were calculated by multiplying the computed SSL by the ratio of the total drainage area (gaged plus ungaged) to the gaged drainage area.

The daily SSL at two inflow monitoring stations (Fall Creek Inflow and Winberry Creek) were summed to compute the sediment input to Fall Creek Lake (fig.7). During the pre-drawdown period, these inflows transported a combined 16,410 tons of sediment into the reservoir. Over 75 percent of that SSL was transported during storm events on November 20, 2012 and December 2-5, 2012. During the pre-drawdown period, the total SSL at Fall Creek Outflow was 4,300 tons. The net sediment storage in the reservoir during the 34 days was approximately 12,000 tons, indicating a reservoir trap efficiency of 74 percent. During the 6 days of the drawdown, 1,350 tons of sediment was transported into the reservoir by the two inflow stations. The SSL measured at Fall Creek Outflow totaled 51,600 tons, resulting in a net sediment transport of approximately 50,300 tons from Fall Creek Lake. For the remainder of the study period, the two inflows transported approximately 12,000 tons of sediment into Fall Creek Lake. During the post-drawdown period, the only sizeable storm occurred on January 29, 2013, and contributed 17 percent (2,090 tons) of the combined SSL for the period. At Fall Creek Outflow, 4,000 tons were transported during the post drawdown period, resulting in a net storage of approximately 8,000 tons and a reservoir trap efficiency of 67 percent. For the entire period of the sediment budget analysis (93 days), the net balance of the suspended-sediment load was approximately 30,100 tons transported out of Fall Creek Lake. 
Table 7. Suspended-sediment loads at the two inflow stations to Fall Creek Lake and the outflow of Fall Creek Lake, and net sediment transported from Fall Creek Lake, Middle Fork Willamette River Basin, Oregon.

[Load values are in tons. Station reference: Complete station names are shown in table 1; locations are shown in figure 1. Negative suspended-sediment loads (SSL) values for Fall Creek Lake represent net suspended sediment transported from the lake, positive SSL values represent net suspended sediment deposited in the lake]

\begin{tabular}{|c|c|c|c|c|}
\hline Station reference & $\begin{array}{l}\text { Analysis period } \\
\text { (93 days) }\end{array}$ & $\begin{array}{l}\text { Pre-drawdown } \\
\text { (34 days) }\end{array}$ & $\begin{array}{l}\text { Drawdown } \\
\text { (6 days) }\end{array}$ & $\begin{array}{l}\text { Post-drawdown } \\
\text { (53 days) }\end{array}$ \\
\hline Fall Creek Inflow & 27,500 & 14,800 & 1,300 & 11,400 \\
\hline Winberry Creek & 2,270 & 1,610 & 50 & 610 \\
\hline Fall Creek Outflow & 59,900 & 4,300 & 51,600 & 4,000 \\
\hline $\begin{array}{l}\text { Fall Creek Lake (net } \\
\text { transport from the lake) }\end{array}$ & $-30,130$ & 12,110 & $-50,250$ & 8,010 \\
\hline
\end{tabular}

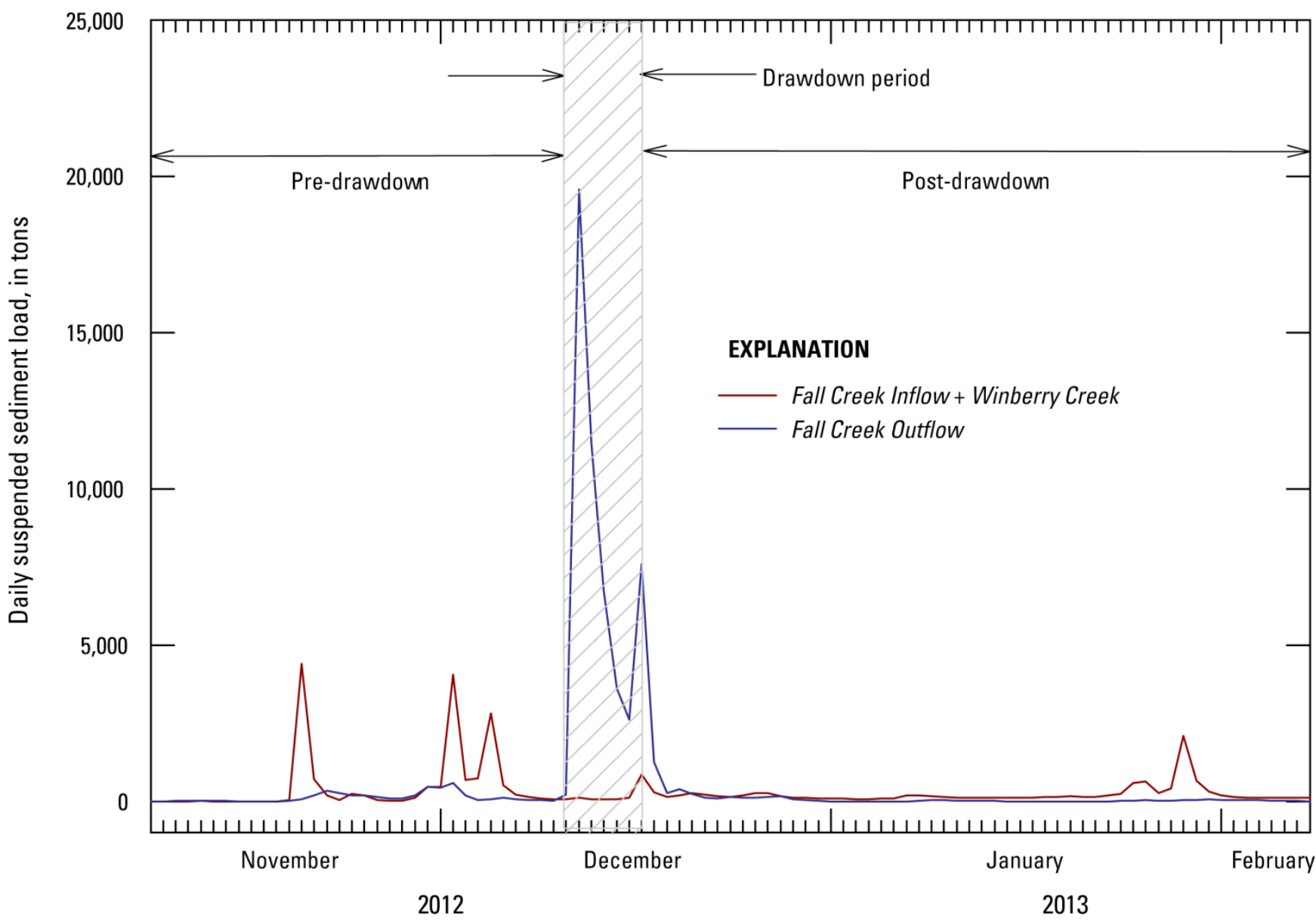

Figure 7. Time series graph showing computed daily suspended-sediment loads at the two Fall Creek Lake inflow stations (Fall Creek Inflow + Winberry Creek) and Fall Creek Lake Outflow, Middle Fork Willamette River Basin, Oregon, 2012-13. 


\section{Middle Fork Willamette River}

Suspended-sediment budget computations were conducted for the period November 8, 2012 February 21, 2013, when daily SSL values were available for the four monitoring stations on streams affecting sediment loads on the Middle Fork Willamette River (Little Fall Creek, Fall
Creek Outflow, Dexter, and Jasper) (table 8). Within those dates, three periods were analyzed: pre-drawdown (November 8-December 11, 2012; 34 days), drawdown (December 12-17, 2012; 6 days), and post-drawdown (December 18, 2012 February 21, 2013; 66 days) (fig. 8).

Table 8. Suspended-sediment loads at the three monitoring stations upstream of Jasper, at Jasper, and the budget for Fall Creek-Middle Fork Willamette River, Middle Fork Willamette River Basin, Oregon.

[All load values are in tons. Station reference: Complete station names are shown in table 1; locations are shown in figure 1. Positive suspended-sediment load (SSL) values for Fall Creek-Middle Fork Willamette River indicate less SSL at Jasper than measured at the three upstream stations, negative SSL values indicate more SSL at Jasper than measured at the three upstream stations]

\begin{tabular}{lcccc}
\hline \multicolumn{1}{c}{ Station reference } & $\begin{array}{c}\text { Analysis period } \\
\text { (106 days) }\end{array}$ & $\begin{array}{c}\text { Pre-drawdown } \\
\text { (34 days) }\end{array}$ & $\begin{array}{c}\text { Drawdown } \\
\text { (6 days) }\end{array}$ & $\begin{array}{c}\text { Post-drawdown } \\
\text { (66 days) }\end{array}$ \\
\hline Dexter & 10,200 & 6,900 & 1,400 & 1,900 \\
Fall Creek Outflow & 60,000 & 4,300 & 51,600 & 4,100 \\
Little Fall Creek & 3,500 & 2,470 & 100 & 930 \\
Jasper & 81,900 & 38,200 & 25,500 & 18,200 \\
\hline SSL budget: Fall & & & & \\
Creek-Middle Fork & $-8,200$ & $-24,530$ & 27,600 & $-11,270$ \\
Willamette River & & & & \\
\hline
\end{tabular}

Computed SSL at Fall Creek Outflow, Little Fall Creek, and Dexter contributed to the SSL at the Jasper monitoring station. Bank erosion, streambed re-suspension, and suspended sediment from unmonitored creeks also may have considerably contributed to the SSL measured at Jasper, especially during storm events. The ungaged area of the Jasper drainage basin is 97 $\mathrm{mi}^{2}$, approximately 7 percent of the total drainage basin. The ungaged area includes Hills Creek and Lost Creek, as well as parts of lower Fall Creek and the Middle Fork Willamette River. SSL from Hills Creek and Lost Creek contributed an unquantified amount of sediment into the Middle Fork Willamette River upstream of the Jasper monitoring station, increasing the uncertainty of the sediment budget computations. 


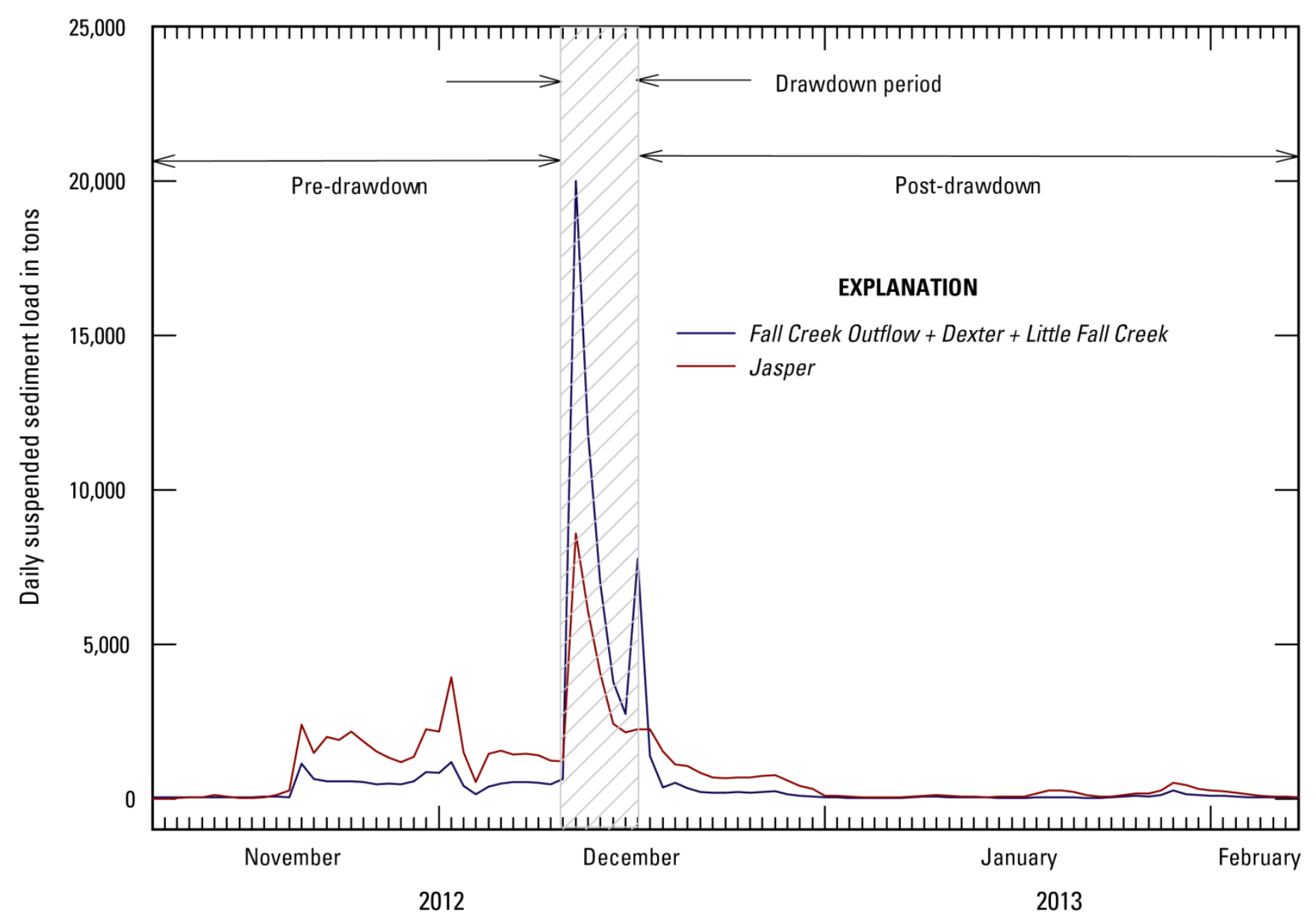

Figure 8. Time series graph showing computed daily suspended-sediment loads at three monitoring stations upstream of the Jasper monitoring station (Fall Creek Outflow, Dexter, and Little Fall Creek) and at Jasper, Middle Fork Willamette River Basin, Oregon, 2012-13.

During the pre-drawdown period, a combined 13,670 tons of sediment were transported past the three monitoring stations upstream of Jasper (not including the inflows to Fall Creek Lake). At Jasper, 38,200 tons were computed, indicating a negative difference of approximately 24,500 tons of sediment for the river reaches between Jasper and the upstream stations (for purposes of this report, a negative difference in sediment load indicates sediment transport out of the river reaches between the monitoring stations, and a positive difference indicates sediment deposition). Because two of the three contributing sites are downstream of dams, the influence of storms was not as substantial as at the unregulated station (Little Fall Creek). For Fall Creek Outflow, Little Fall Creek, and Dexter, the November 20, 2012 and December 2-5, 2012, storm events constituted 24 percent of the total sediment load for the pre- drawdown period. At Jasper, the SSL for those storm events constituted 26 percent of the total sediment load for the pre-drawdown period.

During the 6-day drawdown, 53,100 tons of sediment was transported past the three sites upstream of Jasper, with 97 percent of the total from Fall Creek Outflow (51,600 tons). The SSL transported past Jasper totaled 25,500 tons during the same 6 days, resulting in a positive difference of 27,600 tons for the Fall Creek and Middle Fork Willamette River reaches between Jasper and the upstream sites. Visual observation confirmed that there was considerable sediment deposition in these reaches during this time.

During the post-drawdown period, the sites upstream of Jasper transported approximately 6,900 tons of sediment. At Jasper, 18,200 tons were computed, resulting in a negative difference 
of approximately 11,300 tons of sediment for the river reaches between Jasper and the upstream sites. Therefore, for the period during and after the drawdown (72 days), the net balance of the suspended-sediment load indicates that there was approximately 16,300 tons of sediment deposited within the reaches of Fall Creek and the Middle Fork Willamette River between Fall Creek Dam and Jasper. However, for the entire period of analysis (106 days), the net balance of the suspended-sediment load indicates 8,200 tons of sediment transported out of those river reaches.

\section{Bedload below Fall Creek Dam}

Six bedload samples were collected at Fall Creek Outflow over 3 days during the drawdown (December 12-14, 2012) to provide data to compute instantaneous bedload discharge in tons per day. The following equation from Edwards and Glysson (1999) was used for the bedload computations:

$Q_{B^{-}}=K \frac{W_{T}}{t_{T}} M_{T}$

where

$Q_{B} \quad$ is the bedload discharge, as measured by bedload sampler, in tons per day;

$W_{T} \quad$ is the total width of stream from which samples were collected, in feet, and is equal to the increment width times $n$ (where $n=$ total number of vertical samples);

$t_{T} \quad$ is the total time the sampler was on the bed, in seconds;

$M_{T} \quad$ is the total mass of sample collected from verticals sampled in the cross section, in grams; and

$K \quad$ is the conversion factor (0.381) specific to the US BL-84 sampler used in this study with a 3 in. nozzle opening.
Average instantaneous bedload for the six samples was 104 tons/d, with a range of 70-127 tons/d (table 9). Average streamflow associated with the mean times of the sample collection was $802 \mathrm{ft}^{3} / \mathrm{s}$, with a range of 737-894 $\mathrm{ft}^{3} / \mathrm{s}$. As a percentage of total load (SSL plus bedload), bedload averaged 11 percent of the total sediment load on the 3 days of sample collection, with a range of 8-15 percent. Prior to the drawdown, samples were collected to determine predrawdown bedload conditions resulting in no material in the sample bag. Bedload was therefore assumed to be negligible at this station prior to the drawdown when the lake was operated under normal conditions.

In addition to total mass of dried sediment in the bedload samples, grain size analysis and LOI was conducted. Fine to medium sand-sized particles constituted an average of 71 percent of the bedload samples. Very little gravel sized material was present in the bedload samples, averaging 2.3 percent of the particle size distribution (table 10). Noticeable amounts of leaf litter were observed during sample collection, at times clogging the 3 in. by 3 in. opening of the BL-84 sampler. LOI results show that on average, 24 percent of the bedload samples were comprised of organic matter, with a range of 18-42 percent.

The highest LOI value was in the first bedload sample on December 12, 2012 at 09:47 during the first morning of the drawdown; LOI values decreased steadily until reaching a minimum value in the last bedload sample collected on December 14, 2012. These results represent organic content in the form of leaf litter and other unqualified organic matter that moved along the bed of the stream at the time of sample collection. Large amounts of leaf litter also were observed in the water column of Fall Creek during the drawdown, but that organic matter was not quantified as part of this study. 
Table 9. Bedload samples collected during the drawdown at Fall Creek Outflow, Middle Fork Willamette River Basin, Oregon, December 12-14, 2012

[Date format is $\mathrm{mm} / \mathrm{dd} / \mathrm{yy}$ ]

\begin{tabular}{ccccccccc}
\hline Date & $\begin{array}{c}\text { Mean } \\
\text { sample } \\
\text { time }\end{array}$ & $\begin{array}{c}\text { Sampling time at } \\
\text { each vertical } \\
\text { section } \\
\text { (seconds) }\end{array}$ & $\begin{array}{c}\text { Total } \\
\text { sampling } \\
\text { time } \\
\text { (seconds) }\end{array}$ & $\begin{array}{c}\text { Channel } \\
\text { width } \\
\text { (feet) }\end{array}$ & $\begin{array}{c}\text { Streamflow } \\
\text { (cubic feet } \\
\text { per second) }\end{array}$ & $\begin{array}{c}\text { Daily mean } \\
\text { SSL } \\
\text { (tons per } \\
\text { day) }\end{array}$ & $\begin{array}{c}\text { Instantaneous } \\
\text { bedload } \\
\text { discharge } \\
\text { (tons per day) }\end{array}$ & $\begin{array}{c}\text { Loss on } \\
\text { ignition } \\
\text { (milligrams } \\
\text { per liter) }\end{array}$ \\
\hline $12 / 12 / 12$ & $09: 47$ & 40 & 320 & 94 & 894 & 19,620 & 95 & 295,087 \\
$12 / 12 / 12$ & $15: 04$ & 40 & 360 & 94 & 857 & 19,620 & 116 & 198,372 \\
$12 / 13 / 12$ & $11: 45$ & 40 & 360 & 94 & 778 & 11,468 & 99 & 187,296 \\
$12 / 13 / 12$ & $12: 39$ & 40 & 360 & 94 & 783 & 11,468 & 113 & 154,903 \\
$12 / 13 / 12$ & $15: 31$ & 40 & 360 & 94 & 766 & 11,468 & 70 & 159,917 \\
$12 / 14 / 12$ & $09: 17$ & 40 & 360 & 94 & 737 & 6,709 & 127 & 160,541 \\
\hline
\end{tabular}

Table 10. Grain size distribution of bedload samples at Fall Creek Outflow, below Fall Creek Lake, Oregon. [Values are percentage of total sample. Date format is mm/dd/yy. Abbreviation: mm, millimeter; <, less than]

\begin{tabular}{|c|c|c|c|c|c|c|c|c|}
\hline & & $4-2 \mathrm{~mm}$ & $2-1 \mathrm{~mm}$ & $1-0.5 \mathrm{~mm}$ & $0.5-0.25 \mathrm{~mm}$ & $\begin{array}{c}0.25- \\
0.125 \mathrm{~mm}\end{array}$ & $\begin{array}{c}0.125- \\
0.063 \mathrm{~mm}\end{array}$ & $<0.063 \mathrm{~mm}$ \\
\hline Date & $\begin{array}{c}\text { Mean } \\
\text { sample time }\end{array}$ & Gravel & $\begin{array}{c}\text { Very coarse } \\
\text { sand }\end{array}$ & Coarse sand & $\begin{array}{l}\text { Medium } \\
\text { sand }\end{array}$ & Fine sand & $\begin{array}{l}\text { Very fine } \\
\text { sand }\end{array}$ & Silt/clay \\
\hline $12 / 12 / 12$ & 0947 & 2.7 & 5.5 & 11.7 & 40.1 & 30.2 & 7.4 & 2.4 \\
\hline $12 / 12 / 12$ & 1504 & 1.8 & 3.8 & 12.6 & 43.7 & 28.4 & 7.1 & 2.6 \\
\hline $12 / 13 / 12$ & 1145 & 2.1 & 4.3 & 11.2 & 40.8 & 31.4 & 7.5 & 2.7 \\
\hline $12 / 13 / 12$ & 1239 & 2.4 & 4.5 & 7.8 & 34.0 & 38.3 & 2.4 & 10.6 \\
\hline $12 / 13 / 12$ & 1531 & 1.9 & 4.2 & 10.3 & 42.7 & 32.9 & 6.0 & 2.0 \\
\hline $12 / 14 / 12$ & 0917 & 3.0 & 7.1 & 8.3 & 24.9 & 39.0 & 10.5 & 7.2 \\
\hline
\end{tabular}

\section{Dissolved Oxygen}

Based on LOI data in bedload samples and observations by field staff, large amounts of unquantified particulate and dissolved organic carbon appear to have been released with the sediment during the drawdown operation at Fall Creek Lake, potentially causing conditions unfavorable to aquatic life downstream of the lake in Fall Creek and the Middle Fork Willamette River. The mobilization of sediment from behind constructed dams can lead to extended periods of hypoxia when the sediments are high in organic content, as described by modeling efforts on dam removal scenarios on the Klamath River in Oregon and California (Stillwater Sciences, 2011). Therefore, continuous DO data were collected at Fall Creek Outflow and Jasper using LDO sensors deployed on Hydrolab ${ }^{\circledR}$ data sondes to investigate the effect of the drawdown and associated sediment release on water quality downstream of Fall Creek Lake (fig. 9). LDO (optical) sensors are more robust in field environments because of their stability in maintaining calibration over extended deployments and have low interferences, among other advantages (Rounds and others, 2013). Despite the sensor resistance to interferences, extreme sensor fouling occurred at both sites during the drawdown. These fouling events led to periods of missing data during the drawdown at 
Fall Creek Outflow, and after the drawdown at Jasper, when erratic DO data coincided with high percentages of sand in the SSC samples and a scratched membrane cap was observed during a station visit. 


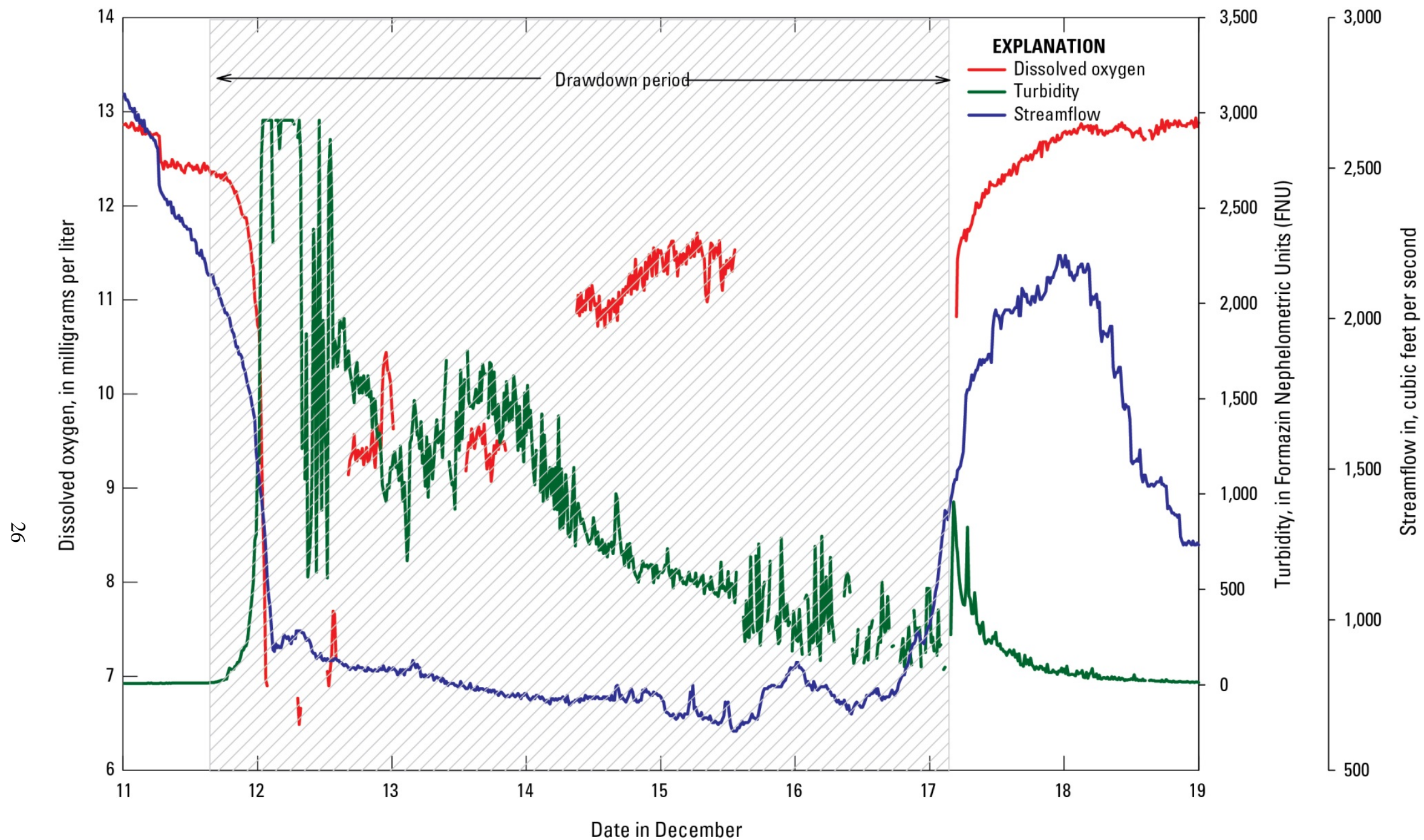

Figure 9. Dissolved oxygen, turbidity, and streamflow during the drawdown at Fall Creek Outflow, Middle Fork Willamette River Basin, Oregon, December 2012. 
Daily mean DO values ranged from 10.26 to $13.02 \mathrm{mg} / \mathrm{L}$ prior to the drawdown, and 12.20 to $13.82 \mathrm{mg} / \mathrm{L}$ after the drawdown at Fall Creek Outflow. A noticeable rapid decrease in DO coincided with an increase in turbidity at the onset of the drawdown when large amounts of sediment were released from behind the dam (fig. 9). Initial data showed DO decreasing to values less than 3.0 $\mathrm{mg} / \mathrm{L}$ in the early morning (0230) of December 12, 2012. However, station visit observations the morning of the drawdown at 0645 reported large amounts of leaf litter and sediment in the sonde probe guard and the deployment pipe that housed the sonde. After cleaning the deployment tube and probe guard, DO values increased immediately to $6.50 \mathrm{mg} / \mathrm{L}$, suggesting that the hypoxic values were the result of extreme sensor fouling and therefore erroneous. From December 12, 2012 (onset of the drawdown) until December 17, 2012, multiple cleanings were required, with several periods of data deemed erroneous owing to similar sensor fouling, and data were subsequently deleted from the record. Due to the extreme fouling, it is unknown if Fall Creek had episodic hypoxia as a result of the drawdown. However, the resulting data reveal that a decrease in dissolved oxygen from approximately 13.0 to approximately 6.50 $\mathrm{mg} / \mathrm{L}$ occurred on the morning of the drawdown. At the end of the drawdown, on December 17, 2012, DO increased to $10.8 \mathrm{mg} / \mathrm{L}$, which coincides with a recession in turbidity and an increase in streamflow (fig. 9). The regulating outlets of the dam were closed on December 17, 2012, marking the end of the drawdown operation, and likely significantly reduced the transport of suspended sediment and organic material.

DO unit values at Jasper ranged from 9.79 to $13.2 \mathrm{mg} / \mathrm{L}$ for the study period, with values showing a slight decrease the morning of December 12, 2012, lagging the onset of the drawdown at Fall Creek Lake. The minimum DO value at Jasper on December 12, 2012, was 11.6 $\mathrm{mg} / \mathrm{L}$, with a maximum of $12.2 \mathrm{mg} / \mathrm{L}$, well above the minimum DO value for the study period. Therefore, although a small effect is possible, Jasper, which is approximately 10 miles downstream of Fall Creek Dam, did not have a large, rapid decrease in DO during the drawdown as was observed at Fall Creek Outflow.

\section{Summary and Conclusions}

The drawdown of Fall Creek Lake resulted in the net transport of approximately 50,300 tons of sediment from the lake during the 6-day drawdown operation, based on computed daily values of SSL downstream of Fall Creek Dam and the two main tributaries to Fall Creek Lake. The transported sediments likely were deposited primarily in Fall Creek downstream of Fall Creek Lake, but also were mobilized downstream to the Middle Fork Willamette River. A suspendedsediment budget calculated for 72 days of the study period indicates that there was approximately 16,300 tons of sediment deposition within the reaches of Fall Creek and the Middle Fork Willamette River between Fall Creek Dam and the streamgage on the Middle Fork Willamette River at Jasper as a result of drawdown operations.

Sediment mass balance downstream of Fall Creek Lake for the study period indicates a negative difference in measured suspendedsediment load (SSL) for the Fall Creek and Middle Fork Willamette River reaches between Jasper and the upstream sites during the pre-drawdown and post-drawdown periods. This difference may represent unquantified SSL from tributaries downstream of Fall Creek Lake and Dexter; resuspension of sediment stored in Fall Creek and the Middle Fork Willamette River; underestimation of SSL from the upstream sites; overestimation of SSL at Jasper; or a combination of all four. Conversely, the positive difference during the 6-day drawdown indicates sediment deposition and storage in the same river reaches; an overestimation of SSL from the upstream sites; underestimation of SSL at Jasper, or a combination of all three. Given that the SSL measured at Fall Creek Outflow totaled 51,600 tons during the drawdown and the stream velocities were low during that period, it is likely that the positive difference in measured versus summed SSL at Jasper was primarily due to sediment deposition in Fall Creek or the Middle Fork Willamette River as a result of the 
drawdown. Therefore, the negative difference in measured versus summed at Jasper during postdrawdown also may be attributable to resuspension of sediments deposited during the drawdown, potentially mobilized by variations in flow regimes on Fall Creek and the Middle Fork Willamette River.

Bedload samples collected at the station downstream of Fall Creek Dam during the drawdown were primarily comprised of medium to fine sands, and accounted for an average of 11 percent of the total instantaneous sediment load during sample collection. Low stream velocities during the drawdown likely were not able to transport any large material that may have been entrained behind the dam.

Monitoring of dissolved oxygen (DO) at Fall Creek Outflow showed an initial decrease in DO concurrent with the sediment release over the span of 5 hours, though the extent of DO depletion is unknown due to extreme and rapid fouling of the probe by the large amount of sediment in transport. During the drawdown, DO data at Fall Creek Outflow decreased rapidly at the onset of the large sediment release from approximately 13 $\mathrm{mg} / \mathrm{L}$ to a minimum value of $6.50 \mathrm{mg} / \mathrm{L}$, although multiple periods of data were lost owing to extreme sensor fouling. Following the drawdown, DO at Fall Creek Outflow increased to approximately $11 \mathrm{mg} / \mathrm{L}$. DO at Jasper decreased slightly during the drawdown to a minimum value of $11.63 \mathrm{mg} / \mathrm{L}$, suggesting that although a small effect is possible, the sediment release from Fall Creek Lake did not cause a rapid decrease in DO approximately 10 river miles downstream of the dam.

Future monitoring could be improved with the use of alternate turbidity sensor technology such as optical backscatter units, which can accurately measure more extreme turbidity events at Fall Creek Outflow. Modification to the existing Hydrolab ${ }^{\circledR}$ deployment setup, to encourage the flushing of sediment through the probe guard, also could prove useful to alleviate sensor fouling during anticipated high sediment loads. Standard deployment setups did not prove to be reliable when high sediment loads occurred in December
2012, resulting in periods of missing data. Additional suspended-sediment samples, to enhance the regressions at Fall Creek Inflow, Winberry Creek, and Little Fall Creek, would lead to more accurate estimates of suspended-sediment loads at the unregulated sites for this study, reducing uncertainty in the suspended-sediment budget for the study sites. Long-term monitoring of turbidity and suspended sediment at Fall Creek Outflow and Jasper could lead to inferences regarding the spatial extent of sediment deposition, storage, and mobilization after drawdown operations occur. An independent estimate of sediment stored in Fall Creek Lake over multiple years of drawdown operations could provide a complementary assessment of sediment lost owing to the drawdowns. Downstream studies including bedload and other bed material sampling could give insight into the spatial extent of fine sediment deposition, and related effect on salmonid spawning habitat. These and other continued monitoring efforts would provide important data to the U.S. Army Corps of Engineers in its management of operations at Fall Creek Lake, especially as it pertains to changes in reservoir storage capabilities, and the ecological effects of sediment releases associated with complying with requirements of biological opinions.

\section{Acknowledgements}

This study was made possible by the assistance of many people. Study funding, logistics, and other support came from the USACE, particularly Kathryn Tackley. Close coordination with Greg Taylor at Lookout Point and Mary-Karen Scullion in Reservoir Management at USACE allowed for timing of sampling efforts during the drawdown. Numerous field personnel from the USGS Oregon Water Science Center provided assistance in station installation, storm sampling, and routine monitoring, including David Piatt, Cassandra Smith, Norman Buccola, and Blake Eldridge. Field assistance for data collection platform setup was provided by Richard Kittleson and James King from the USGS Portland Field Office. Ben Beal from the USGS Portland Field Office conducted streamflow measurements at Fall Creek Inflow 
and Fall Creek Outflow. USGS Central Point Field Office personnel provided assistance in bedload sampling, stayline installation, and additional ADCP streamflow measurements at Fall Creek Outflow, including Marc Stewart, Randy Spitzer, and Mark Schuster. Chauncey Anderson, Tamara Wood, and Joseph Rinella provided helpful insight into sample design and study planning prior to study implementation. Adam Stonewall, Kurt Spicer, and Chauncey Anderson reviewed surrogate regressions and SSC records for the study sites.

\section{References Cited}

Anderson, C.W., 2007, Influence of Cougar Reservoir drawdown on sediment and DDT transport and deposition in the McKenzie River basin, Oregon, water years 2002-2004: U.S. Geological Survey Scientific Investigations Report 2007-5164, 42 p.

Anderson, C.W., 2005, Turbidity (ver. 2.1): U.S. Geological Survey Techniques of WaterResources Investigations, book 9, chap. A6., sec. 6.7, September 2006, variously paged, http://pubs.water.usgs.gov/twri9A6/.

American Society for Testing and Materials International, 2003, D1889-00 Standard test method for turbidity of water, in Annual Book of Standards, Water and Environmental Technology: West Conshohockem, Pennsylvania, $6 \mathrm{p}$.

Bilotta, G.S., and Brazier, R.E., 2008, Understanding the influence of suspended solids on water quality and aquatic biota: Water Research, v.42, p. 2849-2861.

Bragg, H.M., and Uhrich, M.A., 2010, Suspendedsediment budget for the North Santiam River basin, Oregon, water years 2005-2008: U.S. Geological Survey Scientific Investigations Report 2010-5038, 26 p.

Bragg, H.M., Sobieszczyk, Steven, Uhrich, M.A., and Piatt, D.R., 2007, Suspended-sediment loads and yields in the North Santiam River basin, Oregon, water years 1999-2004: U.S. Geological Survey Scientific Investigations Report 2007-5187, 26 p.
Edwards, T.K., and Glysson, G.D., 1999, Field methods for measurement of fluvial sediment: Techniques of Water-Resources Investigations of the U.S. Geological Survey, book 3, chap. C2, $89 \mathrm{p}$.

Gray, J.R., Glysson, G.D., and Edwards, T.E., 2008, Suspended sediment samplers and sampling methods, in, Sediment transport measurements, in, Marcelo Garcia, ed., Sedimentation Engineering-Processes, Measurements, Modeling, and Practice: American Society of Civil Engineers Manual 110, Chapter 5.3, p. 320-339.

Helsel, D.R., and Hirsch, R.B., 1992, Statistical methods in water resources: Amsterdam, Elsevier. 510 p.

Heo, J.H., Kho, Y.W., Shin, H., Kim, S. and Kim, T., 2008, Regression equations of probability plot correlation coefficient test statistics from several probability distributions: Journal of Hydrology, v.355, p. 1-15.

Heywood, M.J.T., and Walling, D.E., 2007, The sedimentation of salmonid spawning gravels in the Hampshire Avon Catchment, UK: Implications for the dissolved oxygen content of intragravel water and embryo survival: Hydrological Processes, v.21, p. 770-788.

Jastram, J.D., Zipper, C.E., Zelazny, L.W., and Hyer, K.E., 2010, Increasing precision of turbidity-based suspended sediment concentration and load estimates, v. 39, p. 13061316.

Lewis, M.E., 2006, Dissolved Oxygen (ver. 2.1): U.S. Geological Survey Techniques of WaterResources Investigations, book 9, chap. A6, sec. 6.2, June 2006, http://pubs.water.usgs.gov/twri9A6/

Natural Resource Conservation Service, 2006, Middle Fork Willamette 17090001 8-digit hydrologic unit profile, accessed 08/27/2013 at http://www.nrcs.usda.gov/wps/portal/nrcs/detail/ or/newsroom/?cid=nrcs142p2_044327.

National Marine Fisheries Service, 2008, PCTS consultation summary-Continued operation of 13 dams and maintenance of 43 miles of revetments in the Willamette basin, OR: 
National Oceanographic and Atmospheric

Administration Web page, accessed March 31, 2014 at https://pcts.nmfs.noaa.gov/pctsweb/dispatcher/trackable/NWR-2000-

2117? overrideUserGroup $=$ PUBLIC\&referer $=/ p$ cts-

web/publicAdvancedQuery.pcts?searchAction $=S$ ESSION_SEARCH.

Newcombe, C.P., and Jensen, J.O.T., 1996, Channel suspended sediment and fisheries-A synthesis for quantitative assessment of risk and impact: North American Journal of Fisheries Management, v.16, p. 693-727.

Newcombe, C.P., and MacDonald, D.D., 1991, Effects of suspended sediments on aquatic ecosystems: North American Journal of Fisheries Management, v.11, p. 72-82.

Porterfield, G., 1972, Computations of fluvialsediment discharge: Techniques of WaterResources Investigations of the U.S. Geological Survey, book 3, chap. C3, 66 p.

Rasmussen, P.P., Gray, J.R., Glysson, G.D., and Ziegler, A.C., 2009, Guidelines and procedures for computing time-series suspended-sediment concentrations and loads from in-stream turbidity-sensor and streamflow data: U.S. Geological Survey Techniques and Methods, book 3, chap. C4, 52 p.

Rounds, S.A., Wilde, F.D., and Ritz, G.F., 2013, Dissolved oxygen (ver. 3.0): U.S. Geological Survey Techniques of Water-Resources Investigations, book 9, chap A6, sec. 6.2, http://water.usgs.gov/owq/FieldManual/Chapter 6/6.2_v3.0.pdf.

Sauer, V.B., and Turnipseed, D.P., 2010, State measurement at gaging stations: U.S. Geological Survey Techniques and Methods, book 3, chap A7, 45 p., http://pubs.usgs.gov/tm/tm3-a7/.

Shellberg, J.G., Bolton, S.M., and Montgomery, D.R., 2010, Hydrogeomorphic effects on bedload scour in bull char (Salvelinus confluentus) spawning habitat western Washington, USA: Canadian Journal of Fisheries and Aquatic Sciences, v.67, p. 626640.
Stillwater Sciences, 2011, Model development and estimation of short-term impacts of dam removal on dissolved oxygen in the Klamath River: Berkeley, California, Final Report, prepared by Stillwater Sciences for the Water Quality SubTeam, Klamath River Secretarial Determination, 39 p.

Turnipseed, D.P., and Sauer, V.B., 2010, Discharge measurements at gaging stations: U.S. Geological Survey Techniques and Methods, book 3, chap A8, 87 p., http://pubs.usgs.goc/tm/tm3-a8/.

U.S. Geological Survey, 2008, Continuous records processing implementation plan: U.S.

Geological Survey, Prepared by the Continuous Records Processing Implementation Committee, 29 p., http://water.usgs.gov/admin/memo/policy/wrdpo licy10.02_attachment1.pdf

U.S. Geological Survey, 2013, USGS Water Data for the Nation: U.S. Geological Survey National Water Information System, http://waterdata.usgs.gov/nwis.

U.S. Geological Survey, 2014, The Streamstats program: U.S. Geological Survey Web page, accessed April 21, 2014, at http://water.usgs.gov/osw/streamstats/index.html

Wagner, R.J., Boulger, R.W., Jr., Oblinger, C.J., and Smith, B.A., 2006, Guidelines and standard procedures for continuous water-quality monitors - Station operation, record computation, and data reporting: U.S. Geological Survey Techniques and Methods. 1D3, 51 p., 8 attachments. 


\title{
Appendix A-Monitoring Station Analyses and Sediment Model Descriptions
}

\author{
Dexter
}

\author{
WATER-QUALITY MONITOR STATION ANALYSIS \\ 2013 WATER YEAR \\ SUSPENDED-SEDIMENT RECORD \\ 14150000 Middle Fork Willamette River near Dexter, Oregon
}

\section{PROJECT BACKGROUND}

The U.S. Geological Survey (USGS), in cooperation with the Army Corps of Engineers, monitored suspended sediment on sites in the Fall Creek Lake drainage, near Lowell, Oregon, in the winter of 2012-13. The purpose of the monitoring was to provide data that will be used to estimate suspendedsediment loads transported out of Fall Creek Lake during an operational drawdown to pass endangered juvenile salmonids through the dam. Additionally, monitoring data will be used to estimate a sediment budget for the lake and nearby tributaries. The Middle Fork Willamette River at Dexter represents sediment transport unaffected by the drawdown upstream of the confluence with Fall Creek, where most drawdown-related sediment is sourced. Sediment transport from Dexter and Fall Creeks are quantified downstream at the Middle Fork Willamette River at Jasper sampling site (14152000).

\section{EQUIPMENT}

A McVann self-cleaning turbidity sensor installed on a Hydrolab ${ }^{\circledR}$ DS-5a data sonde was used to collect continuous turbidity data. Data were transmitted via radio from the existing Design Analysis H522 DCP. An ISCO pump sampler was installed on the right bank near the existing streamgage to collect suspended-sediment concentration (SSC) samples.

\section{MODEL-CALIBRATION DATA SET}

Data were collected using USGS protocols and are stored in USGS National Water Information System databases. The turbidity sensor was deployed at the end of October 2012 and retrieved in early March 2013, resulting in an approximate 4 month deployment period. Twenty-nine SSC samples were collected through an ISCO pump sampler installed on the right edge of water at the existing gaging station. SSC results were reported in milligrams per liter of dried sediment, and sand breaks were performed on a subset of the samples due to funding restrictions.

During the project period, two cross section equal width increment EWI samples were collected by boat at the streamgage location (a cableway is not installed at this site). The EWI samples were used to calculate box coefficients to determine if the pump samples were representative of the channel cross section (table A1). The two EWI samples were collected at 3,900 ft $\mathrm{ft}^{3} / \mathrm{s}$ (December 27, 2012) and 2,400 (February 6, 2013) $\mathrm{ft}^{3} / \mathrm{s}$. The range of discharge during the project period was 1,250 to $12,000 \mathrm{ft}^{3} / \mathrm{s}$, so the EWI samples were collected at low flows relative to the maximum for the project period. 
Table A1: Box coefficients for pump samples.

[SSC, suspended sediment concentration; mg/L, milligrams per liter;

EWI, equal width increment]

\begin{tabular}{llcc}
\hline \multicolumn{1}{c}{ Date and time } & \multicolumn{1}{c}{ Sample Type } & $\begin{array}{c}\text { SSC } \\
\text { (mg/L) }\end{array}$ & $\begin{array}{c}\text { Finer than } 63 \boldsymbol{\mu m} \\
\text { (percent) }\end{array}$ \\
\hline 12/27/12 12:30 & PUMP & 12 & 71.6 \\
12/27/12 13:16 & EWI & 6 & 91.9 \\
12/27/12 13:27 & EWI & 6 & \\
12/27/12 13:31 & PUMP & 8 & 83.9 \\
\hline & Box coefficient $=\mathbf{0 . 6}$ & & \\
\hline 2/6/13 11:05 & PUMP & 8 & 71.2 \\
2/6/13 11:13 & EWI & 3 & 89.5 \\
2/6/13 11:28 & EWI & 2 & 86.8 \\
2/6/13 11:35 & PUMP & 4 & 93.8 \\
\hline
\end{tabular}

Box coefficient $=0.42$

The box coefficients of 0.60 and 0.42 suggest that the pump sample concentrations are biased high, and are not representative of the cross section. Evaluation of separate bottles from the second EWI sample on (December 27, 2012) showed that the channel was well mixed during the time of sample collection. However, SSC was very low during the EWI samples, so evaluation of channel mixing at high flows is not possible with the available data set. Analytical uncertainty of the samples in the form of error bars are shown in figure A1. Even at the low concentrations, the pump samples are outside of the uncertainty range of the EWI samples, suggesting that the positive bias is real. However, without a calculated box coefficient at high discharge, it would be unreasonable to apply the two calculated box coefficients to the entire sample set. Low-flow coefficients have reduced relevance at medium flows and little relevance at high flows, and interpolating a low-flow coefficient to 1.0 at medium-to-high flow has been supported by data from some streamflow stations (John Gray, written commun.,July 29, 2013 ). Therefore, the box coefficients of 0.42 and 0.60 were applied to the range of discharge relevant to those samples, and the coefficients were interpolated to a maximum value of 1.0 at the highest discharge during the project period (table A2). The resulting pump sample concentrations used for the model calibration set are shown in table A3. 


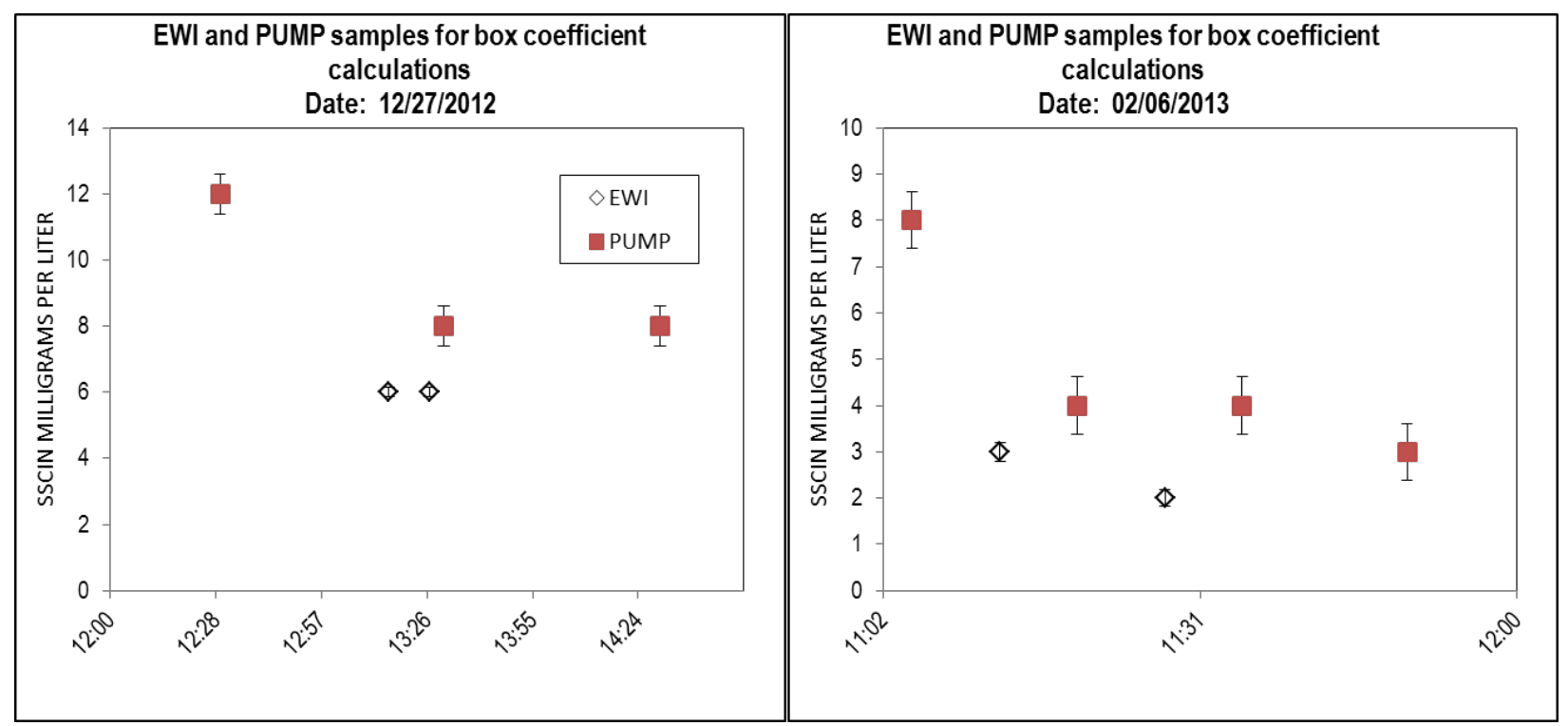

Figure A1. EWI and pump samples for calculating box coefficients, Middle Fork Willamette River near Dexter, OR, 2012-13

Table A2. Box coefficients applied to samples collected within specified ranges of streamflow, Middle Fork Willamette River near Dexter, Oregon, 2012-13.

$\left[\mathrm{ft}^{3} / \mathrm{s}\right.$, cubic feet per second]

\begin{tabular}{cc}
\hline Box Coefficient & Streamflow $\left(\mathrm{ft}^{3} / \mathrm{s}\right)$ \\
\hline 0.42 & $0-2,500$ \\
0.60 & $2,500-5,000$ \\
0.73 & $5,000-7,500$ \\
0.86 & $7,500-10,000$ \\
1.00 & $10,000-12,500$ \\
\hline
\end{tabular}

Table A3. Pump samples results from Middle Fork Willamette at Dexter, Oregon [Adjusted SSC values were used for model calibration data set; PST, Pacific Standard Time; SSC, suspended sediment concentration; mg/L, milligrams per liter; FNU, Formazin Nephelometric Unit; ft3/s]

\begin{tabular}{cccccccc}
$\begin{array}{c}\text { Date and time } \\
\text { (PST) }\end{array}$ & $\begin{array}{c}\text { PUMP SSC } \\
\text { in (mg/L) }\end{array}$ & $\begin{array}{c}\text { Percent } \\
\text { fines }\end{array}$ & $\begin{array}{c}\text { Percent } \\
\text { sand }\end{array}$ & $\begin{array}{c}\text { Applied box } \\
\text { coefficient }\end{array}$ & $\begin{array}{c}\text { Adjusted } \\
\text { SSC (mg/L) }\end{array}$ & $\begin{array}{c}\text { Turbidity } \\
\text { (FNU) }\end{array}$ & $\begin{array}{c}\text { Streamflow } \\
\text { (ft3/s) }\end{array}$ \\
\hline 11/1/12 9:10 & 7 & & & 0.60 & 4.20 & 4.10 & $4,046.90$ \\
11/8/12 11:00 & 10 & & & 0.60 & 6.00 & 3.00 & $3,708.19$ \\
$11 / 13 / 12 ~ 11: 00$ & 4 & & & 0.60 & 2.40 & 2.60 & $3,576.09$ \\
$11 / 19 / 1211: 00$ & 4 & & & 0.73 & 2.92 & 3.80 & $5,057.94$ \\
$11 / 26 / 12 ~ 11: 00$ & 8 & & & 1.00 & 8.00 & 13.80 & $10,216.35$
\end{tabular}


Table A3. Pump samples results from Middle Fork Willamette at Dexter, Oregon-continued [Adjusted SSC values were used for model calibration data set; PST, Pacific Standard Time; SSC, suspended sediment concentration; mg/L, milligrams per liter; FNU, Formazin Nephelometric Unit; f $\mathrm{f} 3 / \mathrm{s}$ ]

\begin{tabular}{|c|c|c|c|c|c|c|c|}
\hline $\begin{array}{l}\text { Date and time } \\
\text { (PST) }\end{array}$ & $\begin{array}{l}\text { PUMP SSC } \\
\text { in (mg/L) }\end{array}$ & $\begin{array}{l}\text { Percent } \\
\text { fines }\end{array}$ & $\begin{array}{l}\text { Percent } \\
\text { sand }\end{array}$ & $\begin{array}{l}\text { Applied box } \\
\text { coefficient }\end{array}$ & $\begin{array}{c}\text { Adjusted } \\
\text { SSC (mg/L) }\end{array}$ & $\begin{array}{l}\text { Turbidity } \\
\text { (FNU) }\end{array}$ & $\begin{array}{c}\text { Streamflow } \\
\left(\mathrm{ft}^{3} / \mathrm{s}\right)\end{array}$ \\
\hline 11/20/12 11:00 & 8 & 73.7 & 26.3 & 0.40 & 3.20 & 4.00 & $2,547.71$ \\
\hline $11 / 22 / 1211: 00$ & 12 & 48.4 & 51.6 & 0.73 & 8.76 & 8.40 & $7,019.15$ \\
\hline $11 / 24 / 1211: 00$ & 8 & 89.8 & 10.2 & 1.00 & 8.00 & 13.50 & $10,141.20$ \\
\hline $12 / 3 / 1211: 00$ & 7 & & & 0.86 & 6.02 & 10.90 & $9,523.74$ \\
\hline 12/6/12 11:00 & 13 & & & 1.00 & 13.00 & 16.20 & $10,166.23$ \\
\hline 12/9/12 11:00 & 18 & & & 1.00 & 18.00 & 22.90 & $12,275.28$ \\
\hline 12/27/12 12:30 & 12 & 71.6 & 28.4 & 0.60 & 7.20 & 12.60 & 3,909.96 \\
\hline 12/27/12 13:31 & 8 & 83.9 & 16.1 & 0.60 & 4.80 & 12.30 & 3,909.96 \\
\hline $12 / 27 / 1214: 30$ & 8 & 82.5 & 17.5 & 0.60 & 4.80 & 12.60 & $3,909.96$ \\
\hline 12/31/12 6:00 & 8 & & & 0.60 & 4.80 & 12.60 & $3,926.97$ \\
\hline 1/4/13 6:00 & 7 & & & 0.42 & 2.94 & 11.40 & $1,989.74$ \\
\hline 1/9/13 6:00 & 7 & & & 0.42 & 2.94 & 11.60 & $2,094.21$ \\
\hline $1 / 20 / 136: 00$ & 5 & 85.0 & 15.0 & 0.60 & 3.00 & 10.90 & $3,270.20$ \\
\hline $1 / 26 / 136: 00$ & 6 & 88.6 & 11.4 & 0.60 & 3.60 & 8.20 & $2,519.21$ \\
\hline 2/1/13 6:00 & 8 & 75.0 & 25.0 & 0.60 & 4.80 & 9.00 & $2,547.71$ \\
\hline 2/7/13 6:00 & 4 & 85.7 & 14.3 & 0.42 & 1.68 & 8.90 & 2,323.34 \\
\hline 2/13/13 6:00 & 6 & 82.0 & 18.0 & 0.42 & 2.52 & 7.90 & $1,364.84$ \\
\hline 2/19/13 6:00 & 5 & 74.4 & 25.6 & 0.42 & 2.10 & 8.10 & $1,342.73$ \\
\hline 2/25/13 6:00 & 6 & 72.9 & 27.1 & 0.42 & 2.52 & 8.10 & $1,353.76$ \\
\hline 2/6/13 11:05 & 8 & 71.2 & 28.8 & 0.42 & 3.36 & 8.90 & $2,401.85$ \\
\hline 2/6/13 11:20 & 4 & 80.6 & 19.4 & 0.42 & 1.68 & 8.60 & $2,392.55$ \\
\hline 2/6/13 11:35 & 4 & 93.8 & 6.2 & 0.42 & 1.68 & 8.60 & $2,397.20$ \\
\hline 2/6/13 11:50 & 3 & 88.9 & 11.1 & 0.42 & 1.26 & 8.85 & 2,392.59 \\
\hline 2/6/13 12:05 & 3 & 85.7 & 14.3 & 0.42 & 1.26 & 8.95 & $2,378.67$ \\
\hline Maximum & 18 & 93.8 & 51.6 & 1 & 18 & 22.9 & $12,275.28$ \\
\hline Minimum & 3 & 48.4 & 6.2 & 0.4 & 1.26 & 2.6 & $1,342.73$ \\
\hline Mean & 7.28 & 79.65 & 20.35 & 0.60 & 4.74 & 9.70 & $4,368.77$ \\
\hline Median & 7.00 & 82.25 & 17.75 & 0.60 & 3.36 & 8.90 & $3,423.15$ \\
\hline
\end{tabular}




\section{METHODS FOR BRACKETING TURBIDITY AND DISCHARGE}

In order to match turbidity values to EWI samples, continuous turbidity data were averaged over the period of EWI sample collection. Turbidity values were averaged starting with the first data punch before the start of the EWI and ending with the data punch after the end of the EWI. For pump samples that were not collected at :00,:15, :30, or :45 after the hour (1/4 hour mark), two turbidity values were averaged, one on the 1/4-hour mark before the pump sample was collected and one on the 1/4-hour mark after the pump sample was collected. For pump sample times that occurred on the 1/4-hour mark, single unit values of turbidity were used. Discharge values were interpolated to match with EWI and pump sample times, starting with the 15-minute data punch before the mean time of the sample, and interpolated to the mean time of the sample. For samples times that occurred on the 1/4-hour mark, single unit values of discharge were used.

\section{MODEL DEVELOPMENT}

Regression analysis was performed using the Excel spreadsheet program from the TM3, chapter 4 publication (Rasmussen and others, 2009). Final output is provided. Turbidity and streamflow were examined together as explanatory variables for estimating SSC.

Untransformed turbidity, discharge, and $S S C$ were selected as the best model for the project period on the basis of residual plots, MSPE, and p-values. Residual plots for evaluating variance, normality, homoscedasticity, and curvature are shown in figure A2. Ninety-percent prediction intervals are also provided for evaluating uncertainty of the estimates in figure A3. 


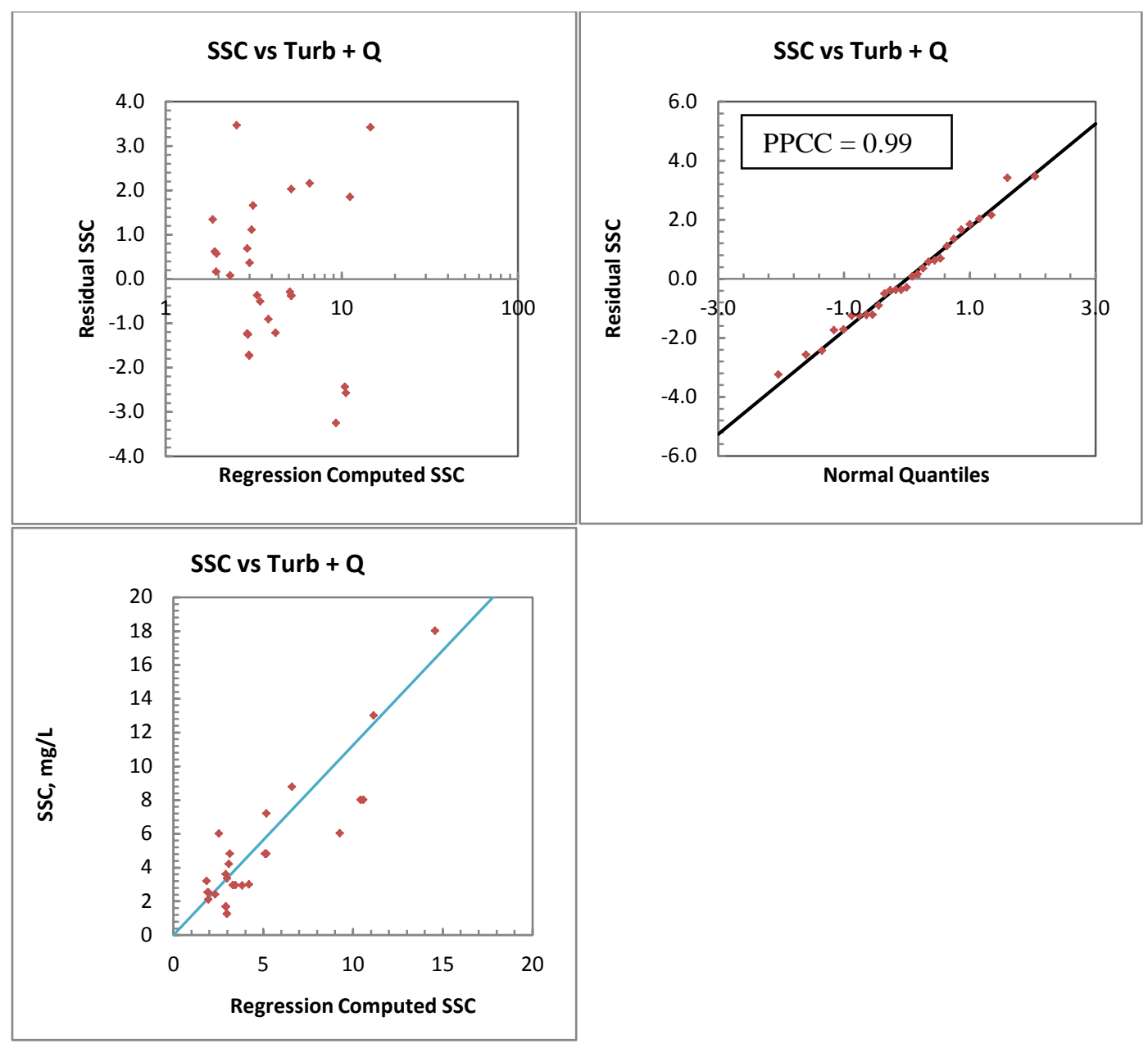

Figure A2. Residual and probability plots for regression model, Middle Fork Willamette River near Dexter, Oregon. 


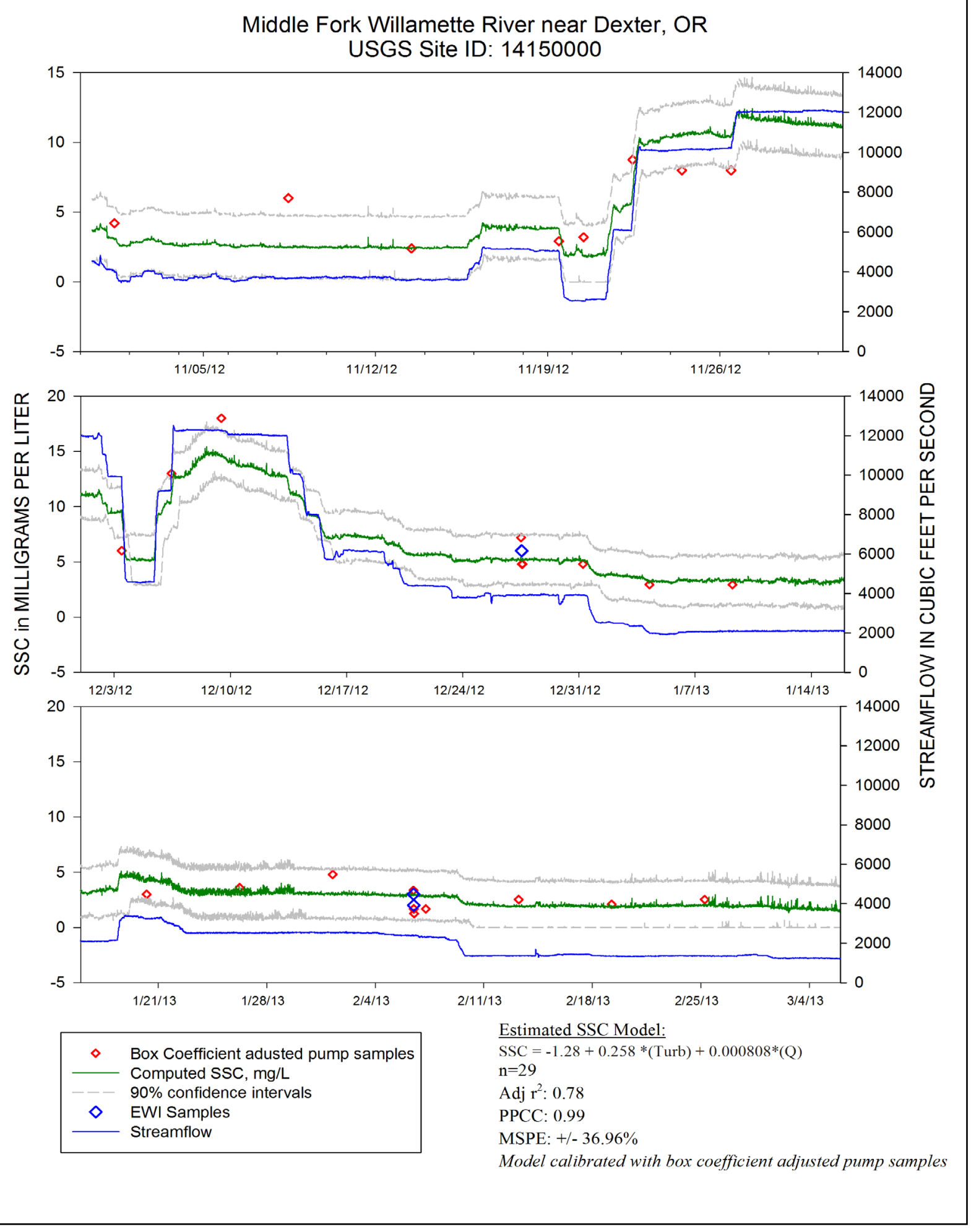

Figure A3. Time-series plots of computed SSC, 90 percent confidence intervals, and streamflow at Middle Fork Willamette River near Dexter, Oregon October 2012 to March 2013 


\section{MODEL SUMMARIES}

Summary of final regression analysis for suspended-sediment concentration at Middle Fork Willamette River near Dexter, Oregon.

SSC $=-1.23+0.258 \times($ Turb $)+0.000808 *(\mathrm{Q})$

$S S C=$ Suspended-sediment concentration, in milligrams per liter

$T B=$ Turbidity (Hydrolab/McVann ${ }^{\circledR}$ Self-Cleaning (SC) Turbidity), in formazin nephelometric units

(FNU).

\section{Model information:}

Number of measurements $=\mathbf{2 9}$

Model standard percentage error $(M S P E)=+/-36.96$ percent

Adj $\mathrm{r}^{2}: \mathbf{0 . 7 8}$

PPCC: 0.99

PRESS: 122.6

\section{EXTREME VALUES}

Maximum Instantaneous SSC: $15 \mathrm{mg} / \mathrm{L}$ on December 8, 9, 10, 2012

Minimum Instantaneous SSC: 1 mg/L on March 2, 5, 6 , 2013

\section{DATA LIMITATIONS}

- The period of record associated with this project is short due to the project requirements of monitoring for SSC during the short term drawdown of Fall Creek Lake. As such, a limited number of samples were able to be collected over the 3 month project period, and the range of the hydrograph for the entire year was not sampled.

- Two EWI samples were collected during the project period at low to medium streamflows to calculate box coefficients used to adjust pump sample concentrations. Box coefficients for highstreamflow samples were therefore interpolated.

- Uncertainty associated with using box-coefficient adjusted pump samples for turbidity-SSC regressions is noted

\section{FUTURE IMPROVEMENTS}

- EWI samples should be collected at high streamflows (5,000-10,000 $\left.\mathrm{ft}^{3} / \mathrm{s}\right)$ to verify interpolated box coefficients used for this record

- Pending availability of funding, turbidity data should be collected over an entire water year to cover the range of the hydrograph

Worked: L. Schenk, August 15, 2013

Checked: H. Bragg,

Reviewed: C. Anderson 


\title{
Fall Creek Inflow
}

\author{
WATER-QUALITY MONITOR STATION ANALYSIS \\ 2013 WATER YEAR \\ SUSPENDED-SEDIMENT RECORD \\ 14150290 Fall Creek above North Fork, near Lowell, Oregon
}

\section{PROJECT BACKGROUND}

The USGS, in cooperation with the Army Corps of Engineers, monitored suspended sediment on a number of sites in the Fall Creek Lake drainage, near Lowell, Oregon, in the winter of 2012-13. The purpose of the monitoring was to provide data that will be used to estimate suspended sediment loads transported out of Fall Creek Lake during an operational drawdown to pass endangered juvenile salmonids through the dam. Additionally, monitoring data will be used to estimate a sediment budget for the lake and nearby tributaries. Fall Creek above North Fork is one of two unregulated tributaries to Fall Creek Lake, and sediment transported into the lake will be used to calculate sediment storage in the lake and net sediment transport out of the Lake.

\section{EQUIPMENT}

A McVan self -cleaning Analite NEP 395 optical turbidity sensor was used to collect continuous turbidity data. Data were transmitted directly to a Campbell Scientific datalogger and downloaded periodically during the project period. Data were logged in 15-minute intervals.

\section{MODEL CALIBRATION DATASET}

All samples were collected using USGS equal-width-increment (EWI) protocols. The discreet turbidity value (in Formazin Nephelometric Units, FNU) associated with each sample was the average of the 15-minute logged values of the instream sensor over the duration of the sample collection (2-4 values). The discreet streamflow value (in cubic feet per second, $\mathrm{ft}^{3} / \mathrm{s}$ ) associated with each sample was interpolated from the 15-minute logged values to the mean time of the sample collection. The samples were analyzed at the USGS Cascade Volcano Observatory (CVO) sediment laboratory, providing the suspended-sediment concentration value (in milligrams per liter [mg/L]) for each sample, as well as the percent finer than 63 microns $(\mu \mathrm{m})$. Calibration data are shown in table A4. 
Table A4. Calibration data for regression model at Fall Creek above North Fork near Lowell, Oregon, 201213

[PST, Pacific Standard Time; FNU, Formazin Nephelopmetric Unit; $\mathrm{ft}^{3}$ /s, cubic feet per second; mg/L, milligrams per liter; $\mu \mathrm{m}$, micron (micrometer)]

\begin{tabular}{lcccc}
\hline \multicolumn{1}{c}{$\begin{array}{c}\text { Date and time } \\
\text { (PST) }\end{array}$} & $\begin{array}{c}\text { Turbidity } \\
\text { (FNU) }\end{array}$ & $\begin{array}{c}\text { Streamflow } \\
\left(\mathrm{ft}^{3} / \mathrm{s}\right)\end{array}$ & $\begin{array}{c}\text { SSC } \\
(\mathrm{mg} / \mathrm{L})\end{array}$ & $\begin{array}{c}\text { Finer than } 63 \mu \mathrm{m} \\
\text { (percent) }\end{array}$ \\
\hline 11/8/2012 9:31 & 2.7 & 132 & 2 & 71 \\
11/13/2012 16:42 & 2.4 & 418 & 3 & 80 \\
$11 / 20 / 20129: 55$ & 190 & 6,528 & 368 & 56 \\
12/3/2012 9:47 & 10.7 & 1,572 & 14 & 63 \\
$1 / 3 / 201315: 02$ & 2.3 & 289 & 2 & 50 \\
\hline
\end{tabular}

\section{MODEL DEVELOPMENT}

Initial plots of the response variable (SSC) with the possible explanatory variables (turbidity and streamflow) indicated that both are correlated to SSC. Regression analyses were done with the Turbidity Sediment Spreadsheet using the methods described in the USGS Techniques and Methods Report, Book 3, Chapter C4. Turbidity and streamflow were evaluated together and separately as possible surrogates. The log-10 transformations of each parameter were also evaluated together and separately as possible surrogates. The turbidity and streamflow were determined to be too highly correlated to one another for a model to use both parameters. The simple linear regression with logtransformed turbidity was selected as the best model for estimating SSC based on the residual plots, the MPSE and the $\mathrm{R}^{2}$ value (fig. A4). Time series of SSC based on the primary model with 90 percent confidence intervals are shown in figure A5.

During the period of missing turbidity data (November 20-29, 2012), simple linear regression with log-transformed streamflow was used to compute SSC. Four discrete SSC values were interpolated to transition between the two models, two values at the beginning of the $\log (\mathrm{SSC})-\log (\mathrm{Q})$ record, and two at the end (fig. A6). Regression model, residual, and probability plots for this model are shown in figure A7.

\section{MODEL SUMMARIES}

\section{Primary model:}

$\log (S S C)=1.17 \log ($ Turbidity $)-0.0841$

Bias correction factor $=1.02$

Number of measurements $=5$

Model standard percent error $(\mathrm{MSPE})=+27.3$ percent , -21.37 percent

Adjusted coefficient of determination $\left(\right.$ Adj $\left.\mathrm{R}^{2}\right)=.99$

PRESS $=0.07$

$\mathrm{PPCC}=0.98$ 


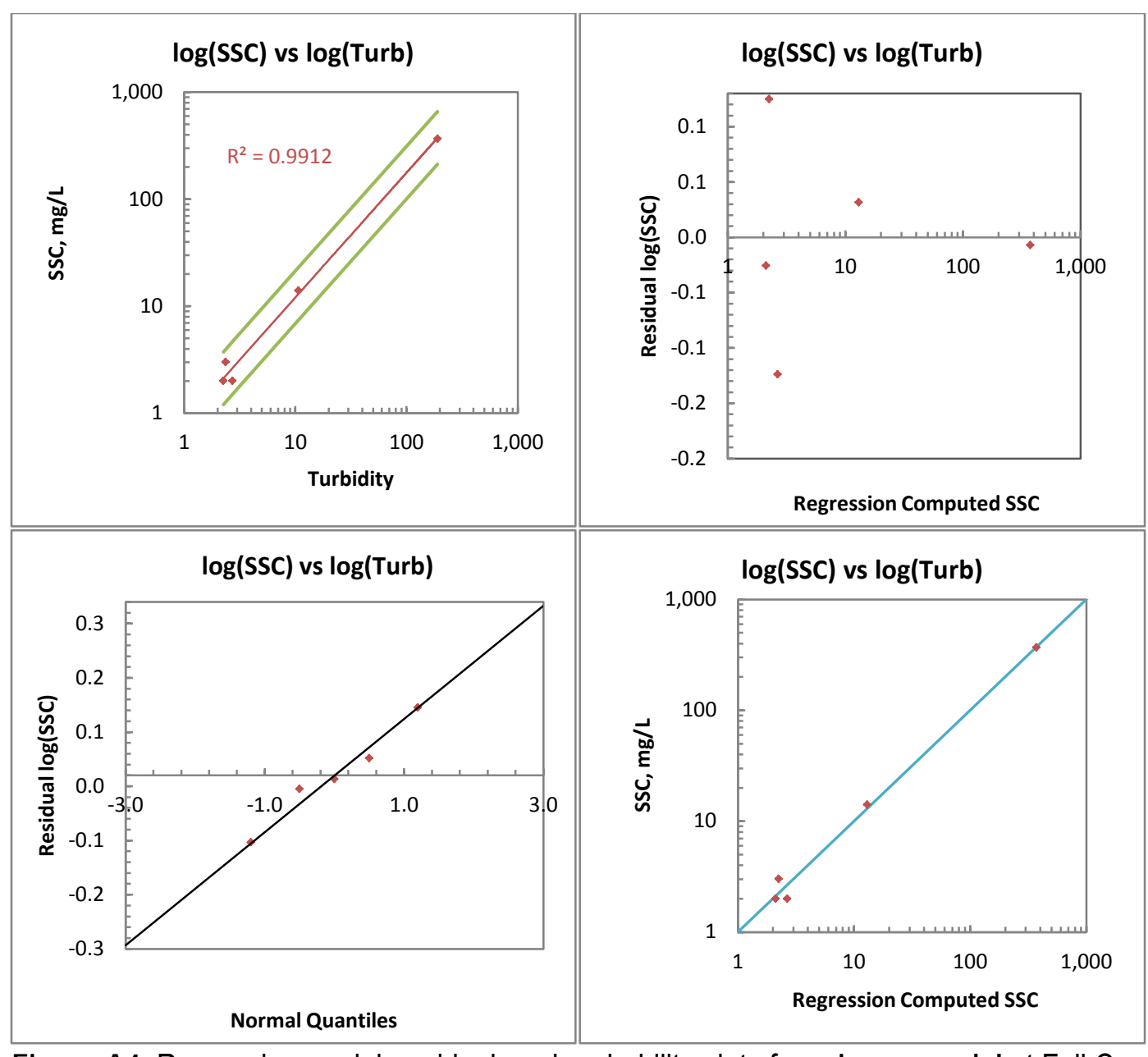

Figure A4. Regression model, residual, and probability plots for primary model at Fall Creek above North Fork near Lowell, Oregon. 


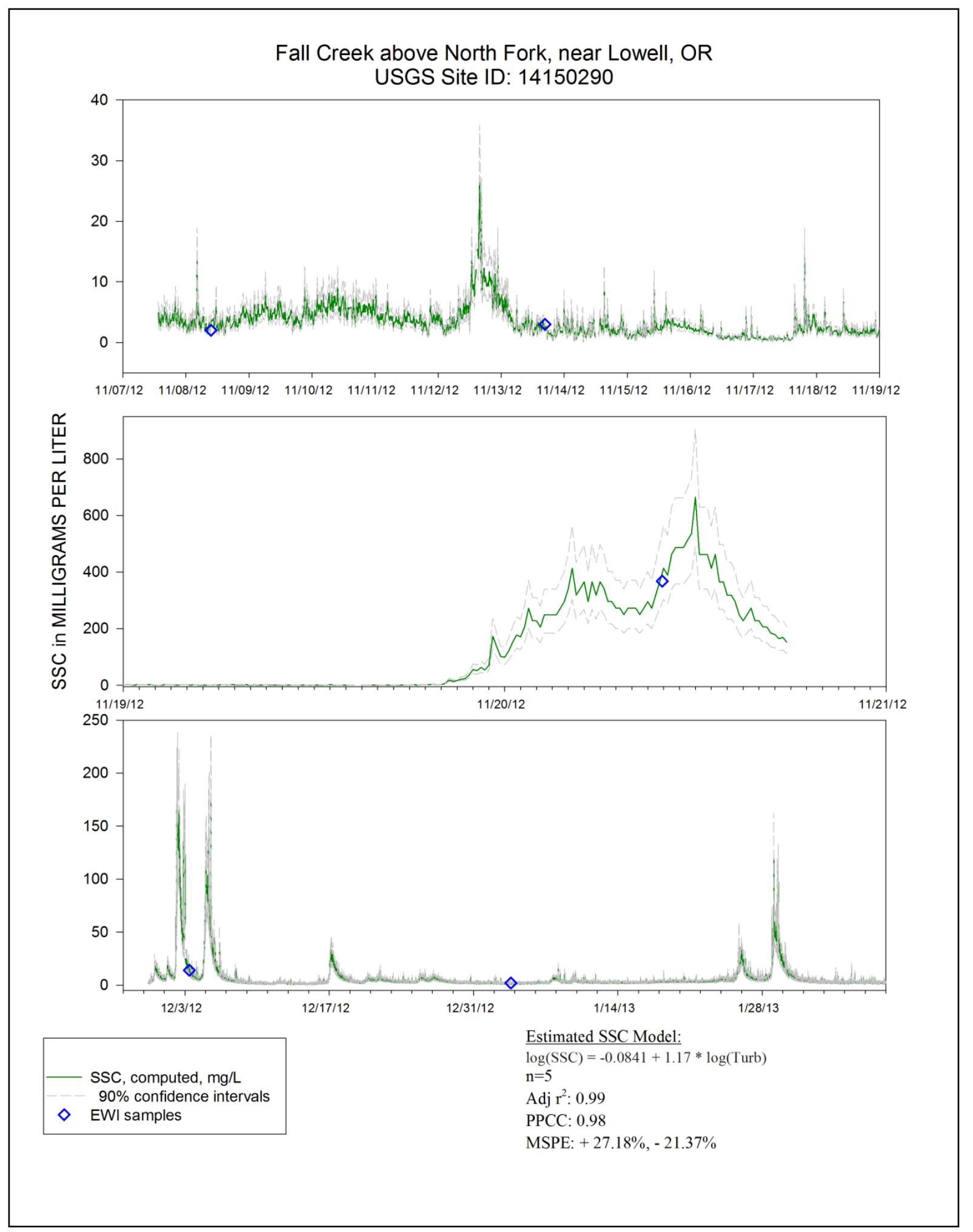

Figure A5.: Time-series plots of computed SSC and 90 percent confidence intervals using log(Turb) as an explanatory variable, primary model, Fall Creek above North Fork near Lowell, Oregon. 


\section{Secondary model:}

$\log ($ SSC $)=1.38 L_{L O G}($ Streamflow $)-2.96$

Bias correction factor $=1.19$

Number of measurements $=5$

Model standard percent error $(\mathrm{MSPE})=+113.11$ percent, -53 .1percent

Adjusted coefficient of determination $\left(\operatorname{Adj} \mathrm{R}^{2}\right)=.88$

PRESS $=1.68$

PPCC $=0.94$ 


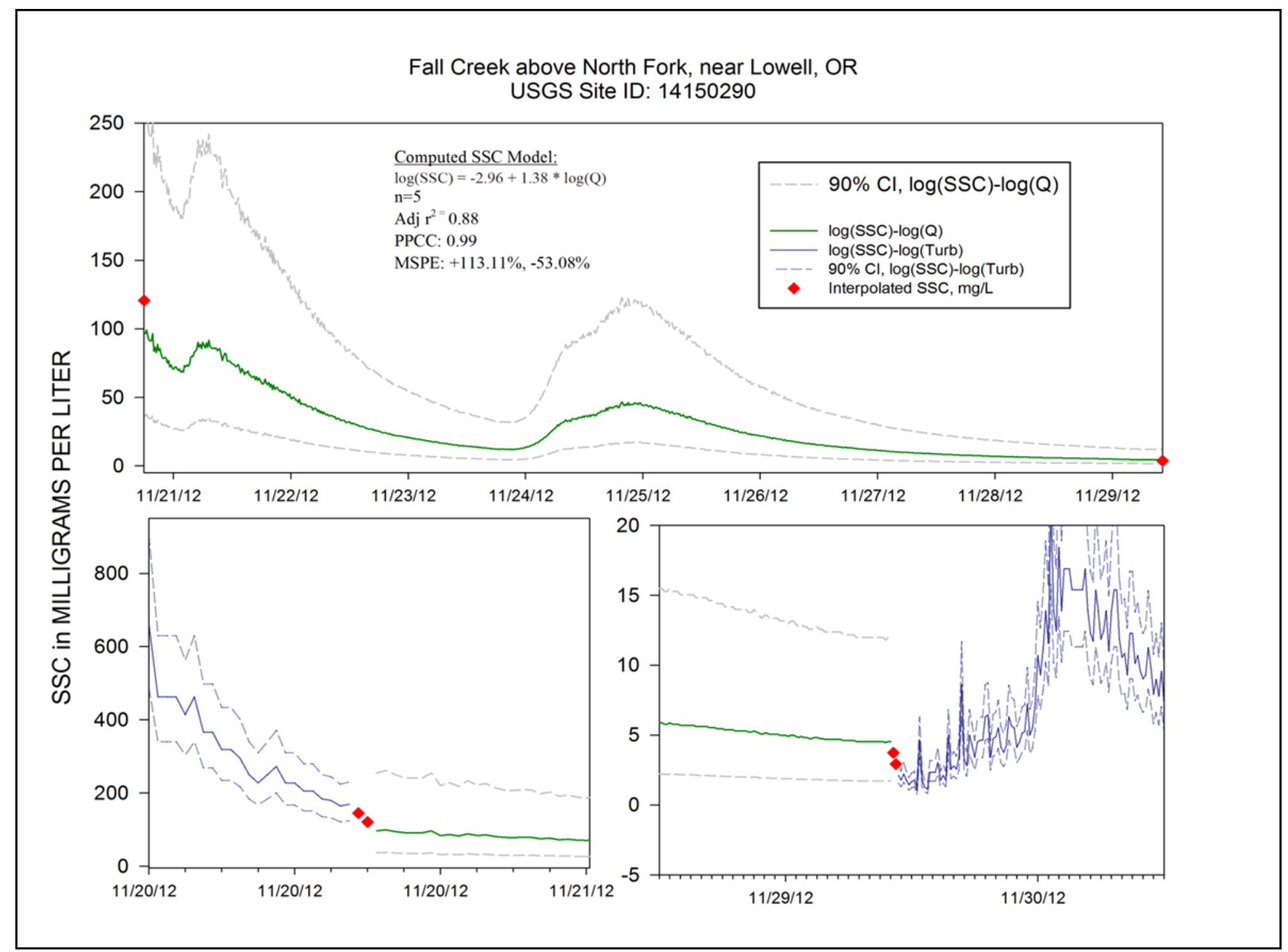

Figure A6. Time series plots of computed SSC and 90 percent confidence intervals using $\log (\mathrm{Q})$ and $\log (\mathrm{Turb})$ as an explanatory variable, Fall Creek above North Fork near Lowell, OR, November 2012 


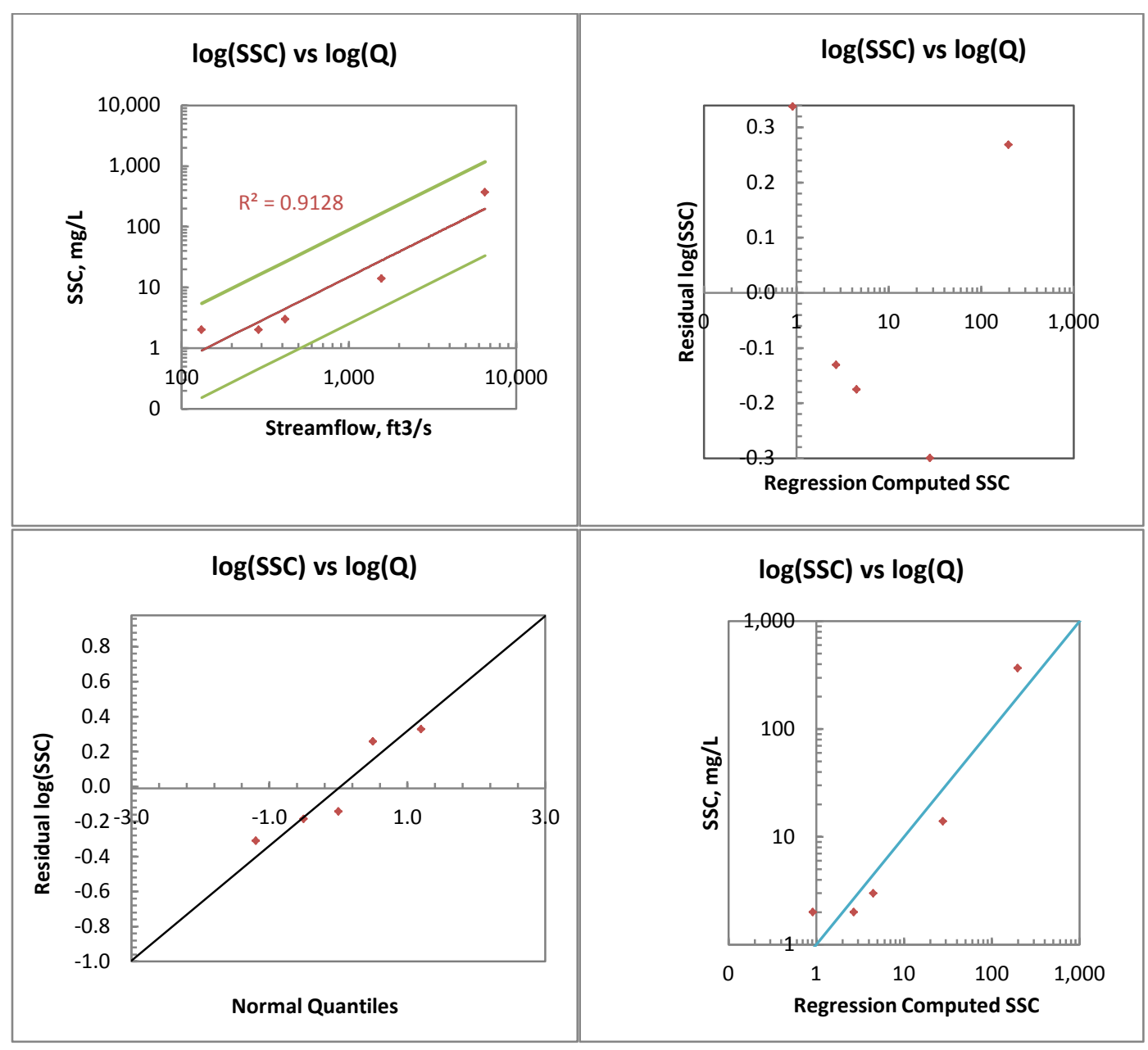

Figure A7. Regression model, residual, and probability plots of secondary model, Fall Creek above North Fork near Lowell, Oregon. 


\section{RECORD}

Because turbidity data were logged every 15 minutes, SSC data were computed for each quarter hour. During short periods of missing or deleted turbidity data, SSC was estimated in ADAPS by interpolating between the computed SSC values. During the period from 11/20/12 18:00 to 11/29/12 10:15 when turbidity data were deleted, the SSC was computed using the secondary regression model based on streamflow.

\section{EXTREMES VALUES}

Maximum instantaneous SSC: 665 mg/L on 2012-11-20@12:00

Minimum instantaneous SSC: 0.1 mg/L on 2012-11-17@ 03:15 and 11:30

\section{DATA LIMITATIONS AND FUTURE IMPROVEMENTS}

The model calibration data set has very few samples and they are not well distributed over the range of conditions at the monitoring site during the analysis period. Because of this, the entire record is flagged as "estimated.” Future sample collection should target the moderate to high turbidity and streamflow conditions.

Worked: L. Schenk, 08/16/13

Checked: H. Bragg

Reviewed: A. Stonewall 


\title{
Winberry Creek
}

\author{
WATER-QUALITY MONITOR STATION ANALYSIS \\ 2013 WATER YEAR \\ SUSPENDED-SEDIMENT RECORD \\ 14150800 Winberry Creek near Lowell, Oregon
}

Analysis Period: November 7, 2012-March 7, 2013

\section{PROJECT BACKGROUND}

The USGS, in cooperation with the U.S. Army Corps of Engineers, monitored suspended sediment on a number of sites in the Fall Creek Lake drainage, near Lowell, Oregon, in the winter of 2012-13. The purpose of the monitoring was to provide data that will be used to estimate suspended-sediment loads transported out of Fall Creek Lake during an operational drawdown to pass endangered juvenile salmonids through the dam. Additionally, monitoring data will be used to estimate a sediment budget for the lake and nearby tributaries. Winberry Creek near Lowell, Oregon is one of two unregulated tributaries to Fall Creek Lake, and sediment transported into the lake will be used to calculate sediment storage in the lake and net sediment transport out of the Lake.

\section{EQUIPMENT}

A McVan self -cleaning Analite NEP 395 optical turbidity sensor was used to collect continuous turbidity data. Data were transmitted directly to a Campbell Scientific datalogger and downloaded periodically during the project period. Data were logged in 15-minute intervals.

\section{MODEL CALIBRATION DATASET}

Samples were collected using USGS equal-width-increment (EWI) protocols. The discreet turbidity value (in Formazin Nephelometric Units, FNU) associated with each sample was the average of the 15minute logged values of the instream sensor over the duration of the sample collection (3-4 values). The discreet streamflow value (in cubic feet per second, $\mathrm{ft}^{3} / \mathrm{s}$ ) associated with each sample was interpolated from the 15-minute logged values to the mean time of the sample collection. The samples were analyzed at the USGS Cascade Volcano Observatory (CVO) sediment laboratory, providing the suspendedsediment concentration value (in milligrams per liter $[\mathrm{mg} / \mathrm{L}]$ ) for each sample, as well as the percent finer than 63 microns $(\mu \mathrm{m})$ (table A5).

Table A5: Calibration dataset for regression model at Winberry Creek near Lowell, Oregon

[PST, Pacific Standard Time; FNU, Formazin nephelometric unit; $\mathrm{ft}^{3} / \mathrm{s}$, cubic feet per second; SSC, suspended sediment concentration; $\mathrm{mg} / \mathrm{L}$, milligram per liter; $\mu \mathrm{m}$, micron or micrometer]

\begin{tabular}{ccccc}
\hline $\begin{array}{c}\text { Date and time } \\
\text { (PST) }\end{array}$ & $\begin{array}{c}\text { Turbidity } \\
\text { (FNU) }\end{array}$ & $\begin{array}{c}\text { Streamflow } \\
\text { (ft3/s) }\end{array}$ & $\begin{array}{c}\text { SSC } \\
(\mathbf{m g} / \mathbf{L})\end{array}$ & $\begin{array}{c}\text { Finer than } 63 \mu \mathrm{m} \\
\text { (percent) }\end{array}$ \\
\hline 11/08/12 11:11 & 0.2 & 19 & 1 & 93.1 \\
11/14/12 14:05 & 2.3 & 59 & 1 & 95.6 \\
11/20/12 11:53 & 338 & 2490 & 376 & 60.3 \\
11/30/12 09:46 & 7.2 & 224 & 16 & 29.6 \\
$01 / 09 / 13 ~ 13: 59$ & 2.5 & 210 & 6 & 67.8 \\
\hline
\end{tabular}




\section{MODEL DEVELOPMENT}

Initial plots of the response variable (SSC) with the possible explanatory variables (turbidity and streamflow) indicated that both are correlated to SSC. Regression analyses were done with the Turbidity Sediment Spreadsheet using the methods described in Rasmussen and Others (2009). . Turbidity and streamflow were evaluated together and separately as possible surrogates. The log-10 transformations of each parameter were also evaluated together and separately as possible surrogates. The turbidity and streamflow were found to be too highly correlated to one another for a model to use both parameters. The simple linear regression with un-transformed turbidity was selected as the best model for estimating SSC based on the residual plots, the MPSE, PPCC, and $\mathrm{R}^{2}$ values (fig. A8).

\section{MODEL SUMMARIES}

$S S C=1.10$ Turbidity +2.61

Number of measurements $=5$

Root-mean-squared error (RMSE) $=4.104$

Model standard percent error $(\mathrm{MSPE})= \pm 5.13$ percent

Adjusted coefficient of determination $\left(\right.$ Adj R $\left.^{2}\right)=0.999$

Probability Plot Correlation Coefficient $($ PPCC $)=0.974$

PRESS $=152484.6$ 


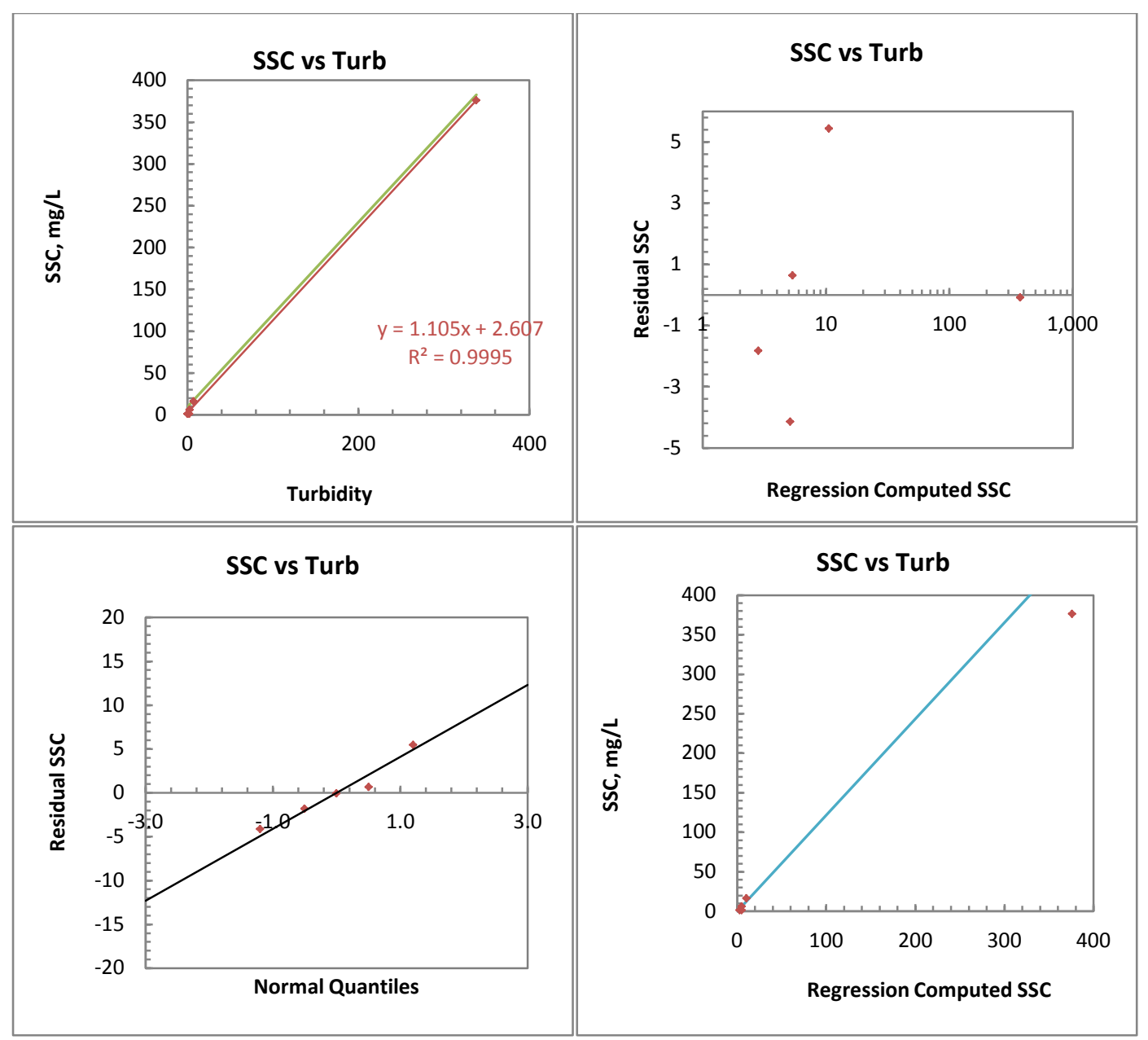

Figure A8: Regression plot, residual plot, and probability plot for Winberry Creek near Lowell, Oregon.

\section{RECORD}

SSC data was computed every 15 minutes from the 15-minute turbidity and streamflow data.

During periods of missing or deleted turbidity data, the SSC was estimated by interpolating between the computed SSC values. The continuous SSC record with 90 percent confidence intervals is shown in figure A9.

EXTREMES FOR PERIOD (November 7, 2012 to March 7, 2013)

Max: 420 mg/L, November 20, 2012

Min: $0.0 \mathrm{mg} / \mathrm{L}$, Many days during the period of analysis.

\section{DATA LIMITATIONS AND FUTURE IMPROVEMENTS}

The model calibration data set has very few samples and they are not well distributed over the range of conditions at the monitoring site during the analysis period. Because of this, all daily mean values are flagged as "estimated." Future sample collection should target the moderate to high turbidity and streamflow conditions. 


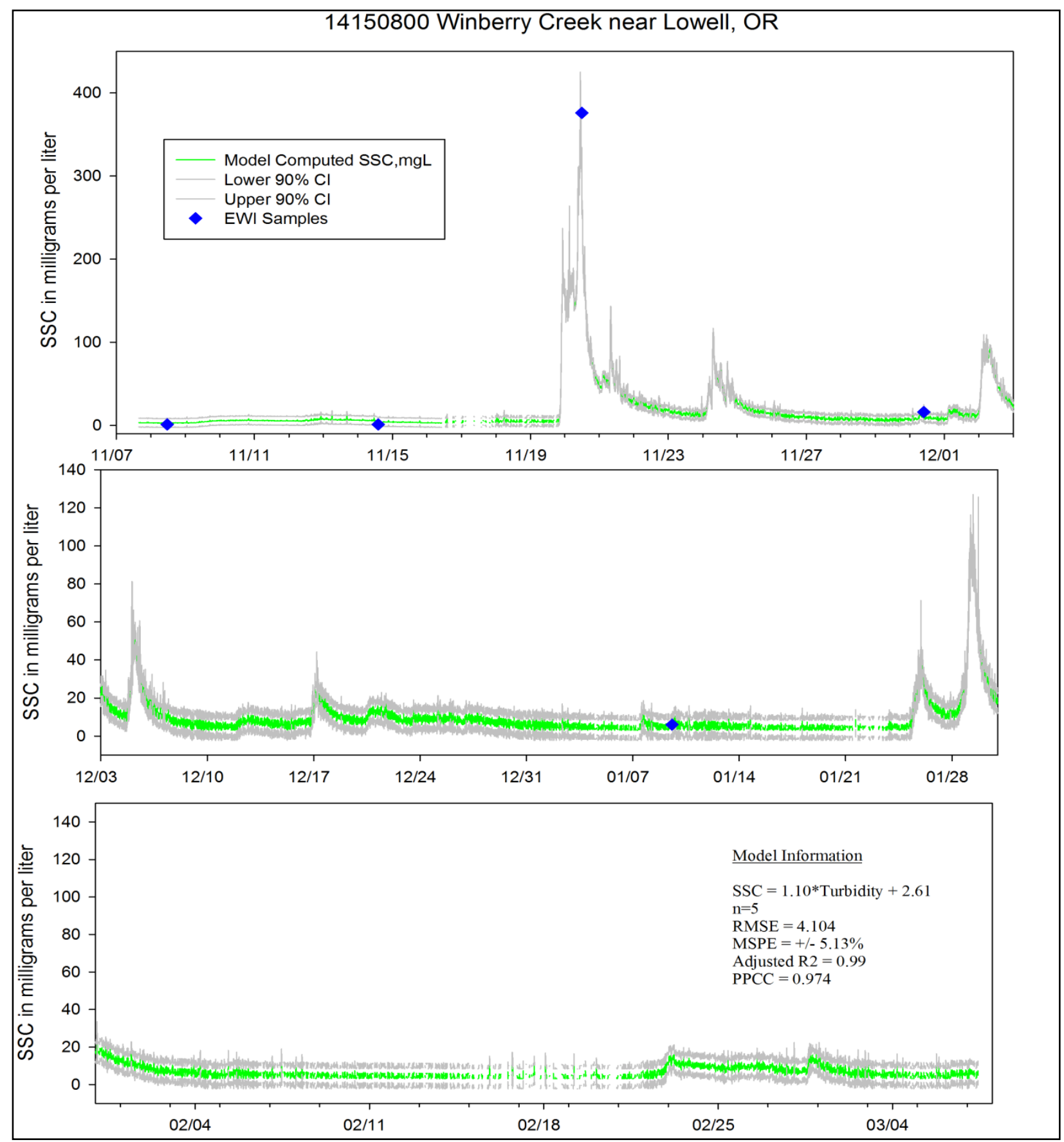

Figure A9. Time series plots of computed SSC and 90 percent confidence intervals at Winberry Creek near Lowell, Oregon, November 2012 to March 2013

Worked: H. Bragg, 08/26/13

Checked: L. Schenk

Reviewed: A. Stonewall 


\title{
Fall Creek Outflow
}

\author{
WATER-QUALITY MONITOR STATION ANALYSIS \\ 2013 WATER YEAR \\ SUSPENDED-SEDIMENT RECORD \\ 14151000 Fall Creek below Winberry Creek near Lowell, Oregon
}

Analysis Period: October 26, 2012-February 22, 2013

\section{PROJECT BACKGROUND}

Suspended sediment, turbidity, and dissolved oxygen were monitored for the period because of an operational drawdown of Fall Creek Lake, 0.9 mi upstream of the station. In December, the elevation of the lake was gradually lowered to normal minimum pool elevation until, on 12/12/12, it was lowered to the point where the regulating outlets of Fall Creek Dam were open and water was flowing freely through the dam. The regulating outlets remained open until 12/17/12, when they were closed and the reservoir began to refill. Sediment transport at Fall Creek below Winberry Creek will be used to calculate net sediment transport out of the lake during the project period.

\section{EQUIPMENT}

A McVann self-cleaning turbidity sensor installed on a Hydrolab DS-5a data sonde was used to collect continuous turbidity data. Data were transmitted by radio from the existing Sutron 8210 DCP. Samples were collected from a cableway approximately $0.1 \mathrm{mi}$ upstream of the gage house.

\section{MODEL CALIBRATION DATASET}

Suspended-sediment samples were collected using USGS equal-width-increment (EWI) protocols from the cableway approximately $550 \mathrm{ft}$ upstream of the monitoring station. The discreet turbidity values (in Formazin Nephelometric Units, FNU) associated with the samples are the average of the 15minute logged values of the instream sensor over the duration of the sample collection (2-4 values). The discreet streamflow values (in cubic feet per second, $\mathrm{ft}^{3} / \mathrm{s}$ ) associated with each sample are interpolated from the 15-minute logged values to the mean time of the sample collection. The samples were analyzed at the USGS Cascade Volcano Observatory (CVO) sediment laboratory, providing the suspendedsediment concentration value (in milligrams per liter $[\mathrm{mg} / \mathrm{L}]$ ) for each sample, as well as the percent finer than 63 microns $(\mu \mathrm{m})$.

\section{MODEL DEVELOPMENT}

The samples (table A6) can be divided according to the reservoir conditions at the time they were collected: Pre-drawdown (samples \#1-5), Drawdown (samples \#6-13), and Post-drawdown (samples \#14-16). Initial analysis of the data indicates that this timing is evident in the ranges of concentrations and the percent fines of the samples. Plots of the response variable (SSC) with the possible explanatory variables (turbidity and streamflow) (fig. A10) suggest that there are correlations with one or both variables, possibly for subsets of the samples during these distinct time periods. 
Table A6. Calibration data set for SSC regression model, Fall Creek below Winberry Creek near Lowell, OR, 2012-13.

[PST, Pacific Standard Time; FNU, Formazin nephelometric unit; $\mathrm{ft}^{3} / \mathrm{s}$, cubic feet per second; SSC, suspended sediment concentration; mg/L, milligram per liter; $\mu \mathrm{m}$, micron or micrometer; -, not analyzed]

\begin{tabular}{clcccc}
\hline Sample \# & \multicolumn{1}{c}{$\begin{array}{c}\text { Date and time } \\
\text { (PST) }\end{array}$} & $\begin{array}{c}\text { Turbidity } \\
\text { (FNU) }\end{array}$ & $\begin{array}{c}\text { Streamflow } \\
\left(\mathrm{ft}^{3} / \mathbf{s}\right)\end{array}$ & $\begin{array}{c}\text { SSC } \\
(\mathbf{m g} / \mathbf{L})\end{array}$ & $\begin{array}{c}\text { Finer than } 63 \mu \mathrm{m} \\
\text { (percent) }\end{array}$ \\
\hline 1 & $10 / 31 / 201215: 04$ & 2.8 & 1,460 & 4 & - \\
2 & $11 / 14 / 201215: 41$ & 5.7 & 721 & 6 & 86.1 \\
3 & $11 / 28 / 20129: 35$ & 21.0 & 3,200 & 11 & 89.3 \\
4 & $11 / 30 / 201212: 40$ & 112 & 2,020 & 85 & 99.6 \\
5 & $12 / 3 / 20129: 00$ & 67.9 & 2,410 & 48 & 97.0 \\
6 & $12 / 12 / 20127: 38$ & 2,865 & 964 & 9,400 & 71.3 \\
7 & $12 / 12 / 20128: 03$ & 2,005 & 957 & 10,091 & 72.9 \\
8 & $12 / 12 / 201211: 24$ & 1,405 & 878 & 8234 & 62.3 \\
9 & $12 / 12 / 201211: 44$ & 1,392 & 865 & 7973 & 64.2 \\
10 & $12 / 13 / 201213: 57$ & 1,473 & 786 & 4,805 & 67.1 \\
11 & $12 / 13 / 201216: 30$ & 1,647 & 766 & 4,942 & 69.3 \\
12 & $12 / 14 / 201210: 12$ & 782 & 745 & 3,076 & 51.4 \\
13 & $12 / 14 / 201211: 05$ & 761 & 740 & 2,754 & 51.7 \\
14 & $12 / 18 / 201215: 58$ & 20.8 & 1,440 & 118 & 16.4 \\
15 & $1 / 10 / 20139: 20$ & 1.2 & 1,400 & 9 & 23.9 \\
16 & $1 / 23 / 201316: 53$ & 0.2 & 570 & 10 & 32.3 \\
\hline
\end{tabular}



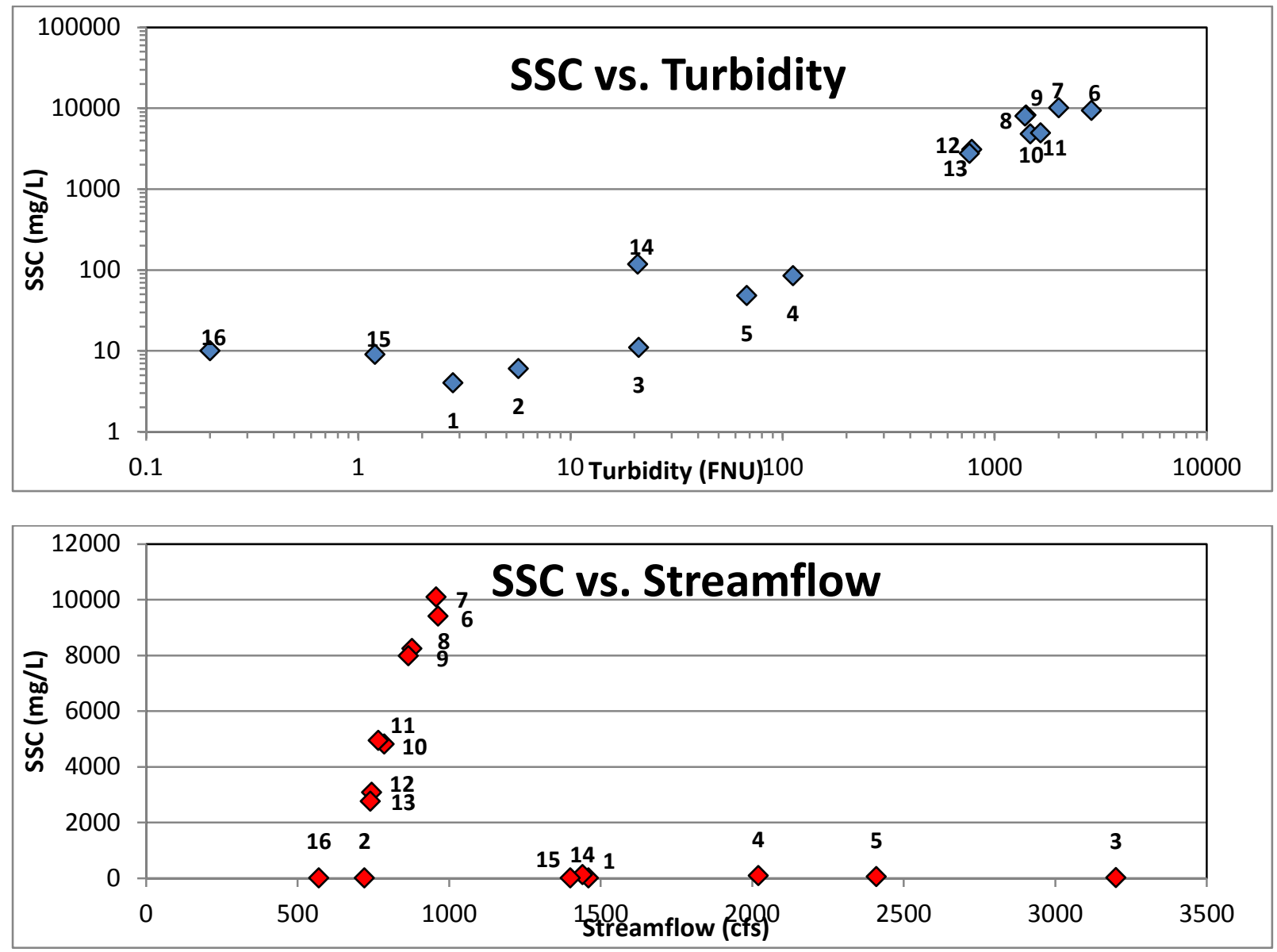

Figure A10: Scatterplot of SSC vs turbidity and SSC vs streamflow at Fall Creek below Winberry Creek near Lowell, OR, 2012-13

Regression analyses were done with the Turbidity Sediment Spreadsheet using the methods described in Rasmussen and others (2009). Each subset of samples was analyzed in the same manner: Turbidity and streamflow were evaluated together and separately as possible surrogates. The log-10 transformations of each parameter were also evaluated together and separately as possible surrogates. Turbidity and streamflow were not found to be too highly correlated to one another in any of the analyses to preclude them both from being used in a model.

\section{MODEL SUMMARIES}

Model 1: Pre-Drawdown (Samples \# 1-5)

Samples collected before the drawdown began have very high percent fines (86-99 percent) and low to moderate SSC values. The multiple linear regression with untransformed turbidity and untransformed streamflow (fig. A11) was selected as the best model for computing SSC based on the MPSE, PPCC, and $\mathrm{R}^{2}$ values. This model is used to compute the SSC from the beginning of the analysis period (10/26/12 11:30) through the onset of the reservoir drawdown (12/12/12, 00:45). By midJanuary, sediment transport seems to have gradually returned to pre-drawdown conditions and this model is again used to compute the SSC from 01/15/13, 04:15 through the end of the analysis period $(02 / 22 / 13,12: 15)$. 
SSC $=4.91+0.764$ Turbidity -0.00312 Streamflow

Number of measurements $=5$

Root-mean-squared error $(\mathrm{RMSE})=1.67$

Model standard percent error $(\mathrm{MSPE})= \pm 5.42$ percent

Adjusted coefficient of determination $\left(\right.$ Adj R $\left.^{2}\right)=0.998$

Probability Plot Correlation Coefficient $($ PPCC $)=0.980$

PRESS $=34.7$

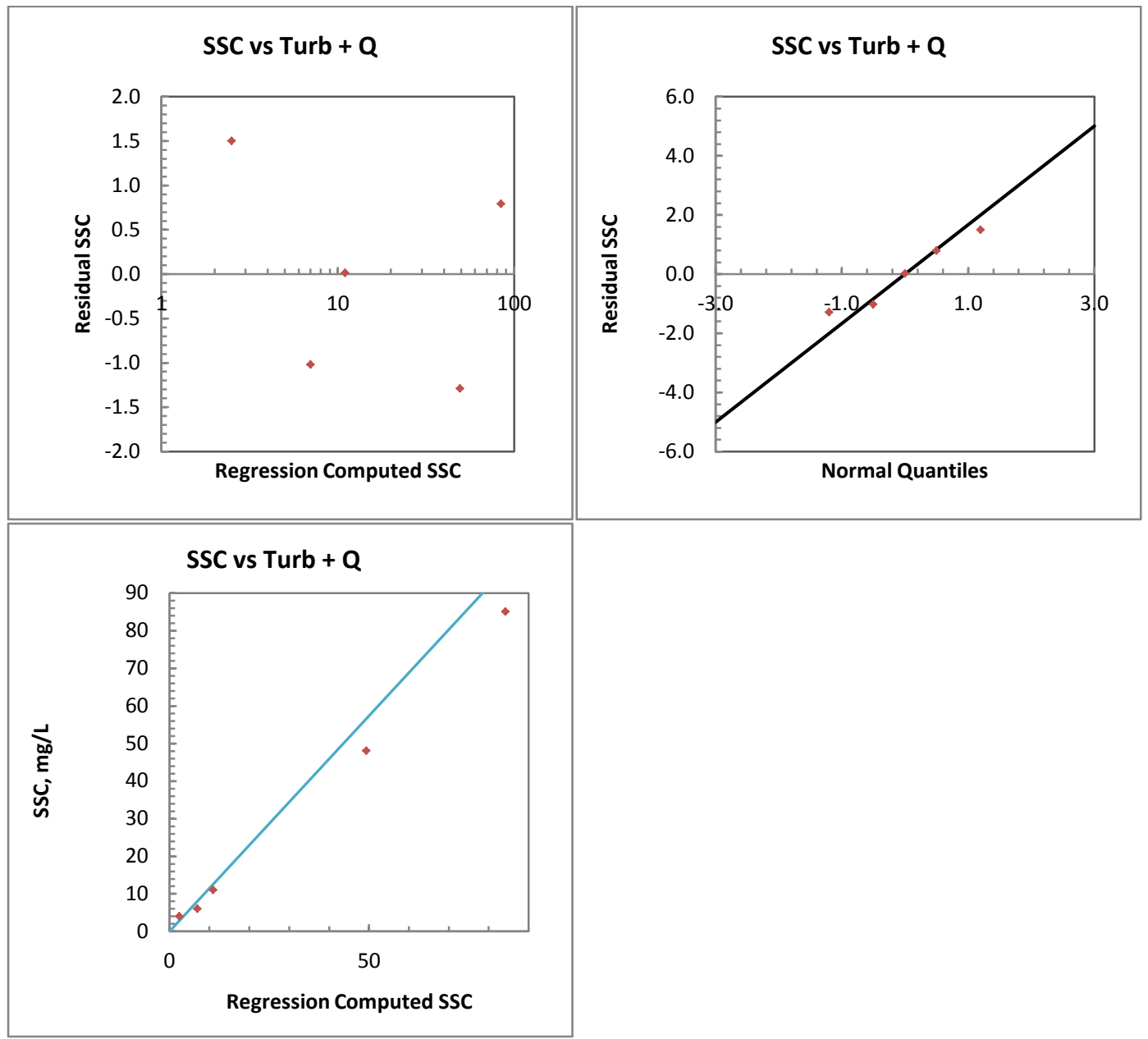

Figure A11. Residual and probability plots for Model 1, Fall Creek below Winberry Creek near Lowell, Oregon, 2012-13. 
Model 2: Drawdown/Post-Drawdown (samples 6-15)

Samples collected during the drawdown operations have moderate percent fines (51-71 percent) and very high SSC (2,700-10,000 mg/L). After the drawdown operations ended on 12/17/12, a dramatic decrease in the percent fines of samples collected at this station and downstream (10-17 percent) indicate a coarsening of the sediment load. This effect was temporary and seemed to taper off by midJanuary. Using the samples from both the drawdown and post-drawdown periods, the multiple linear regression with transformed turbidity and transformed streamflow (fig. A12) was selected as the best model for computing SSC based on the MPSE, PPCC, and $\mathrm{R}^{2}$ values. This model is used to compute the SSC from the shortly after the beginning of the drawdown (12/12/12 02:45) through mid-January $(01 / 15 / 13,04: 00)$

$\log _{10}$ SSC $=-1.07+0.966 \log _{10}$ Turbidity $+0.612 \log _{10}$ Streamflow

Bias correction factor $=1.02$

Number of measurements $=10$

Root-mean-squared error $(\mathrm{RMSE})=0.108$

Model standard percent error $(\mathrm{MSPE})=+28.7$ percent $/-22.0$ percent

Adjusted coefficient of determination $\left(\operatorname{Adj~} \mathrm{R}^{2}\right)=0.988$

Probability Plot Correlation Coefficient $($ PPCC $)=0.975$

PRESS $=0.146$ 


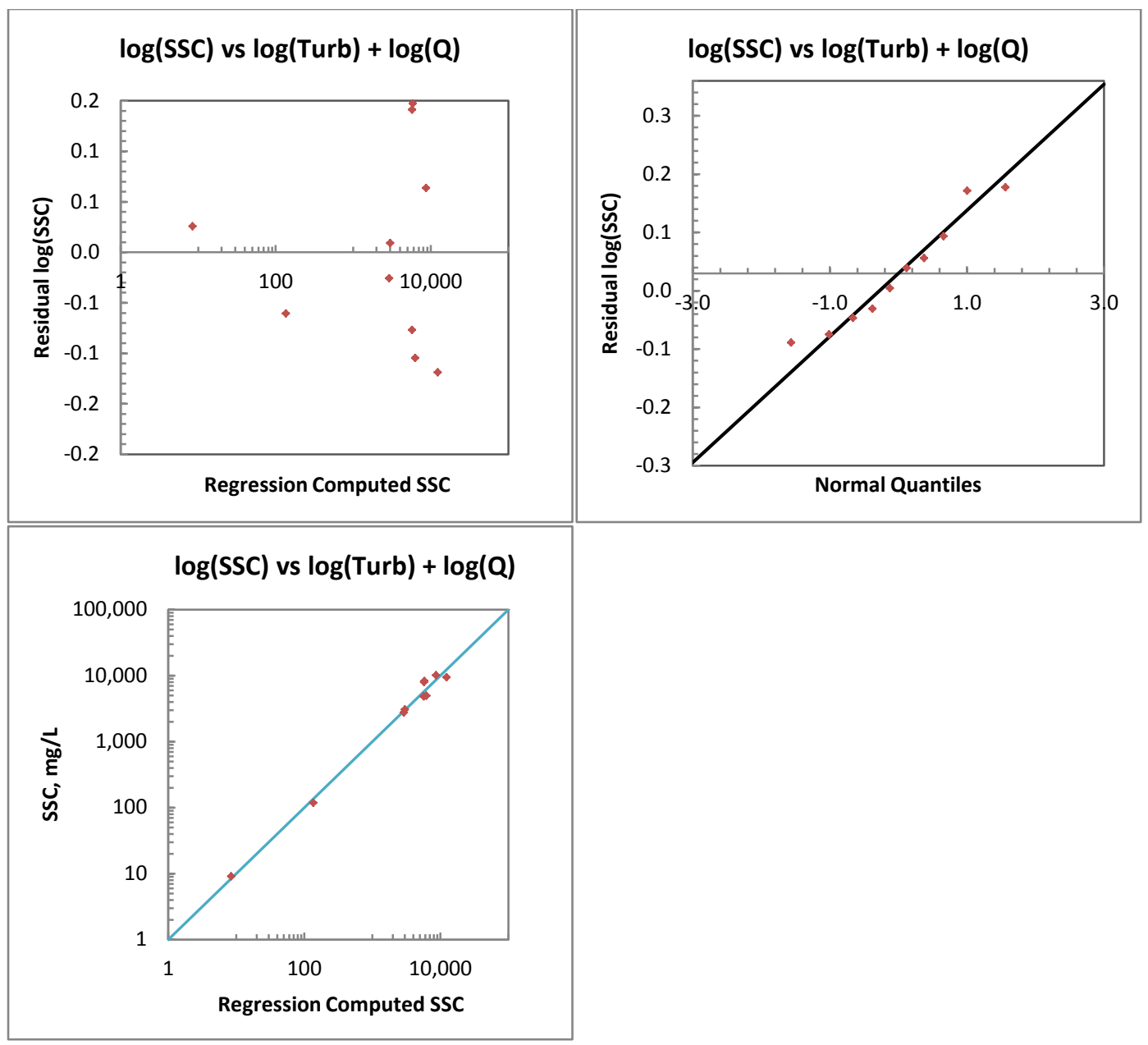

Figure A12. Residual and probability plots for Model 2, Fall Creek below Winberry Creek near Lowell, Oregon, 2012-13.

Note: Sample \# 16 was excluded from the Model 2 regression analyses. Both the turbidity and streamflow were very low during the sample collection. The relatively high SSC value $(10 \mathrm{mg} / \mathrm{L})$ is more likely a result of the sampler hitting the river bed and stirring up deposited sand than a true representation of the sediment transport at that time.

\section{RECORD}

Fifteen-minute SSC data was computed from the 15-minute turbidity and streamflow data (figs. A13-A16). During periods of missing or deleted turbidity or streamflow data, the SSC unit values were estimated by interpolating between the computed SSC values. During the analysis period (119 days), 71 percent of the SSC record was computed by Model 1 and 29 percent by Model 2.

At the beginning of the drawdown (12/12/12 01:00-02:30), the turbidity sensor limit (2,960 FNU) was reached as the streamflow was still decreasing. During this period, Model 1 greatly underestimated the SSC, while Model 2 possibly overestimated. To estimate SSC conservatively, five unit SSC values (12/12/12 01:30-02:30) were estimated to equal the computed SSC value at 04:45, when turbidity was at the sensor limit, but the streamflow had stabilized. Additionally, two values were interpolated to smooth the transition from Model 1 to the estimated values (12/12/12 01:00-01:15). These 7 SSC unit values and 12 others computed from the maximum turbidity value were flagged as "estimated." 
EXTREMES FOR PERIOD (October 26, 2012-February 22, 2013)

Max: 13,100 mg/L, December 12, 2012

Min: $0.27 \mathrm{mg} / \mathrm{L}$, October 27, 2012

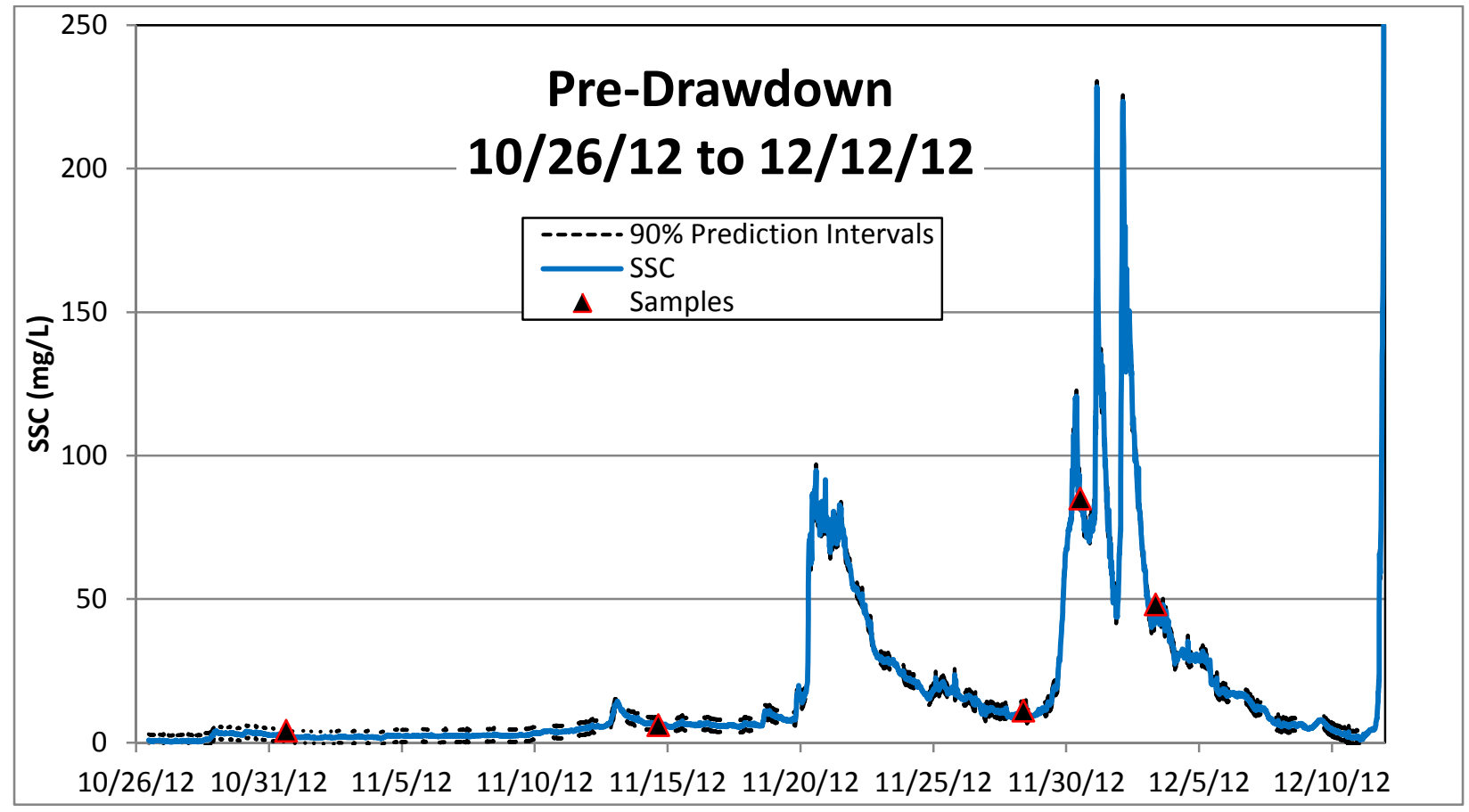

Figure A13. Time series of computed SSC and 90 percent prediction intervals for pre-drawdown conditions, Fall Creek below Winberry Creek near Lowell, Oregon, October-December 2012 


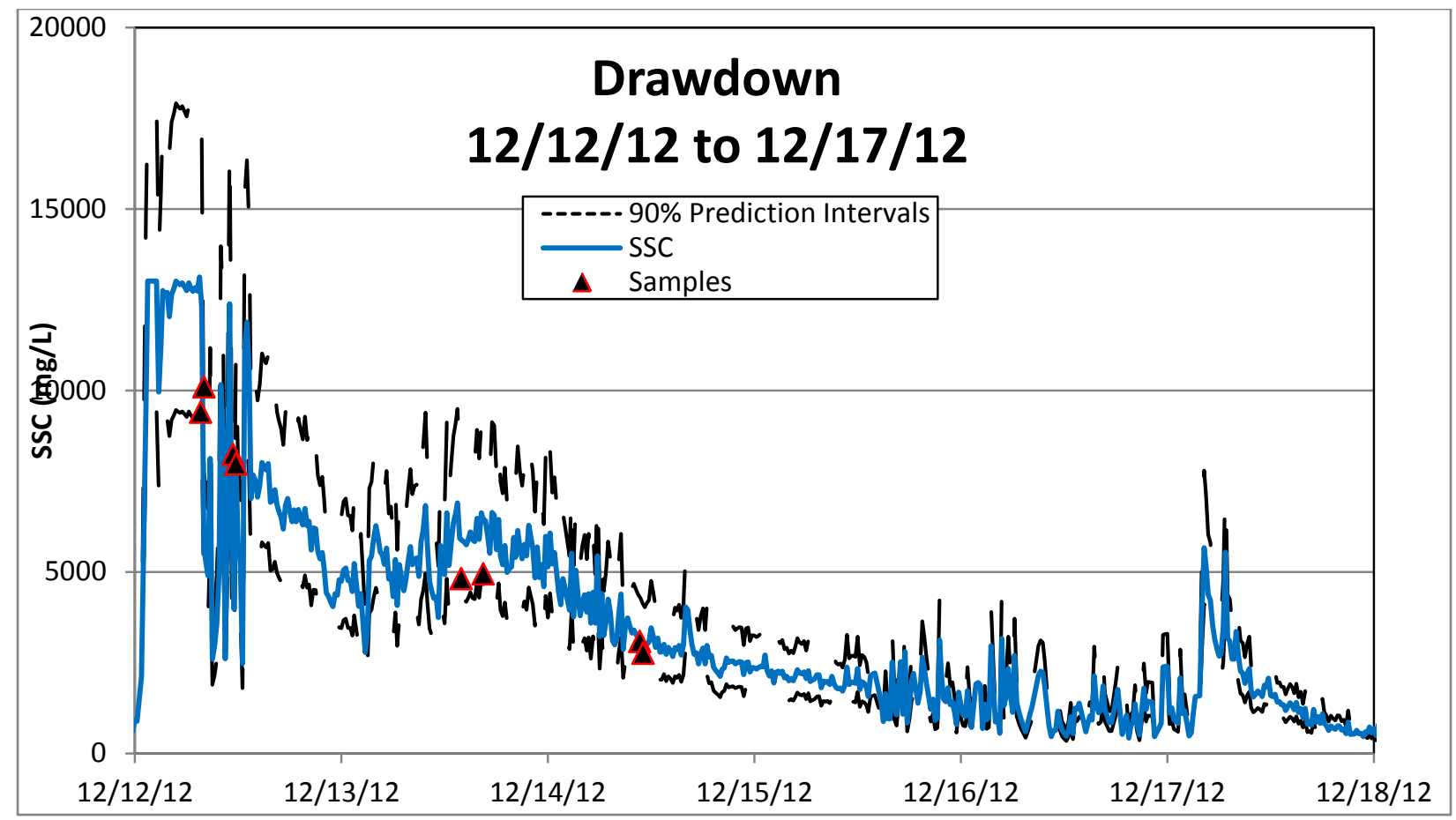

Figure A14.Time series of computed SSC and 90 percent prediction intervals for drawdown conditions, Fall Creek below Winberry Creek near Lowell, Oregon, December 2012

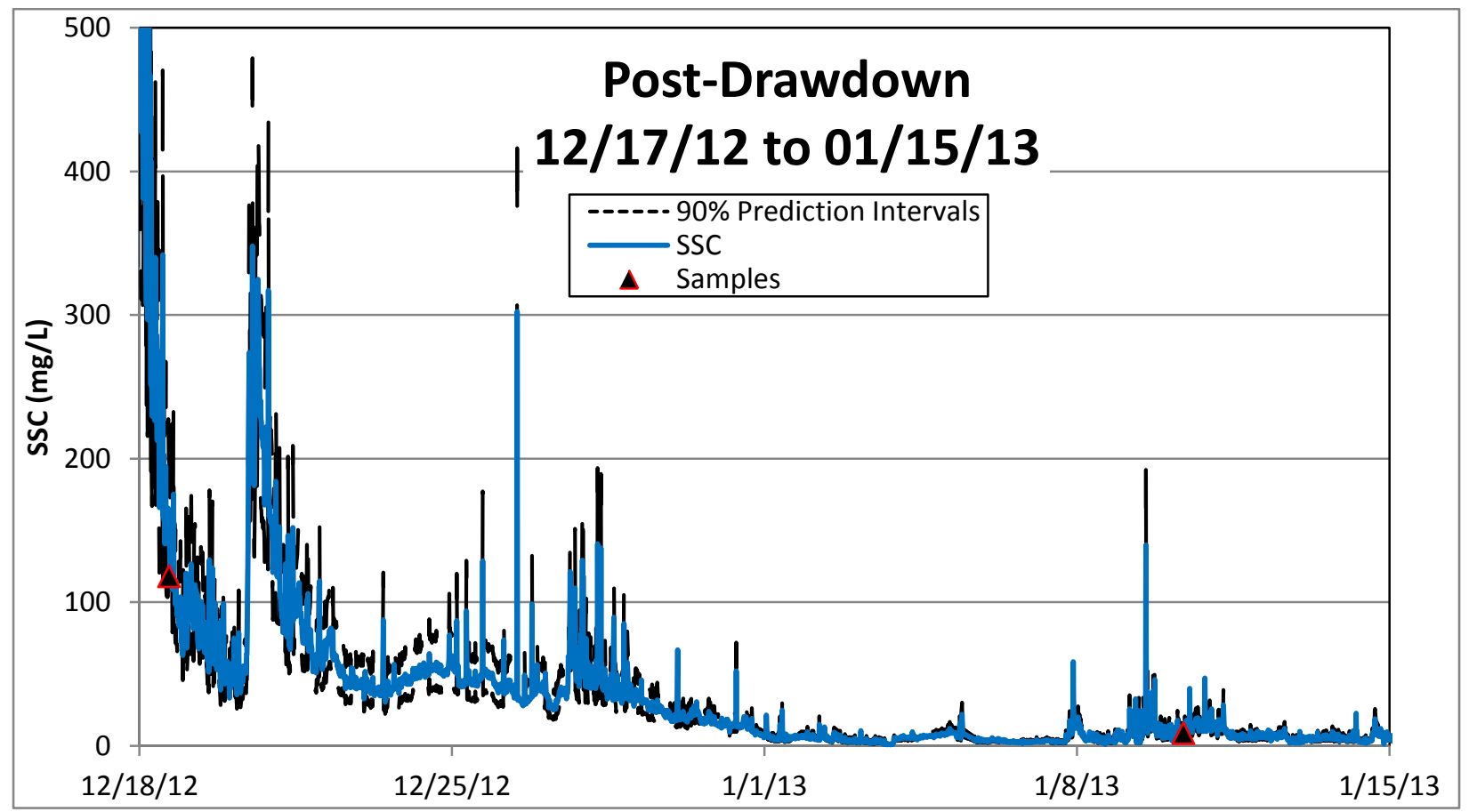

Figure A15. Time series of computed SSC and 90 percent prediction intervals for post-drawdown conditions, Fall Creek below Winberry Creek near Lowell, Oregon, December 2012 to January 2013. 


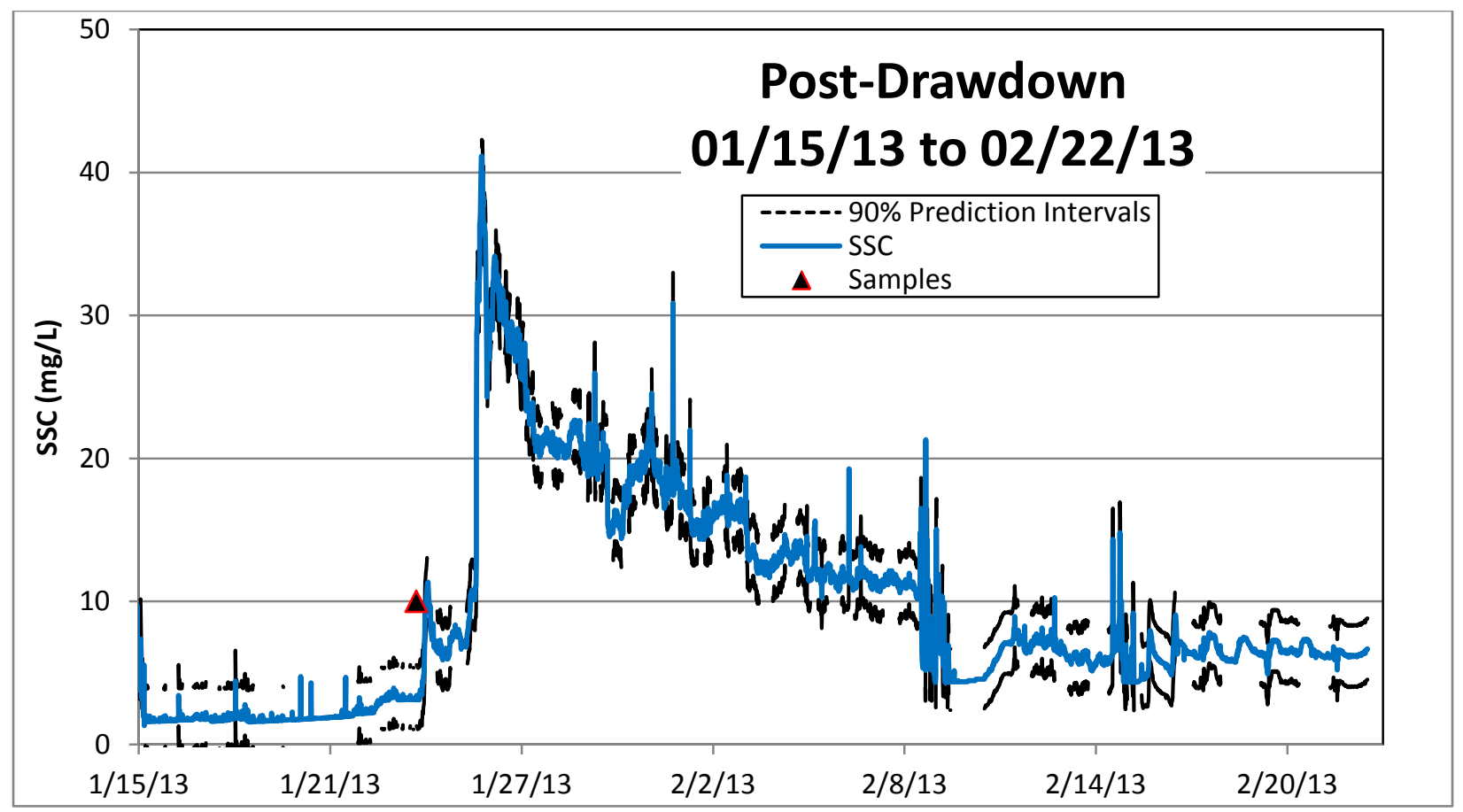

Figure A16. Time series of computed SSC and 90 percent prediction intervals for post-drawdown conditions, Fall Creek below Winberry Creek near Lowell, Oregon, January to February 2013.

Worked: H. Bragg, 08/26/13

Checked: L. Schenk

Reviewed:C. Anderson 


\title{
Little Fall Creek
}

\author{
WATER-OUALITY MONITOR STATION ANALYSIS \\ 2013 WATER YEAR \\ SUSPENDED-SEDIMENT RECORD \\ 435730122483201 Little Fall Creek near Lowell, Oregon
}

Analysis Period: November 7, 2012-February 24, 2013

\section{PROJECT BACKGROUND}

The USGS, in cooperation with the Army Corps of Engineers, monitored suspended sediment on a number of sites in the Fall Creek Lake drainage, near Lowell, Oregon, in the winter of 2012-13. The purpose of the monitoring was to provide data that will be used to estimate suspended sediment loads transported out of Fall Creek Lake during an operational drawdown to pass endangered juvenile salmonids through the dam. Additionally, monitoring data will be used to estimate a sediment budget for the Lake and nearby tributaries. Little Fall Creek is an unregulated tributary to Fall Creek downstream of Fall Creek Dam. Sediment transported by Little Fall Creek contributes to the sediment load in Fall Creek before the confluence of Fall Creek with the Middle Fork Willamette River.

\section{EQUIPMENT}

A McVann self-cleaning turbidity sensor installed on a Hydrolab DS-4a data sonde was used to collect continuous turbidity data. Data were logged internally on the data sonde and were downloaded periodically during the project period.

\section{MODEL CALIBRATION DATASET}

Samples (table A7) were collected using USGS equal-width-increment (EWI) protocols. The discreet turbidity value (in Formazin Nephelometric Units, FNU) associated with each sample was the average of the 15-minute logged values of the instream sensor over the duration of the sample collection (2-5 values). The discreet streamflow value (in cubic feet per second, $\mathrm{ft}^{3} / \mathrm{s}$ ) associated with each sample was interpolated from the estimated 15-minute values (see Discussion of Data) to the mean time of the sample collection. The samples were analyzed at the USGS Cascade Volcano Observatory (CVO) sediment laboratory, providing the suspended-sediment concentration value (in milligrams per liter $[\mathrm{mg} / \mathrm{L}])$ for each sample, as well as the percent finer than 63 microns $(\mu \mathrm{m})$.

Table A7. Calibration data set for SSC regression model, Little Fall Creek near Lowell, Oregon, 2012-13. [PST, Pacific Standard Time; FNU, Formazin nephelometric unit; ft3/s, cubic feet per second; SSC, suspended sediment concentration; $\mathrm{mg} / \mathrm{L}$, milligram per liter; $\mu \mathrm{m}$, micron or micrometer]

\begin{tabular}{lcccc}
$\begin{array}{c}\text { Date and Time } \\
\text { (PST) }\end{array}$ & $\begin{array}{c}\text { Turbidity } \\
\text { (FNU) }\end{array}$ & $\begin{array}{c}\text { Streamflow } \\
\left(\mathrm{ft}^{3} / \mathbf{s}\right)\end{array}$ & $\begin{array}{c}\text { SSC } \\
(\mathbf{m g} / \mathbf{L})\end{array}$ & $\begin{array}{c}\text { Finer than } 63 \boldsymbol{\mu m} \\
\text { (percent) }\end{array}$ \\
\hline 11/8/2012 12:40 & 0.6 & 278 & 2 & 79.5 \\
$11 / 15 / 201212: 23$ & 2.0 & 363 & 2 & 79.8 \\
11/20/2012 8:15 & 158 & 4,540 & 269 & 73.1 \\
11/30/2012 11:32 & 25.0 & 1,080 & 15 & 64.0 \\
1/9/2013 15:59 & 5.4 & 505 & 10 & 62.9 \\
\hline
\end{tabular}




\section{MODEL DEVELOPMENT}

Initial plots of the response variable (SSC) with the possible explanatory variables (turbidity and streamflow) indicated that both are correlated to SSC. Regression analyses were done with the Turbidity Sediment Spreadsheet using the methods described in the USGS Techniques and Methods Report, Book 3, Chapter C4. Turbidity and streamflow were evaluated together and separately as possible surrogates. The log-10 transformations of each parameter were also evaluated together and separately as possible surrogates. The turbidity and streamflow were found to be too highly correlated to one another for a model to use both parameters. Two models were selected to compute the SSC during different time periods because of how well the computed SSC compared to the measured (sample) SSC.

\section{MODEL SUMMARIES}

\section{Model 1}

The simple linear regression with transformed turbidity (fig. A17) was selected as the best model for estimating SSC for this period based on the residual plots, the PPCC, and $\mathrm{R}^{2}$ values. This model is used to compute the SSC from the beginning of the analysis period (11/07/12 17:00) through the onset of the largest storm of the season (11/19/12 14:45). This model is again used to compute the SSC after a second, smaller storm in late November (12/01/12 14:45) through the end of the analysis period (02/24/13 03:00).

$\log _{10} \mathrm{SSC}=0.265+0.881 \log _{10}$ Turbidity

Bias correction factor $=1.14$

Number of measurements $=5$

Root-mean-squared error $(\mathrm{RMSE})=0.299$

Model standard percent error $(\mathrm{MSPE})=+99.2$ percent $/$-49.8 percent

Adjusted coefficient of determination $\left(\operatorname{Adj~} R^{2}\right)=0.882$

Probability Plot Correlation Coefficient $($ PPCC $)=0.935$

PRESS $=1.09$ 


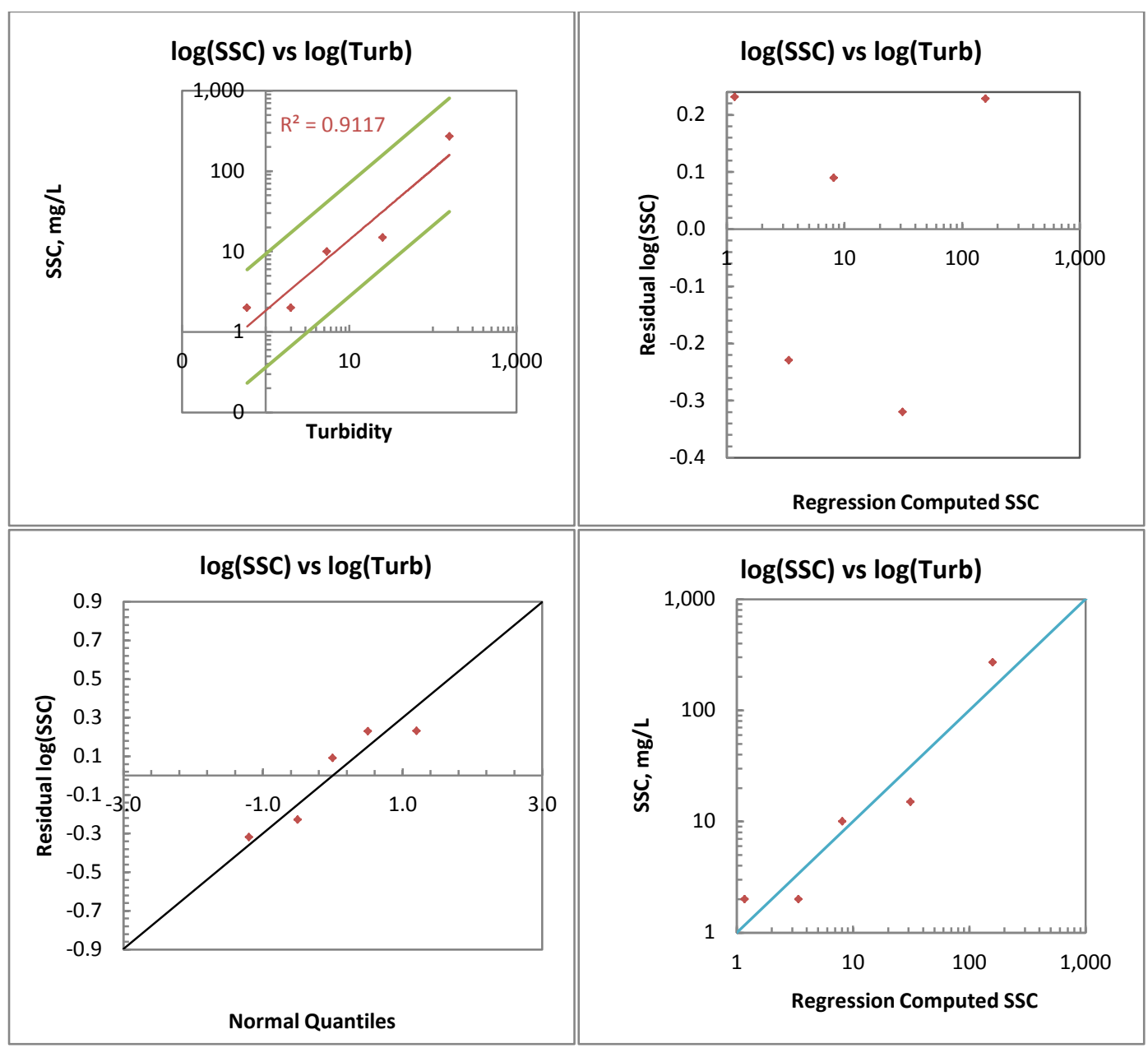

Figure A17. Regression, residual, and probability plots for Model 1, Little Fall Creek near Lowell, Oregon, 2012-13.

\section{Model 2:}

The simple linear regression with transformed streamflow (fig. A18) was selected as the best model for estimating SSC for this period based on the residual plots, the PPCC, and $\mathrm{R}^{2}$ values. This model is used to compute the SSC from the onset of the largest storm of the season (11/19/12 15:00) until the streamflow had subsided following a second, smaller storm in late November (12/01/12 14:30).

$\log _{10}$ SSC $=-4.00+1.75 \log _{10}$ Streamflow

Bias correction factor $=1.07$

Number of measurements $=5$

Root-mean-squared error (RMSE) $=0.203$

Model standard percent error $(\mathrm{MSPE})=+59.5$ percent $/-37.3$ percent

Adjusted coefficient of determination $\left(\right.$ Adj R $\left.{ }^{2}\right)=0.946$

Probability Plot Correlation Coefficient $($ PPCC $)=0.956$

PRESS $=0.25$ 


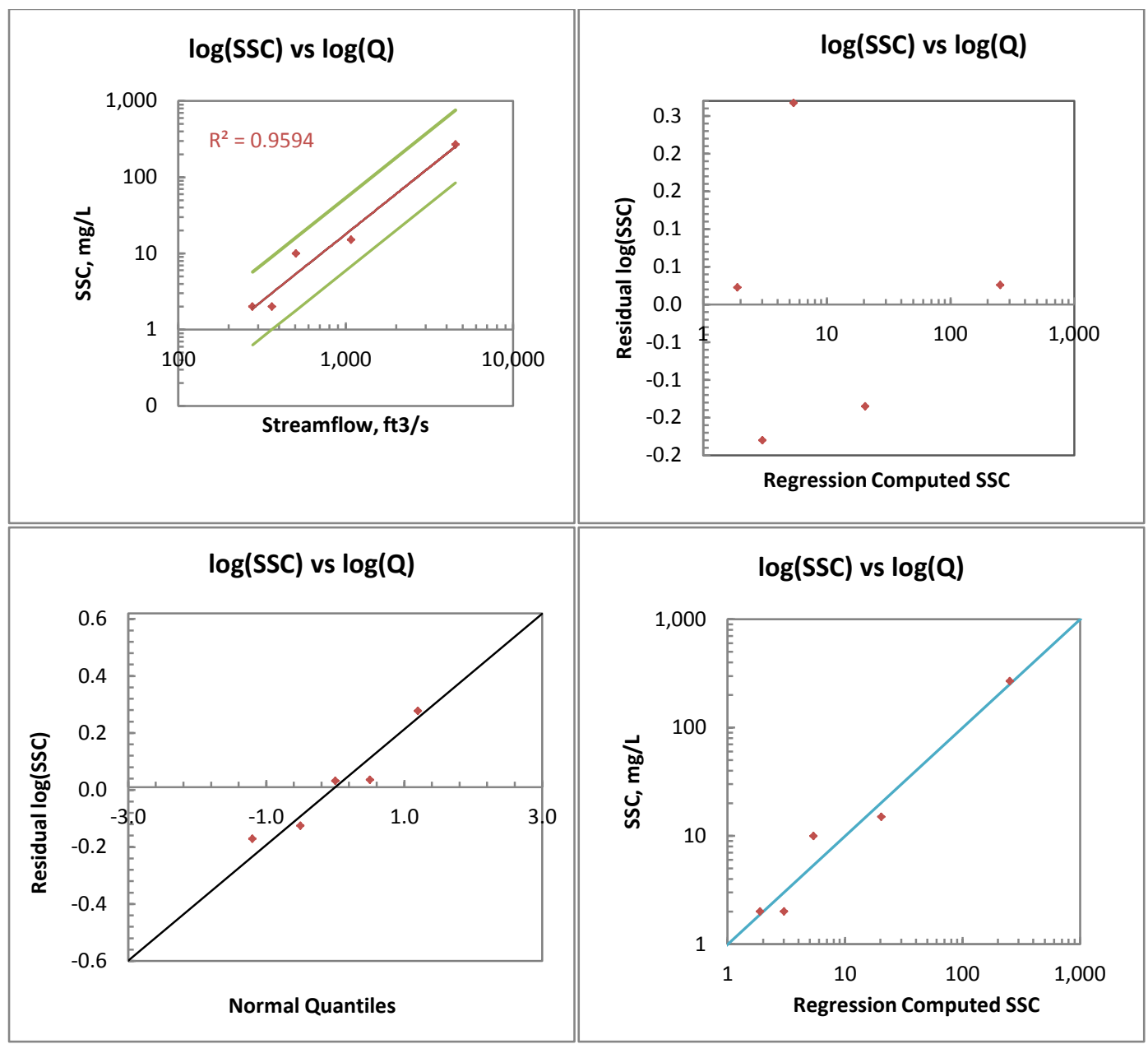

Figure A18. Regression, residual, probability plots for Model 2, Little Fall Creek near Lowell, Oregon, 201213.

\section{RECORD}

SSC data was computed every 15 minutes from the 15-minute turbidity and estimated streamflow data. During periods of missing or deleted turbidity data, the SSC was estimated by interpolating between the computed SSC values. During the analysis period (109 days), 89 percent of the SSC record was computed by Model 1 and 11 percent by Model 2 .

EXTREMES FOR PERIOD (11/07/12-02/24/13)

Max: $276 \mathrm{mg} / \mathrm{L}, 11 / 20 / 12$

Min: $0.5 \mathrm{mg} / \mathrm{L}, 11 / 11 / 12$ 


\section{DATA LIMITATIONS AND FUTURE IMPROVEMENTS}

Little Fall Creek is an ungaged river and no streamflow measurements were made during the analysis period. The streamflow values used to compute the SSC record (figs. A19 and A20) were estimated by calculating the difference in streamflow at nearby gaging stations (station numbers 14152000, 14151000, and 14150000). These calculations included time-shifts to account for time-oftravel between the stations. The remaining streamflow was attributed to Little Fall Creek and Hills Creek (the adjacent basin to the north) and apportioned according to the ratio of the two basins' drainage areas.

The model calibration data set has very few samples and they are not well distributed over the range of conditions at the monitoring site during the analysis period. Because of this (and the estimated streamflow used to compute SSC with Model 2) all daily mean values are flagged as "estimated." Future sample collection should target the moderate to high turbidity and streamflow conditions.

\section{Little Fall Creek}
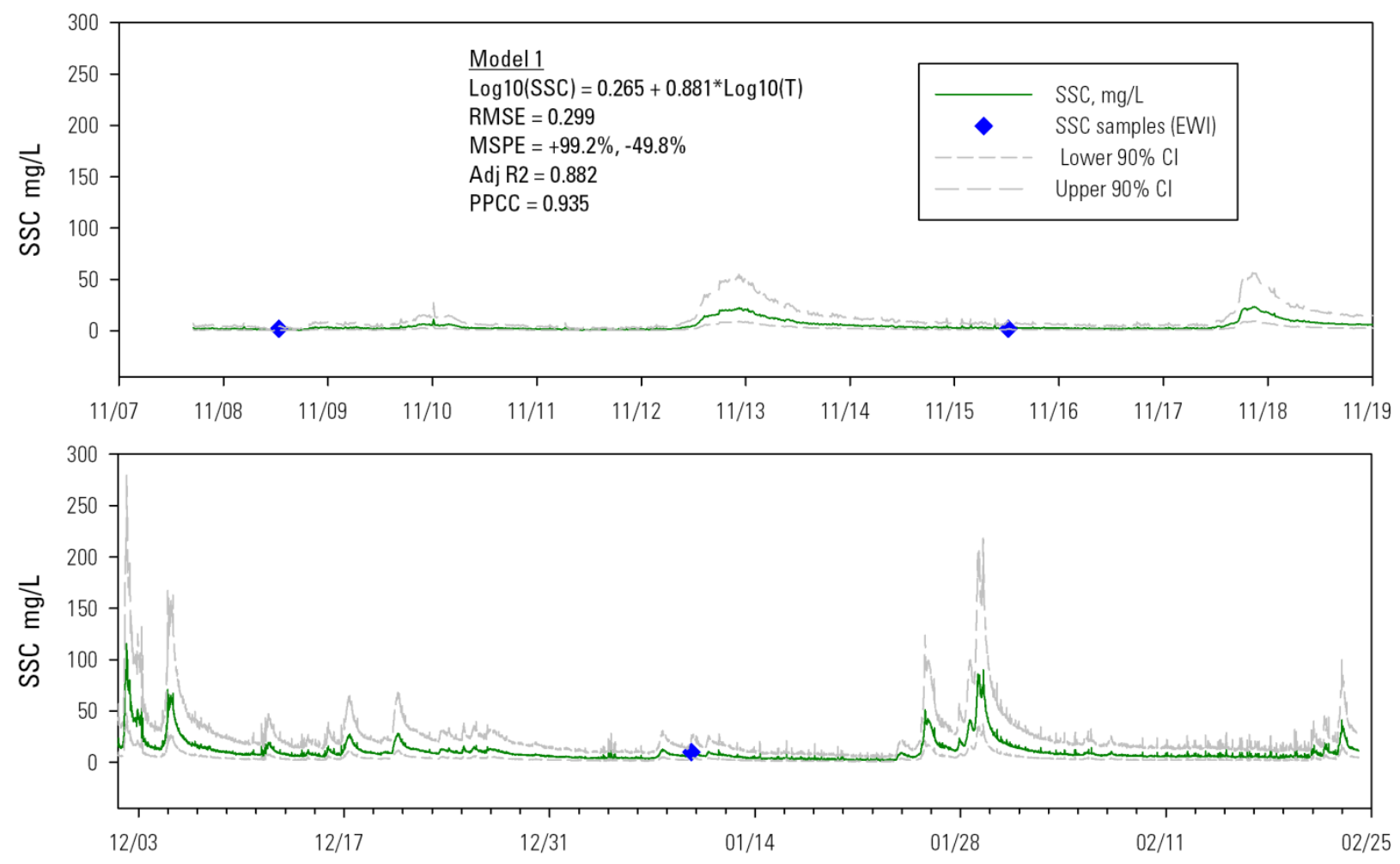

Figure A19.Time series plot of computed SSC and 90 percent confidence intervals for model 1, Little Fall Creek near Lowell, Oregon, November 2012 and December 2012 to February 2013 


\section{Little Fall Creek}

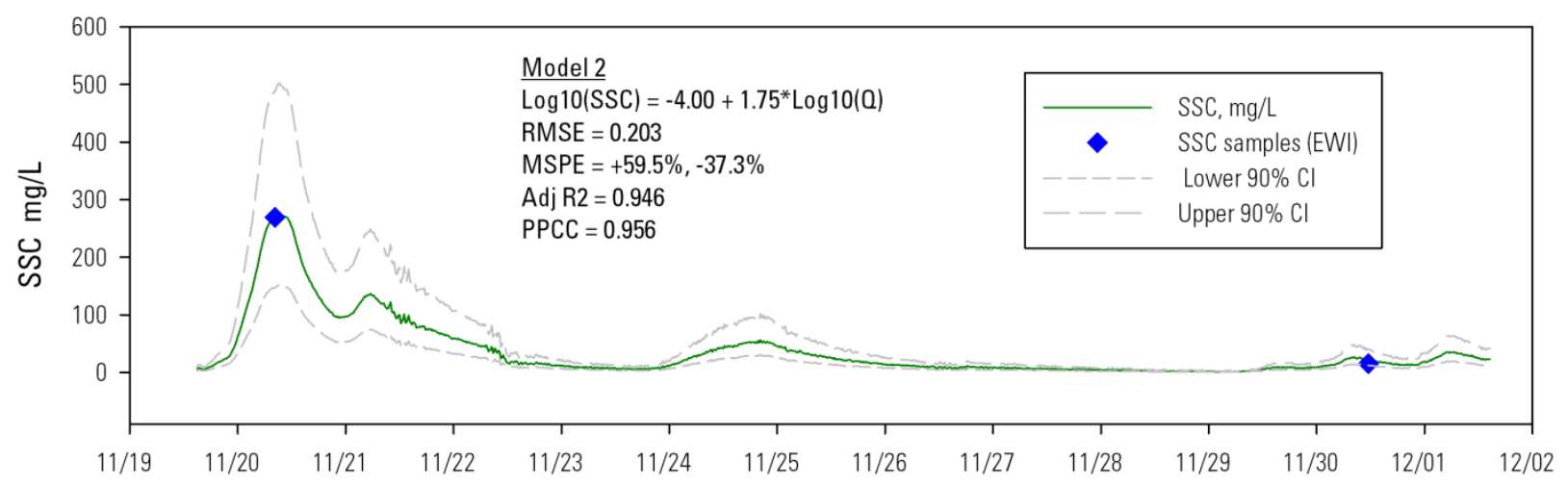

Figure A20, Time series plot of computed SSC and 90 percent confidence intervals for model 2, Little Fall Creek near Lowell, Oregon, November 19 to December 1, 2012

Worked: H. Bragg, 08/27/13

Checked:L. Schenk 08/28/13

Reviewed: K. Spicer 


\author{
WATER-QUALITY MONITOR STATION ANALYSIS \\ 2013 WATER YEAR \\ SUSPENDED-SEDIMENT RECORD \\ 14152000 Middle Fork Willamette River at Jasper, Oregon
}

\title{
PROJECT BACKGROUND
}

The USGS, in cooperation with the Army Corps of Engineers, monitored suspended sediment on a number of sites in the Fall Creek Lake drainage, near Lowell, Oregon, in the winter of 2012/2013. The purpose of the monitoring was to provide data that will be used to estimate suspended-sediment loads transported out of Fall Creek Lake during an operational drawdown to pass endangered juvenile salmonids through the dam. Additionally, monitoring data will be used to estimate a sediment budget for the lake and nearby tributaries. The Middle Fork Willamette River at Jasper is the farthest downstream site of the sites associated with the Fall Creek drawdown monitoring. It represents sediment transported by Fall Creek below Fall Creek Dam, Little Fall Creek, The Middle Fork Willamette downstream of the Dexter re-regulating dam, and other tributaries.

\section{EQUIPMENT}

A McVann self -cleaning turbidity sensor installed on a Hydrolab DS-5a data sonde was used to collect continuous turbidity data. Turbidity data were transmitted via radio from an existing Sutron 8210 data logger, and values were logged every 15 minutes. SSC samples were collected from a cableway approximately $0.1 \mathrm{mi}$ upstream of the existing gage house, and by an ISCO pump sampler installed on the right edge of water at the gage house.

\section{MODEL-CALIBRATION DATA SET}

Turbidity (TB) and SSC data were collected during the operational drawdown of an impounded reservoir (approximately $11 \mathrm{mi}$ upstream of the station) when large amounts of sediment were expected to be transported from behind the dam. The reservoir water elevation was drawn down to a point where the regulating outlets were open, and water was flowing freely through the dam unimpeded.

Data were collected using USGS protocols and are stored in USGS NWIS databases. The turbidity sensor was deployed in October 2012 and retrieved in February 2013, resulting in an approximate 3month deployment period. EWI samples were collected from a cableway approximately $450 \mathrm{ft}$ upstream of the monitoring station In addition to EWI samples, an ISCO pump sampler was installed on the right edge of water to collect samples between EWI samples. As a result, both EWI samples and pump samples were evaluated for use in SSC-TB regressions.

EWI samples were used to calculate box coefficients to determine if the concentrations of the pump samples were representative of the cross section (table A8). Box coefficients were calculated one of two ways. If there was only one EWI sample collected, that sample concentration was divided by the closest collected pump sample, and the result was used as the box coefficient. This was the case for only the first two calculated box coefficients on 11/01/12 and 12/03/12. For box coefficients calculated during the drawdown, pump samples were taken before and after the EWI sample. With the exception of the EWI sample on 12/12/12 10:28, when one of the EWIs was determined to be biased high, the EWI and pump samples were averaged, and the two averages were divided to obtain the box coefficient. For the 
second EWI sample on 12/13/12 and the one on 12/19/12, only one EWI was collected in between the two pump samples. For those two events, the single EWI concentration was divided by the average of the two pump samples. The result of the box coefficient calculations clearly show that the channel is poorly mixed, with higher concentrations of SSC on the right bank of the channel as compared to the left. This phenomenon was observed in the field by project staff while working off of the cableway at the site. EWI sample bottles were subsequently analyzed separately to determine the difference in SSC on river left and river right. Results of the EWI analyses are shown in table A9. A summary of the samples used in the calibration data set is shown in table A10. 
Table A8. Box coefficients for pump samples, Middle Fork Willamette River at Jasper, Oregon, 2012-13.

[PST, Paciific Standard Time; SSC, suspended sediment concentration; mg/L, millgrams per liter

\begin{tabular}{|c|c|c|c|}
\hline Date and time (PST) & Sample Type & SSC (mg/L) & percent sand \\
\hline 11/1/12 9:10 & Pump & 8 & \\
\hline 11/1/12 9:37 & EWI & 7 & \\
\hline \multicolumn{4}{|c|}{ Box coefficient $=0.875$} \\
\hline 12/3/12 11:00 & Pump & 50 & \\
\hline 12/3/12 12:35 & EWI & 14 & \\
\hline \multicolumn{4}{|c|}{ Box coefficient $=0.280$} \\
\hline 12/12/12 9:23 & Pump & 554 & 3.6 \\
\hline 12/12/12 9:55 & EWI & 289 & 2 \\
\hline $12 / 12 / 12$ 10:28 & EWI & 450 & 2 \\
\hline 12/12/12 10:49 & Pump & 502 & 5.3 \\
\hline \multicolumn{4}{|c|}{ Box coefficient $=0.547$} \\
\hline 12/12/12 11:43 & Pump & 503 & \\
\hline 12/12/12 12:09 & EWI & 283 & 5 \\
\hline 12/12/12 12:36 & EWI & 306 & 16 \\
\hline 12/12/12 12:58 & Pump & 439 & \\
\hline \multicolumn{4}{|c|}{ Box coefficient $=0.625$} \\
\hline $12 / 13 / 128: 45$ & Pump & 236 & 9 \\
\hline 12/13/12 9:25 & EWI & 123 & 10 \\
\hline 12/13/12 9:56 & EWI & 129 & 6 \\
\hline 12/13/12 10:19 & Pump & 252 & 15 \\
\hline \multicolumn{4}{|c|}{ Box coefficient $=0.516$} \\
\hline $12 / 13 / 12$ 15:24 & Pump & 335 & \\
\hline 12/13/12 16:00 & EWI & 217 & 12 \\
\hline 12/13/12 16:31 & Pump & 579 & \\
\hline \multicolumn{4}{|c|}{ Box coefficient $=0.475$} \\
\hline 12/19/12 11:23 & Pump & 213 & 90 \\
\hline 12/19/12 11:47 & EWI & 73 & 83 \\
\hline 12/19/12 12:07 & Pump & 166 & 90 \\
\hline \multicolumn{4}{|c|}{ Box coefficient $=\mathbf{0 . 3 8 5}$} \\
\hline
\end{tabular}


Table A9. Cross section samples, Middle Fork Willamette River at Jasper, Oregon, 2012-13

[Two bottles from an EWI analyzed separately, denoted as "LEFT" and "RIGHT," representing the left half of the channel looking downstream, and the right half of the channel. PST, Pacific Standard Time; SSC, suspended sediment concentration; PST, Pacific Standard Time; mg/L, millgram per liter

\begin{tabular}{lrcc}
\hline \multirow{2}{*}{$\begin{array}{c}\text { Date and time } \\
\text { (PST) }\end{array}$} & \multicolumn{3}{c}{ SSC (mg/L) } \\
\cline { 2 - 4 } Left & Right & Mathematical composite \\
\hline $11 / 25 / 12 ~ 11: 05$ & 6 & 48 & 24 \\
$12 / 3 / 12 ~ 12: 35$ & 10 & 19 & 14 \\
12/12/12 9:55 & 141 & 448 & 289 \\
12/12/12 10:28 & 98 & 827 & 450 \\
12/12/12 12:09 & 66 & 618 & 283 \\
12/12/12 12:36 & 92 & 435 & 306 \\
$12 / 12 / 12 ~ 16: 45$ & 120 & 418 & 261 \\
12/13/12 9:25 & 41 & 167 & 123 \\
12/13/12 9:56 & 42 & 176 & 129 \\
12/13/12 16:00 & 157 & 410 & 217 \\
12/14/12 10:18 & 81 & 174 & 142 \\
$12 / 19 / 12 ~ 11: 47$ & 33 & 112 & 73 \\
1/4/13 9:15 & 10 & 8 & 8 \\
\hline
\end{tabular}

Table A10. Regression model calibration dataset for EWI and pump samples, Middle Fork Willamette River at Jasper, Oregon, 2012-13

[PST, Pacific Standard Time. FNU, Formazin nephelometric unit; $\mathrm{ft}^{3} / \mathrm{s}$, cubic feet per second; SSC, suspended sediment concentration; mg/L, milligram per liter; $\mu \mathrm{m}$, micron or micrometer; -, not analyzed]

\begin{tabular}{lccccccc}
\hline \multicolumn{1}{c}{$\begin{array}{c}\text { Pump samples } \\
\text { Date and time } \\
\text { (PST) }\end{array}$} & $\begin{array}{c}\text { Turbidity } \\
\text { (FNU) }\end{array}$ & $\begin{array}{c}\text { Streamflow } \\
(\mathrm{ft} 3 / \mathrm{s})\end{array}$ & $\begin{array}{c}\text { SSC } \\
(\mathrm{mg} / \mathrm{L})\end{array}$ & $\begin{array}{c}\text { Box } \\
\text { Coefficient }\end{array}$ & $\begin{array}{c}\text { Box- } \\
\text { coefficient- } \\
\text { adjusted SSC }\end{array}$ & $\begin{array}{c}\text { Percent } \\
\text { finer than } \\
63 \mu \mathrm{m}\end{array}$ & $\begin{array}{c}\text { Percent } \\
\text { sand }\end{array}$ \\
\hline 10/28/12 9:10 & 3.5 & 6,125 & 15 & 0.875 & 13.13 & - & - \\
11/1/12 9:10 & 1.1 & 6,042 & 8 & 0.875 & 7.00 & - & - \\
11/8/12 9:10 & 0.1 & 5,112 & 5 & 0.875 & 4.38 & - & - \\
11/13/12 11:00 & 3.1 & 4,805 & 6 & 0.875 & 5.25 & - & - \\
11/19/12 11:00 & 1.0 & 6,065 & 5 & 0.875 & 4.38 & - & - \\
12/2/12 11:00 & 68.4 & 17,895 & 91 & 0.280 & 25.48 & 77.6 & 22.4 \\
12/3/12 11:00 & 27.5 & 14,145 & 50 & 0.280 & 14.00 & - & - \\
12/6/12 11:00 & 19.7 & 13,835 & 33 & 0.280 & 9.24 & - & -
\end{tabular}


Table A10. Regression model calibration dataset for EWI and pump samples, Middle Fork Willamette River at Jasper, Oregon, 2012-13-continued

[PST, Pacific Standard Time. FNU, Formazin nephelometric unit; $\mathrm{ft}^{3} / \mathrm{s}$, cubic feet per second; SSC, suspended sediment concentration; mg/L, milligram per liter; $\mu \mathrm{m}$, micron or micrometer; -, not analyzed]

\begin{tabular}{|c|c|c|c|c|c|c|c|}
\hline \multicolumn{8}{|c|}{ Pump samples (continued) } \\
\hline $\begin{array}{l}\text { Date and time } \\
\text { (PST) }\end{array}$ & $\begin{array}{l}\text { Turbidity } \\
\text { (FNU) }\end{array}$ & $\begin{array}{c}\text { Streamflow } \\
\left(\mathrm{ft}^{3} / \mathrm{s}\right)\end{array}$ & $\begin{array}{c}\text { SSC } \\
\text { (mg/L) }\end{array}$ & $\begin{array}{c}\text { Box } \\
\text { Coefficient }\end{array}$ & $\begin{array}{c}\text { Box- } \\
\text { coefficient- } \\
\text { adjusted SSC }\end{array}$ & $\begin{array}{c}\text { Percent } \\
\text { finer than } \\
63 \mu \mathrm{m}\end{array}$ & $\begin{array}{c}\text { Percent } \\
\text { sand }\end{array}$ \\
\hline 12/9/12 11:00 & 16.3 & 15,673 & 36 & 0.280 & 10.08 & - & - \\
\hline $12 / 12 / 126: 00$ & 513.9 & 13,597 & 853 & 0.541 & 461.44 & 96.5 & 3.5 \\
\hline 12/12/12 9:23 & 332.4 & 13,563 & 554 & 0.541 & 299.69 & 96.4 & 3.6 \\
\hline $12 / 12 / 1210: 49$ & 328.4 & 13,531 & 502 & 0.541 & 271.56 & 94.7 & 5.3 \\
\hline 12/12/12 11:43 & 304.3 & 13,529 & 503 & 0.541 & 272.10 & - & - \\
\hline 12/12/12 12:58 & 277.2 & 13,529 & 439 & 0.541 & 237.48 & - & - \\
\hline $12 / 13 / 128: 45$ & 133.1 & 13,293 & 236 & 0.541 & 127.67 & 91 & 9 \\
\hline 12/13/12 10:19 & 148.9 & 13,293 & 252 & 0.541 & 136.32 & 85 & 15 \\
\hline $12 / 13 / 12$ 15:24 & 191.3 & 11,653 & 335 & 0.541 & 181.22 & - & - \\
\hline 12/13/12 16:31 & 223.8 & 11,446 & 579 & 0.541 & 313.22 & - & - \\
\hline 12/14/12 10:50 & 119.6 & 10,821 & 227 & 0.541 & 122.80 & 83.8 & 16.2 \\
\hline 12/14/12 18:00 & 83.6 & 9,585 & 218 & 0.541 & 117.93 & - & - \\
\hline 12/15/12 6:00 & 65.8 & 9,334 & 159 & 0.541 & 86.01 & 69.7 & 30.3 \\
\hline 12/15/12 18:00 & 55.9 & 7,490 & 156 & 0.541 & 84.39 & - & - \\
\hline $12 / 16 / 126: 00$ & - & 7,615 & 199 & 0.541 & 107.65 & 63.4 & 36.6 \\
\hline $12 / 16 / 12$ 18:00 & - & 7,945 & 266 & 0.541 & 143.90 & - & - \\
\hline $12 / 17 / 126: 00$ & - & 9,529 & 717 & 0.541 & 387.87 & 71.8 & 28.2 \\
\hline 12/17/12 18:00 & - & 10,446 & 362 & 0.541 & 195.83 & - & - \\
\hline 12/18/12 6:00 & - & 10,126 & 346 & 0.541 & 187.17 & 14.6 & 85.4 \\
\hline 12/18/12 18:00 & 18.1 & 9,113 & 334 & 0.385 & 128.66 & - & - \\
\hline 12/19/12 6:00 & 27.4 & 8,733 & 191 & 0.385 & 73.58 & 10.8 & 89.2 \\
\hline 12/19/12 11:23 & 14.5 & 8,152 & 213 & 0.385 & 82.05 & 10 & 90 \\
\hline 12/19/12 12:07 & 13.6 & 8,140 & 166 & 0.385 & 63.95 & 10 & 90 \\
\hline 12/20/12 6:00 & 28.2 & 7,565 & 105 & 0.385 & 40.45 & 17 & 83 \\
\hline 12/20/12 18:00 & 6.8 & 7,843 & 143 & 0.385 & 55.09 & 26.1 & 73.9 \\
\hline 12/24/12 18:00 & 5.9 & 6,454 & 167 & 0.385 & 64.33 & 6.8 & 93.2 \\
\hline 12/27/12 6:00 & 6.2 & 6,783 & 61 & 0.385 & 23.50 & - & - \\
\hline $12 / 31 / 126: 00$ & 5.6 & 5,600 & 26 & 0.385 & 10.02 & - & - \\
\hline 1/18/13 6:00 & 11.3 & 3,568 & 8 & 0.385 & 3.08 & 58.3 & 41.7 \\
\hline
\end{tabular}


Table A10. Regression model calibration dataset for EWI and pump samples, Middle Fork Willamette River at Jasper, Oregon, 2012-13-continued

[PST, Pacific Standard Time. FNU, Formazin nephelometric unit; $\mathrm{ft}^{3} / \mathrm{s}$, cubic feet per second; SSC, suspended sediment concentration; mg/L, milligram per liter; $\mu \mathrm{m}$, micron or micrometer; -, not analyzed]

\begin{tabular}{|c|c|c|c|c|c|c|c|}
\hline \multicolumn{8}{|c|}{ Pump samples (continued) } \\
\hline Date Time & $\begin{array}{l}\text { Turbidity } \\
\text { (FNU) }\end{array}$ & $\begin{array}{c}\text { Streamflow } \\
\left(\mathrm{ft}^{3} / \mathrm{s}\right)\end{array}$ & $\begin{array}{c}\text { SSC } \\
\text { (mg/L) }\end{array}$ & $\begin{array}{c}\text { Box } \\
\text { Coefficient }\end{array}$ & $\begin{array}{c}\text { Box- } \\
\text { coefficient- } \\
\text { adjusted SSC }\end{array}$ & $\begin{array}{c}\text { Percent } \\
\text { finer than } \\
63 \mu \mathrm{m}\end{array}$ & $\begin{array}{c}\text { Percent } \\
\text { sand }\end{array}$ \\
\hline 1/19/13 6:00 & 17.8 & 5,112 & 35 & 0.385 & 13.48 & 20.3 & 79.7 \\
\hline 2/1/13 6:00 & - & 5,133 & 43 & 0.385 & 16.56 & 26.9 & 73.1 \\
\hline 2/7/13 6:00 & 6.1 & 3,535 & 16 & 0.385 & 6.16 & 58.4 & 41.6 \\
\hline 2/13/13 6:00 & 4.6 & 2,408 & 15 & 0.385 & 5.78 & 61.5 & 38.5 \\
\hline \multicolumn{8}{|c|}{ EWI samples } \\
\hline Date and time (PST) & $\begin{array}{c}\text { Turbidity } \\
\text { (FNU) }\end{array}$ & $\begin{array}{c}\text { Streamflow } \\
\left(\mathrm{ft}^{3} / \mathrm{s}\right)\end{array}$ & $\begin{array}{c}\mathrm{SSC} \\
(\mathrm{mg} / \mathrm{L})\end{array}$ & $\begin{array}{l}\text { Percent } \\
\text { finer than } \\
63 \mu \mathrm{m}\end{array}$ & Percent sand & & \\
\hline 11/1/12 9:37 & 1.1 & 6,042 & 7 & - & - & & \\
\hline 11/15/12 10:09 & 0.4 & 4,665 & 2 & 79 & 21 & & \\
\hline 11/28/12 11:05 & 13.5 & 15,734 & 24 & 84 & 16 & & \\
\hline 12/3/12 12:35 & 28.3 & 13,597 & 14 & 84 & 16 & & \\
\hline 12/12/12 9:55 & 308.8 & 13,563 & 289 & 98 & 2 & & \\
\hline 12/12/12 10:28 & 310.7 & 13,563 & 450 & 98 & 2 & & \\
\hline 12/12/12 12:09 & 304.3 & 13,529 & 283 & 95 & 5 & & \\
\hline 12/12/12 12:36 & 282.6 & 13,549 & 306 & 84 & 16 & & \\
\hline 12/12/12 16:45 & 274.0 & 13,495 & 261 & 91 & 9 & & \\
\hline 12/13/12 9:25 & 141.9 & 13,304 & 123 & 90 & 10 & & \\
\hline 12/13/12 9:56 & 148.0 & 13,293 & 129 & 94 & 6 & & \\
\hline 12/13/12 16:00 & 252.7 & 11,509 & 217 & 88 & 12 & & \\
\hline 12/14/12 10:18 & 125.4 & 10,940 & 142 & 88 & 12 & & \\
\hline 12/19/12 11:47 & 14.0 & 8,152 & 73 & 17 & 83 & & \\
\hline 1/4/13 9:14 & 6.4 & 2,970 & 8 & 65 & 35 & & \\
\hline
\end{tabular}

Evaluation of table A9 shows that higher SSC concentrations consistently occurred on the right bank during the project period. This is likely because Fall Creek enters the Middle Fork Willamette on river right approximately $3 \mathrm{mi}$ upstream of the Jasper gaging station. Fall Creek is the outflow of Fall Creek Lake, which experienced the drawdown, and therefore contributed large amounts of sediment to the Middle Fork Willamette. The 3 river miles from the Fall Creek confluence Jasper gaging station was not enough distance for the channel to become fully mixed, owing to the higher SSC concentrations on the right bank. It is also important to note that high concentrations on the right bank were also 
encountered before the drawdown occurred, possibly owing to the influence of Hills Creek, approximately 1/4 mi upstream of the Jasper gaging station on river right, which contributed visually higher concentrations of sediment to the Middle Fork Willamette River during storm events and elevated discharge. Samples were not collected from Hills Creek during the project.

\section{METHODS FOR BRACKETING TURBIDITY AND DISCHARGE}

To match turbidity values to discrete SSC samples, continuous turbidity data were averaged over the period of EWI sample collection. Turbidity values were averaged starting with the first data punch before the start of the EWI and ending with the data punch after the end of the EWI. For pump samples that were not collected at :00,:15,:30, or :45 after the hour, two turbidity values were averaged, one on the 1/4-hour mark before the pump sample was collected and one on the 1/4-hour mark after the pump sample was collected. Only two exceptions are notable for average turbidity bracketing pump samples:

1. Turbidity from the pump sample collected on 12/19/12 @ 06:00 calculated using averaged unit values on 12/18/12@23:30 and 12/19/12@07:15.

2. Turbidity for the pump sample collected on 12/20/12 @ 06:00 calculated using averaged unit values on 12/20/12@05:00 and 12/20/12@07:15

Discharge values were interpolated to match with SSC sample times, starting with the 15-minute data punch before the mean time of the sample, and interpolated to the mean time of the sample. For samples times that occurred at :00,:15,:30, and :45 after the hour, single unit values of discharge were used.

\section{MODEL DEVELOPMENT}

Regression analysis was performed using the excel spreadsheet program from the TM3, chapter 4 publication (TM3C4_SedimentSpreadhseet_TrialV4). Final output is provided. Turbidity and streamflow were examined together as explanatory variables for estimating SSC. Different combinations of untransformed and $\log _{10}$-transformed data were also evaluated for both SLR and MLR models.

After examination of the SSC samples, a determination was made to include both EWI and pump samples for the model calibration data set. Based on model results two separate regressions were used for the approximate 3 month project period to estimate instantaneous SSC:

Model 1 (Pre-drawdown and drawdown)

The first model applied to the project period from 10/26/12 to 12/18/12 is based on 14 concurrent measurements of turbidity and EWI SSC samples. Samples were collected throughout the range of the hydrograph and through the drawdown period when the highest concentrations of suspended sediment were expected. Selected data values used to develop the regression models were removed on the basis of sample evaluation. Only one SSC value was removed from the dataset, a sample that was collected during the drawdown and had a concentration that did not match the trend of concentrations during that period. It is assumed that a sampling error occurred causing a high bias in the sample. Summary statistics and the complete model-calibration data set are provided at the end of this station analysis.

$\log _{10}$-transformed turbidity was selected as the best explanatory variable for this model period (10/26/12-12/18/12, fig. A20) on the basis of residual plots, MSPE, and p-value for streamflow. For the time period before 12/18/12, p-values for discharge were less than 0.05 . Residual plots for evaluating variance, normality, homoscedasticity, and curvature are provided. For $\log _{10}$-transformed models, 
estimated values were multiplied by a calculated retransformation bias correction factor. Ninety-percent prediction intervals are also provided for evaluating uncertainty of the estimates (fig. A21).

Model 2 (Post-drawdown)

The second model applied to the project period from $12 / 18 / 12$ to $02 / 22 / 13$ is based on 17 concurrent measurements of turbidity and a combination of EWI and pump samples, and represents post drawdown conditions. For this calibration data set, two of the SSC samples were EWI, and 15 were pump samples. The pump sample concentrations were adjusted using a box coefficient of 0.385 . This set of samples was evaluated separately from the samples used from 10/26/12 to 12/18/12 based on percentage of sand. After 12/18/12, pump samples reported very high percentages of sand (range 41-93 percent). This was verified by an EWI sample on 12/19/12. A simple linear regression model with log transformed SSC and discharge (Q) provided a better model fit for the period 12/18/12 to 02/22/13, and was applied to that time period. A log-transformed MLR with turbidity in addition to Q was also evaluated but the turbidity explanatory variable was not significant $(\mathrm{p}=0.64)$. $\log _{10}$-transformed streamflow was therefore selected as the best explanatory variable for the period from 12/18/12 to 02/22/13 (fig. A22) on the basis of residual plots, MSPE, and p-value for turbidity. A log transformed SSC-turbidity regression for this time period was also evaluated (fig. A23), resulting in low adjusted $\mathrm{R}^{2}$ (0.07), high MSPE (+180.86 percent, -64.36 percent), and non-significant p-value for turbidity ( $\mathrm{p}=0.18)$. High sand content was encountered in pump samples from 12/18 to 02/16, leading to a better fit with discharge as an explanatory variable. The large amount of sand may be explained by the drawdown of Fall Creek Lake, when large amounts of suspended sediment were initially released from behind the dam, but streamflow was low $\left(600-900 \mathrm{ft}^{3} / \mathrm{s}\right)$, and velocities were not high enough to transport sand sized particles long distances. After the drawdown, streamflow on Fall Creek increased to approximately 2,000 $\mathrm{ft}^{3} / \mathrm{s}$, potentially transporting larger material downstream to the Jasper gaging station, coarsening the sediment load. EWI samples from the site approximately 0.91 mi downstream of Fall Creek Lake also reported high sand content in the samples during this time period (see SSC record for Fall Creek below Winberry Creek, near Lowell, Oregon, 14151000). Times series of SSC and 90 percent confidence intervals for model 2 are shown in figure A24.

\section{MODEL SUMMARIES}

Summary of final regression analysis (fig. A20) for suspended-sediment concentration at Middle Fork Willamette River at Jasper, Oregon

Model 1: 10/26/12 @ 15:00 to 12/18/12 @ 13:30 (pre-drawdown and drawdown)

$\log (S S C)=0.601+0.723 \log (T B)$

$S S C=$ Suspended-sediment concentration, in milligrams per liter

$T B=$ Turbidity (Hydrolab/McVann Self-Cleaning (SC) Turbidity), in formazin nephelometric units (FNU).

\section{Model information:}

Number of measurements $=14$

Model standard percentage error $(\mathrm{MSPE})=+67.36$ and -40.25 percent

Adj r2: 0.91 
Duan BCF: 1.11

PPCC: 0.94

PRESS: 0.76
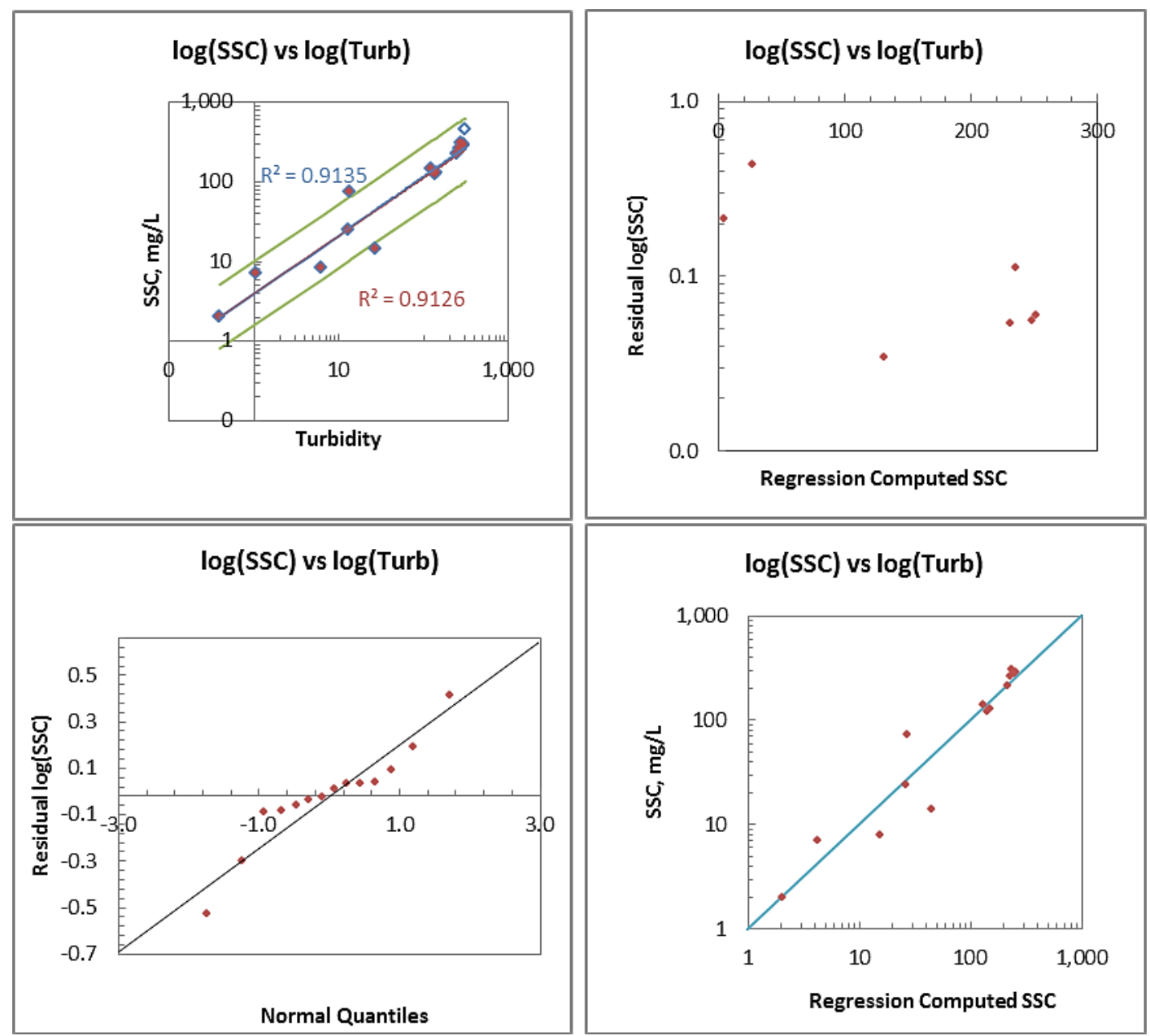

Figure A20: Regression, residual, and probability plots for model 1, Middle Fork Willamette River at Jasper, Oregon, 2012-13 


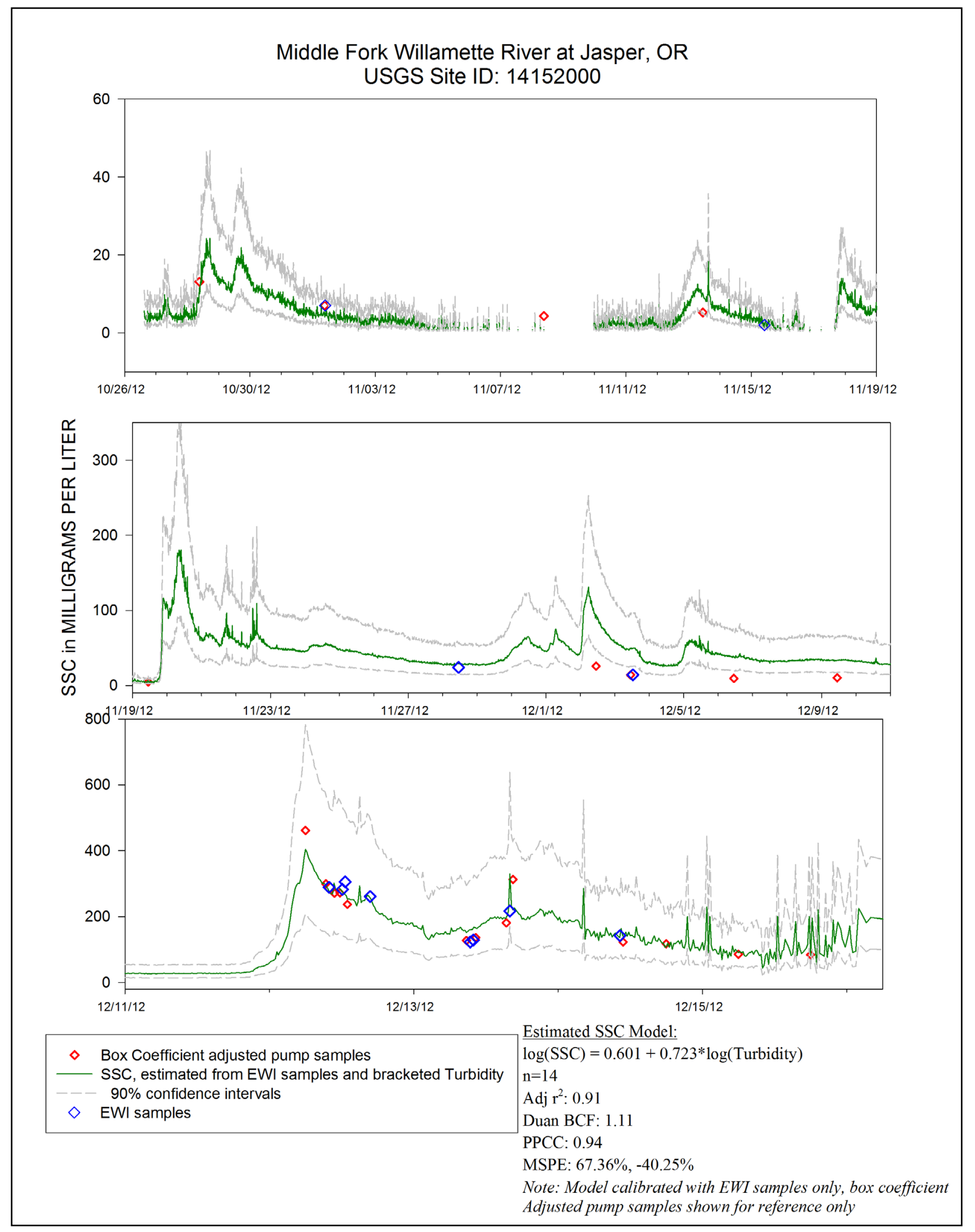

Figure A21. Time series plot of computed SSC and 90 percent confidence intervals, model 1. 
Model 2: 12/18/12 @ 13:45 to 02/16/13 @ 17:00 (post drawdown)

$\log (S S C)=-8.05+2.51 \log _{10}(Q)$

SSC $=$ Suspended-sediment concentration, in milligrams per liter $Q=$ Streamflow, in cubic feet per second

Model information:

Number of measurements $=\mathbf{1 7}$,

Model standard percentage error $(M S P E)=+64.96$ and -39.38 percent

Adj $r^{2}: \mathbf{0 . 8 1}$

Duan BCF: 1.11

PPCC: 0.99

PRESS: 0.99
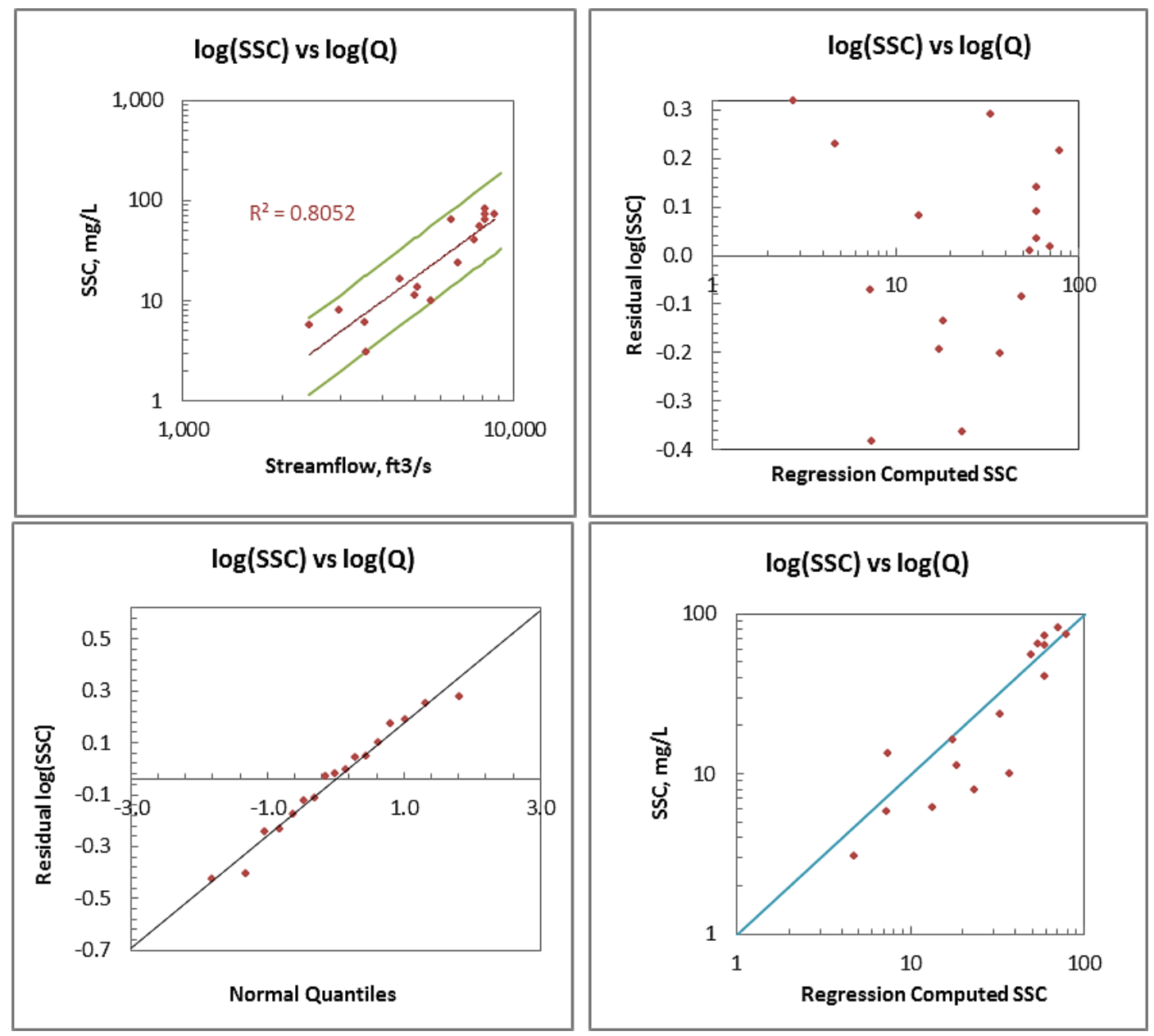

Figure A22. Regression, residual, and probability plots for model 2, Middle Fork Willamette River at Jasper, Oregon, 2012-13. 


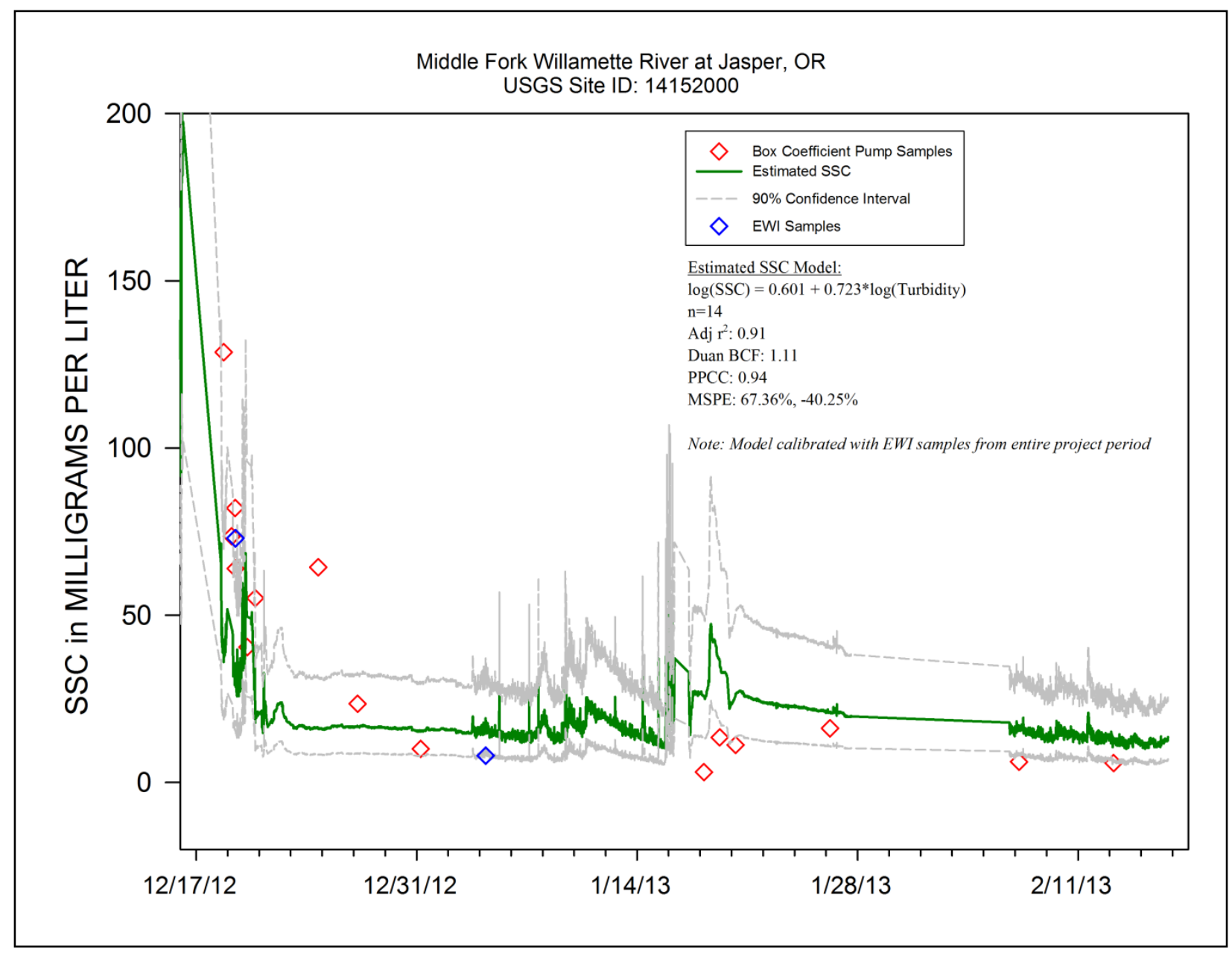

Figure A23. Time series plot of computed SSC and 90 percent confidence intervals using model 1, December 2012 to February 2013. This model was not selected for this period and is shown for comparison purposes only. 


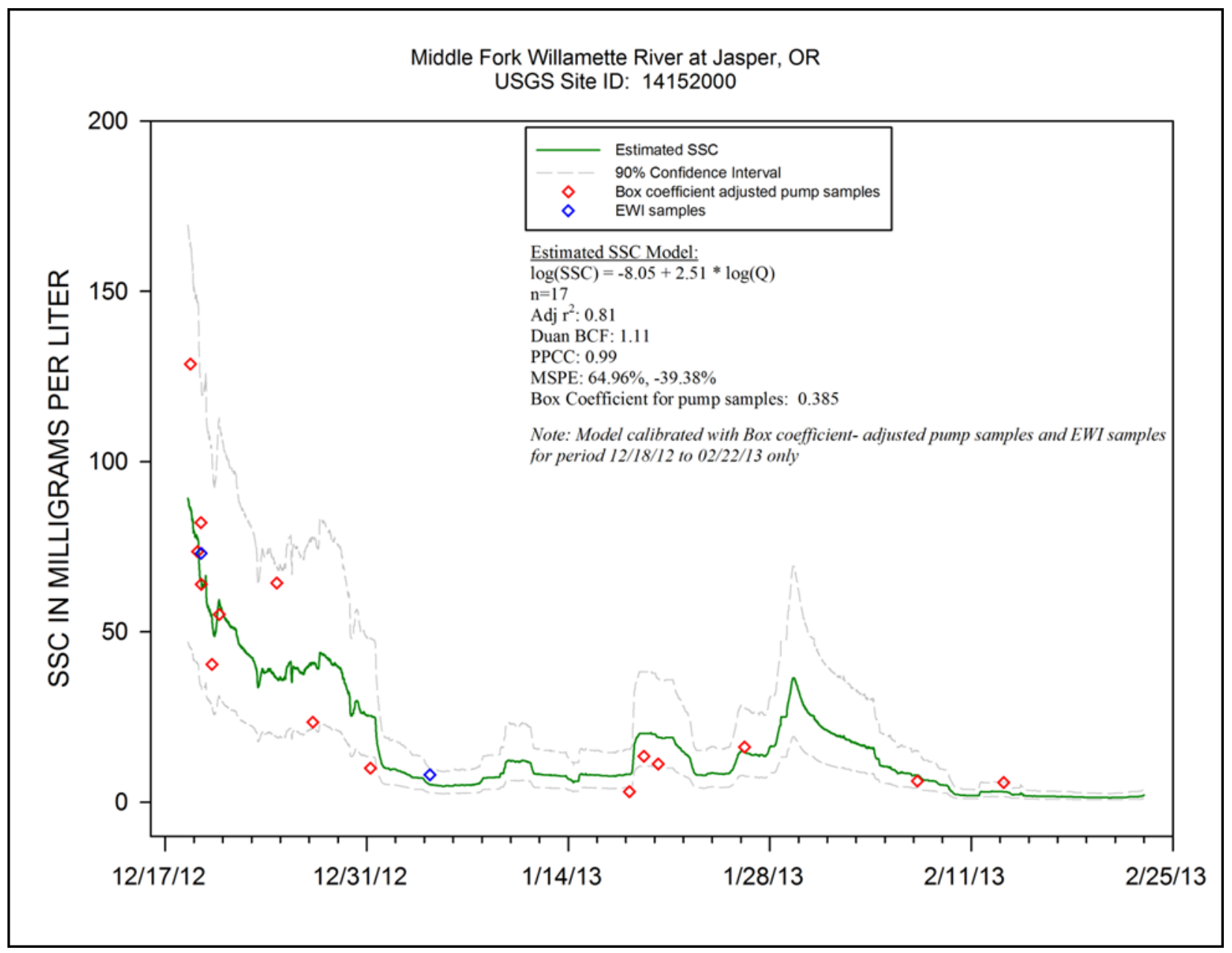

Figure A24. Time series plot of computed SSC, 90 percent confidence intervals for model 2, December 2012 to February 2013

\section{ESTIMATED SSC DATA}

For the project period 10/26/12 to 12/18/12, when SSC was estimated using the $\log (\mathrm{SSC})-\log (\mathrm{TB})$ regression, there were two days of missing data due to extreme fouling of the turbidity sensor, 12/16 and $12 / 17 / 12$.

Mean daily SSC was estimated for this time period using mean daily SSC values calculated from the instantaneous SSC record produced by the $\log$ (SSC) $\rightarrow \log$ (turbidity) model for 3 days before and three days after the missing days. For the 3 days prior (12/13-12/15), daily mean values of SSC were calculated using instantaneous data generated from the $\log (\mathrm{SSC}) \rightarrow \log ($ turbidity) regression. For the 3 days after the missing days (12/18-12/20), daily mean values of SSC were calculated using instantaneous data generated from the $\log (\mathrm{SSC}) \rightarrow \log (\mathrm{Q})$ regression (table A11). A polynomial line was fit to the days with existing data (figs. A25 and A26). Data from 12/18/12 represent a partial day, and mean daily SSC was calculated using 10 hours of data. Daily SSC for these 2 days were estimated independent of sediment discharge. 


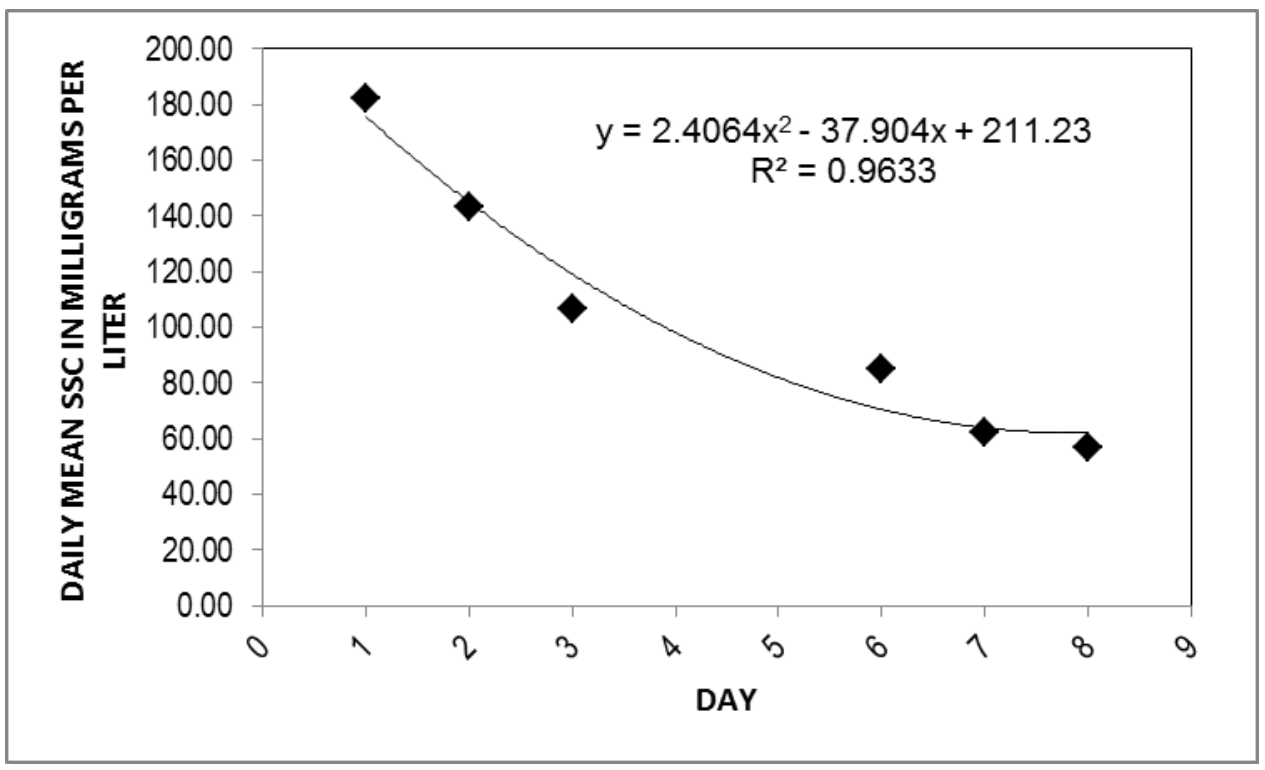

Figure A25. Daily mean SSC data points used to generate a polynomial equation to compute daily mean SSC on days 4 and 5, Middle Fork Willamette River at Jasper, Oregon, December 1320, 2012

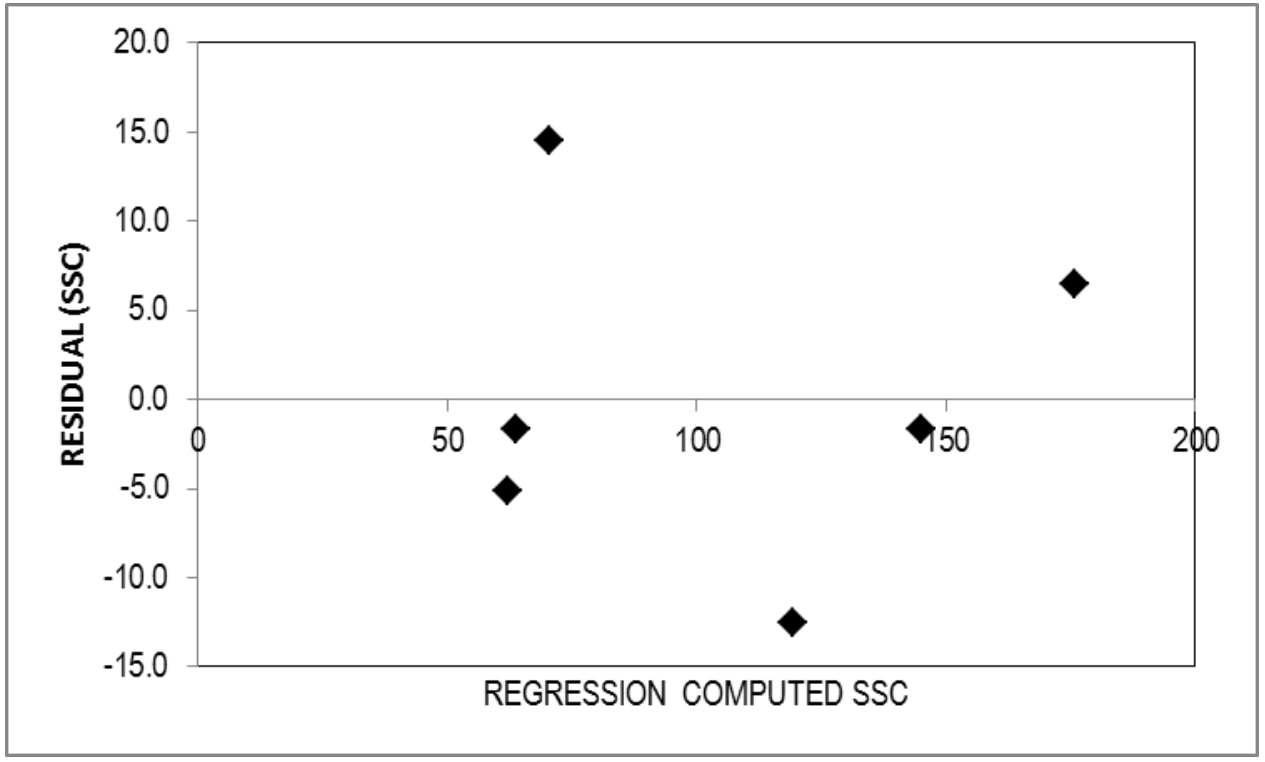

Figure A26. Residual values of regression computed SSC using the polynomial equation in figure A25 
Table A11. Daily mean, regression computed, and residual values of SSC, Middle Fork Willamette River at Jasper, Oregon, December 13-20, 2012

[SSC, suspended sediment concentration; *, estimated computed daily mean SSC]

\begin{tabular}{|c|c|c|c|}
\hline Date & $\begin{array}{l}\text { Daily } \\
\text { mean } \\
\text { SSC }\end{array}$ & $\begin{array}{c}\text { Regression-computed } \\
\text { SSC } \\
\end{array}$ & Residual \\
\hline 12/13/2012 & 182.18 & 175.73 & 6.45 \\
\hline $12 / 14 / 2012$ & 143.39 & 145.05 & -1.66 \\
\hline $12 / 15 / 2012$ & 106.66 & 119.18 & -12.52 \\
\hline 12/16/2012 & & $98.12 *$ & \\
\hline 12/17/2012 & & $81.87^{*}$ & \\
\hline 12/18/2012 & 84.94 & 70.44 & 14.50 \\
\hline 12/19/2012 & 62.16 & 63.82 & -1.66 \\
\hline 12/20/2012 & 56.88 & 62.01 & -5.13 \\
\hline
\end{tabular}

\section{RECORD}

The record is computed using the Sediment Record spreadsheet using two distinct regression models that cover two distinct periods during the project period. Data were uploaded into ADAPS directly, and were computed at 15-minute intervals. The record is complete for the project period only, except as noted. Missing data from 12/16 and 12/17/12 were estimated as daily mean SSC.

\section{EXTREME VALUES}

Maximum Instantaneous SSC: 404 mg/L on 2012-12-12 @ 06:00

Minimum Instantaneous SSC: $0.0 \mathrm{mg} / \mathrm{L}$ multiple days

\section{DATA LIMITATIONS AND FUTURE IMPROVEMENTS}

The period of record associated with this project is short, due to the project requirements of monitoring for SSC during the short term drawdown of Fall Creek Lake. As such, a limited number of samples were collected over the 3-month project period.

Worked: L. Schenk, August 14, 2013

Checked: H. Bragg

Reviewed: K. Spicer 



\section{咅}

